\title{
Chemical characterization and hepatoprotective effects of a standardized triterpenoids-enriched guava leaf extract
}

Yuanyuan Li,${ }^{\dagger}$ Jialin Xu, ${ }^{\dagger}$ Dongli Li, ${ }^{\S}$ Hang Ma,,${ }^{\S}$ ฯ Yu Mu, ${ }^{\dagger}$ Dan Zheng, ${ }^{\dagger}$ Xueshi Huang, ${ }^{*} \dagger$ and Liya $\mathrm{Li}^{*}, \dagger$

$\dagger$ Institute of Microbial Pharmaceuticals, College of Life and Health Sciences, Northeastern University, Shenyang 110819, P. R. China

${ }^{\ddagger}$ Institute of Biochemistry and Molecular Biology, College of Life and Health Sciences, Northeastern University, Shenyang 110819, P. R. China

$\S$ School of Biotechnology and Health Sciences, Wuyi University, Jiangmen 529020, P. R. China

ฯ Bioactive Botanical Research Laboratory, Department of Biomedical and Pharmaceutical Sciences, College of Pharmacy, University of Rhode Island, Kingston, RI, 02881, United States

*Author to whom correspondence should be addressed

* Tel/Fax: 0086-24-83656122; E-mail: 1yli@mail.neu.edu.cn (L.-Y. Li)

* Tel /Fax: 0086-24-83656106; E-mail: huangxs@mail.neu.edu.cn (X.-S. Huang) 


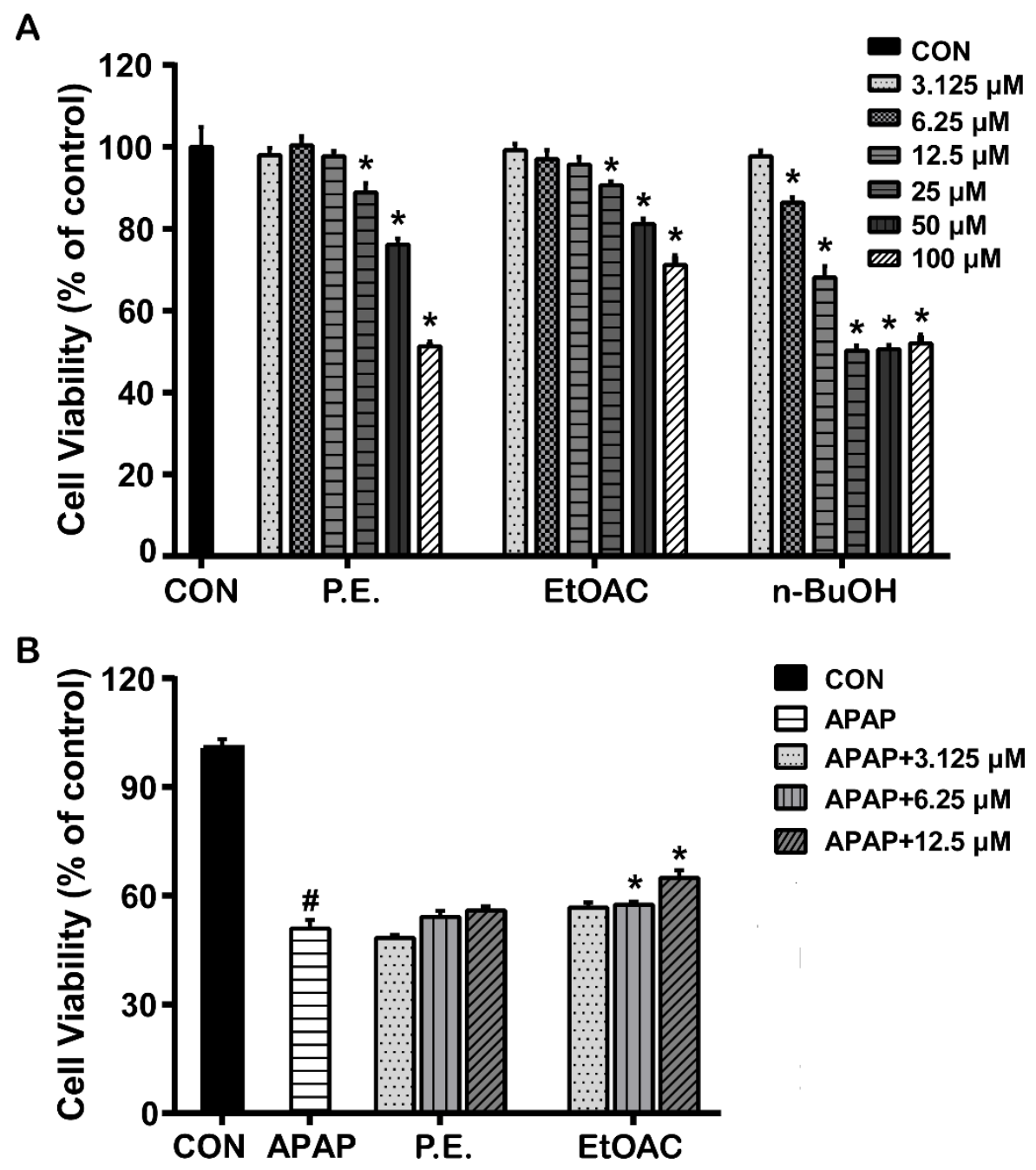

Figure S1. Impact of the petroleum ether extract (P.E.), ethyl acetate extract (EtOAC), and $n-\mathrm{BuOH}$ extract on cell viability of HepG2 Cells with or without APAP. HepG2 cells were seeded onto 96 -well plates at $8 \times 10^{3}$ cells/well. After overnight incubation, the cells were treated with different concentrations of petroleum ether extract, ethyl acetate extract, and $n$-BuOH extract without (A) or with $10 \mathrm{mM}$ APAP (B) for another $48 \mathrm{~h}$. Relative cell viability was expressed as a percentage compared to control group. The experiment was repeated for three independent times and data were presented as mean \pm SE. ${ }^{\#} p<0.05$ as compared with the control group. ${ }^{*} p<0.05$ as compared with the APAP group. 


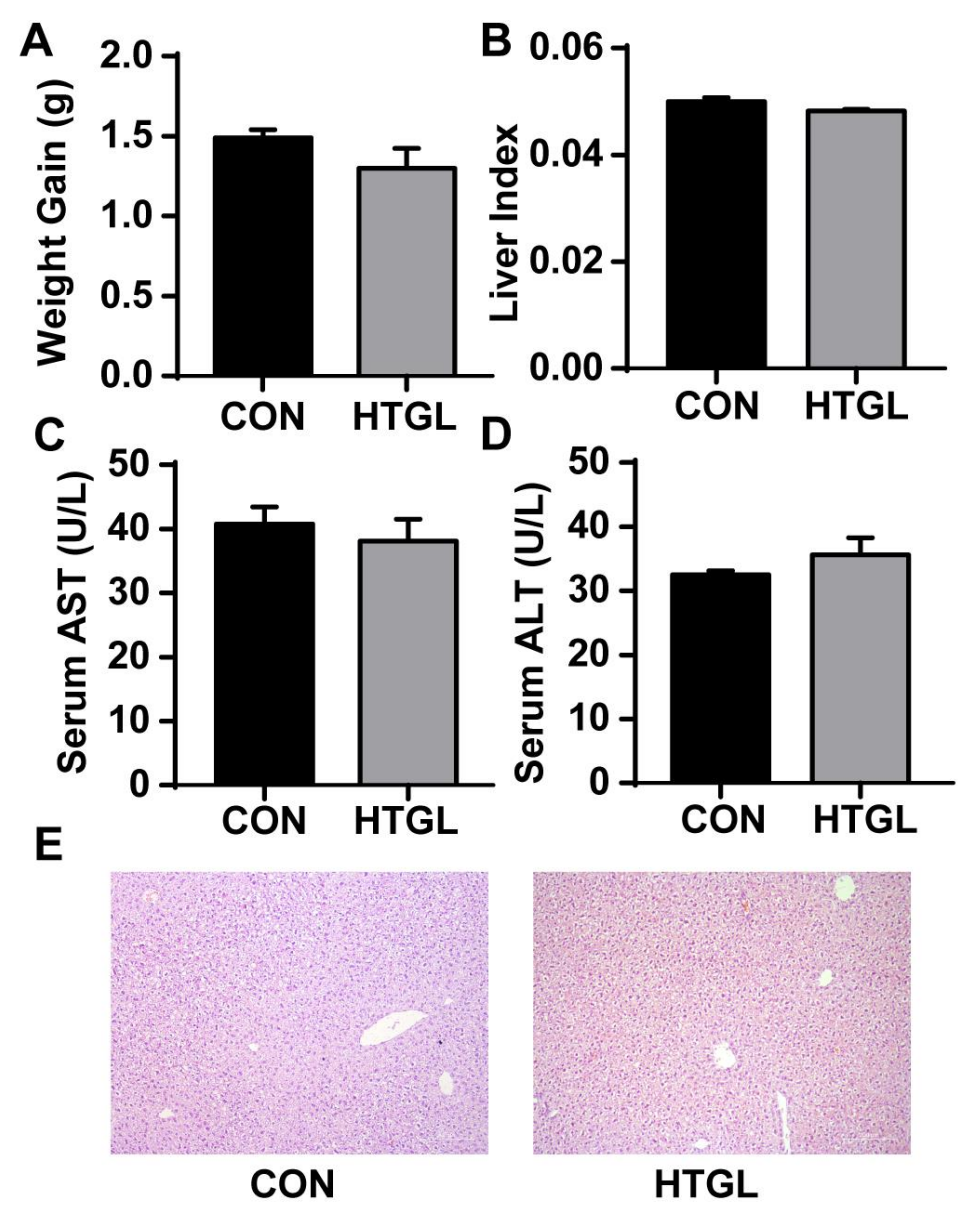

Figure S2. Impact of TGL (150 mg/kg, HTGL) treatment on (A) weight gain, (B) liver index, (C) serum AST, (D) serum ALT, and (E) histological structure in mice. C57BL/6 male mice ( $\mathrm{n}=6$ per group) were gavaged with TGL (prepared with $20 \%$ aqueous $1,2-$ propanediol) for consecutive 14 days. Liver index was calculated according to the formula: Liver index $=$ liver weight/body weight $\times 100 \%$. Data are shown as mean $\pm \mathrm{SE}$. 

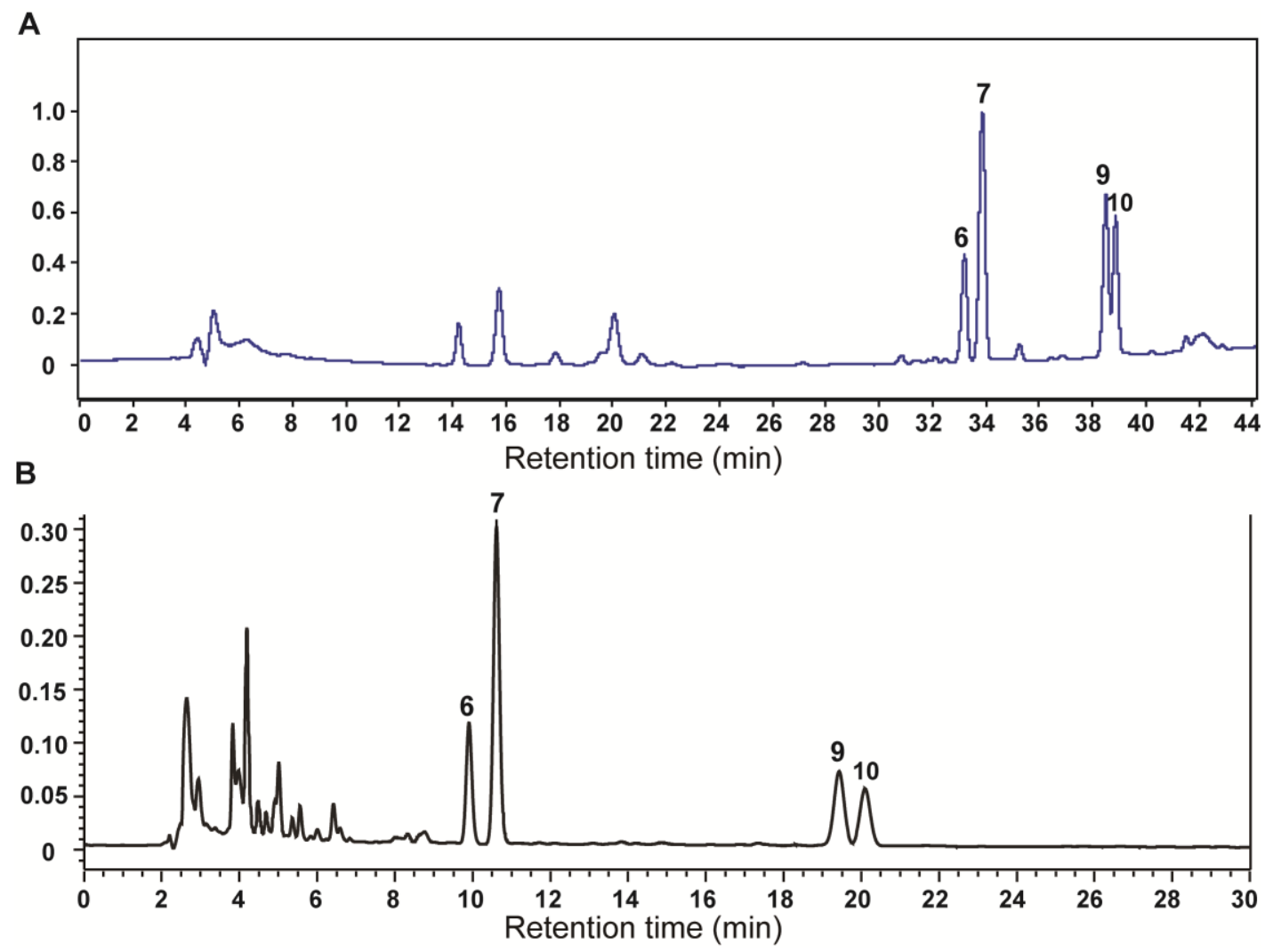

Figure 3 (A) Qualitative analysis of TGL with HPLC-UV method. The separation of TGL was conducted with a YMC-Pack ODS-A column $(150 \times 4.6 \mathrm{~mm}$ i.d., $5 \mu \mathrm{m})$ at a flow rate of $0.4 \mathrm{~mL} / \mathrm{min}$. A gradient elution system consisting of solvent A ( $5 \%$ aqueous acetonitrile containing $0.1 \% \mathrm{HCOOH}$ ) and solvent $\mathrm{B}$ (methanol) was set as: $0-8 \mathrm{~min}$, 60-75\% B; 8-23 min, 75-78\% B; 23-24 min, 78-85\% B; 24-40 min, 85-100\% B. (B) Quantitative analysis of TGL with HPLC-UV method. The separation of TGL was achieved on a YMC-Pack ODS-A column $(250 \times 4.6 \mathrm{~mm}$ i.d., $5 \mu \mathrm{m})$ with a ternary elution system consisting of methanol, acetonitrile, and $0.2 \%$ phosphoric acid aqueous solution (42.5:42.5:15, v/v/v; Flow rate: $1.0 \mathrm{~mL} / \mathrm{min})$. Detection wavelength was set as 203 nm. Peak 6: maslinic acid, Peak 7: corosolic acid, Peak 9: oleanolic acid, Peak 10: ursolic acid. 
A

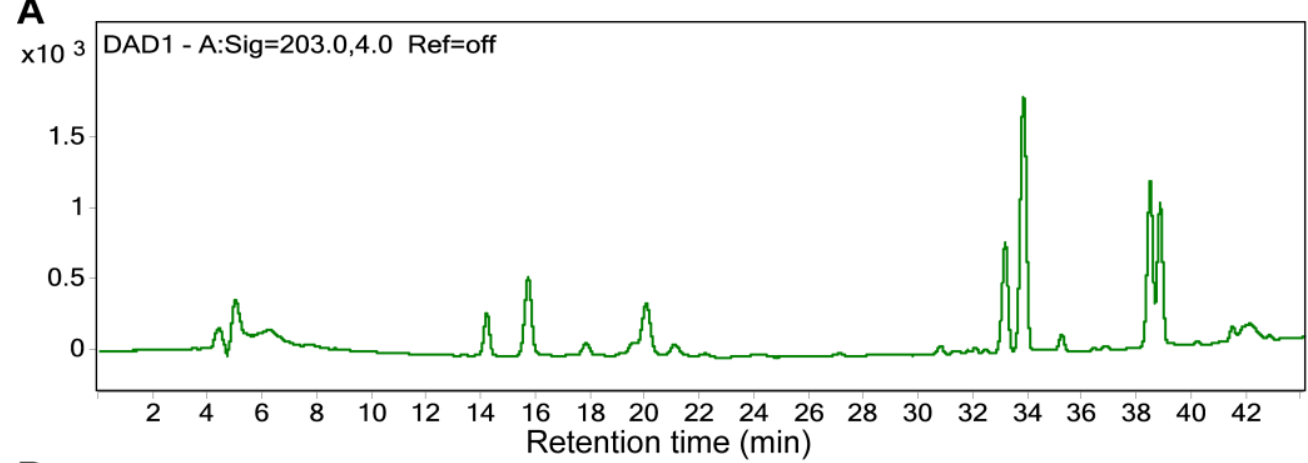

B

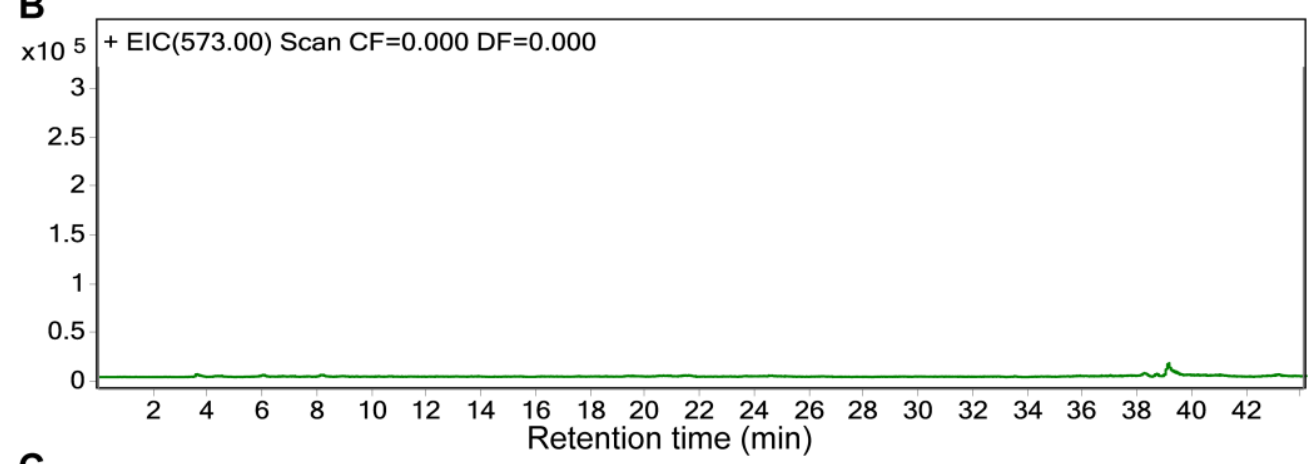

C

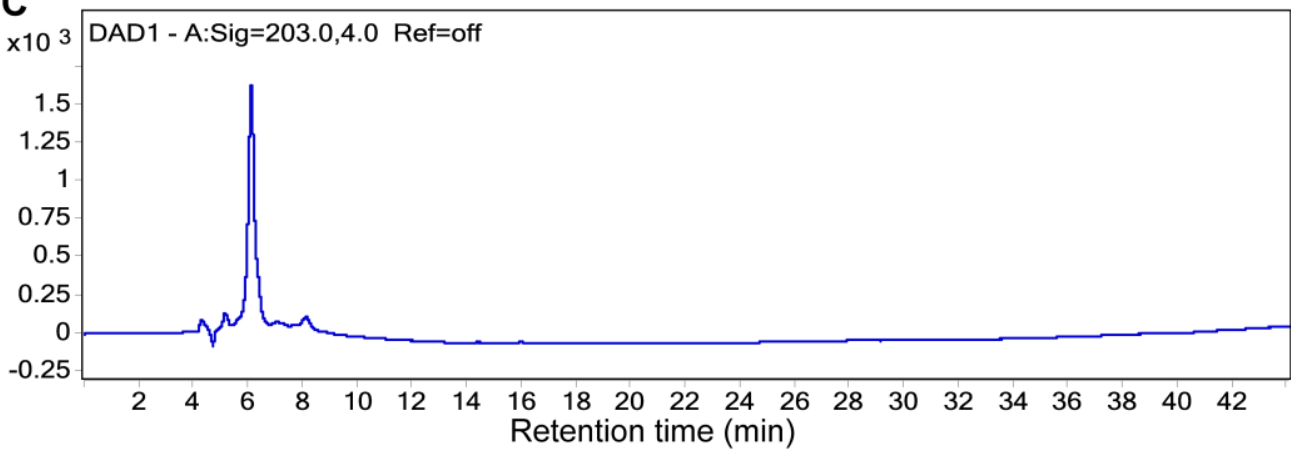

D

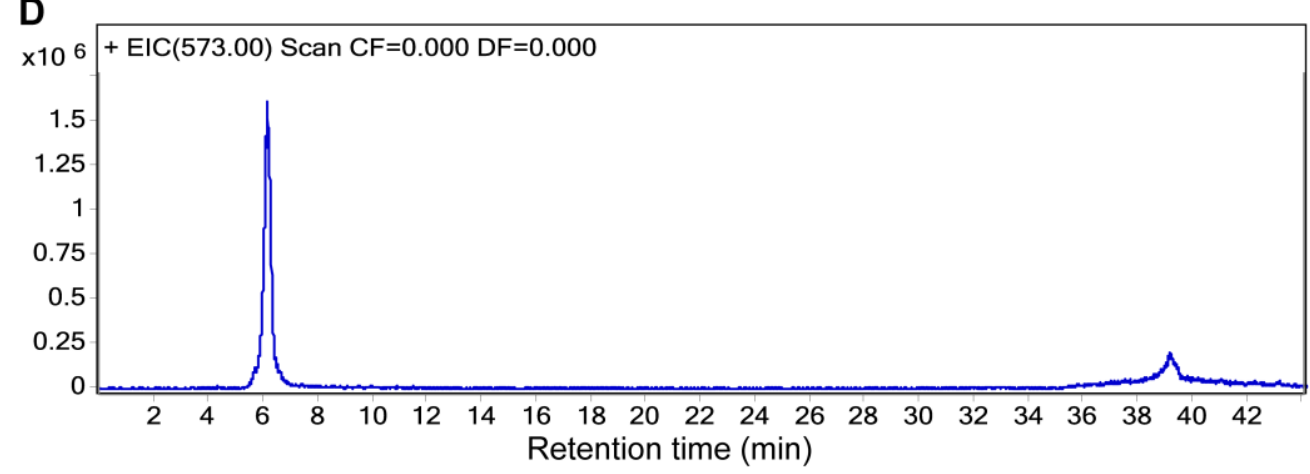

Figure S4. (A) HPLC-UV profile (detection wavelength at $203 \mathrm{~nm}$ ) and (B) extracted ion chromatogram $(m / z: 573.00)$ of TGL, (C) HPLC-UV profile (detection wavelength at $203 \mathrm{~nm})$ and (D) extracted ion chromatogram $(\mathrm{m} / \mathrm{z}: 573.00)$ of GUB. 

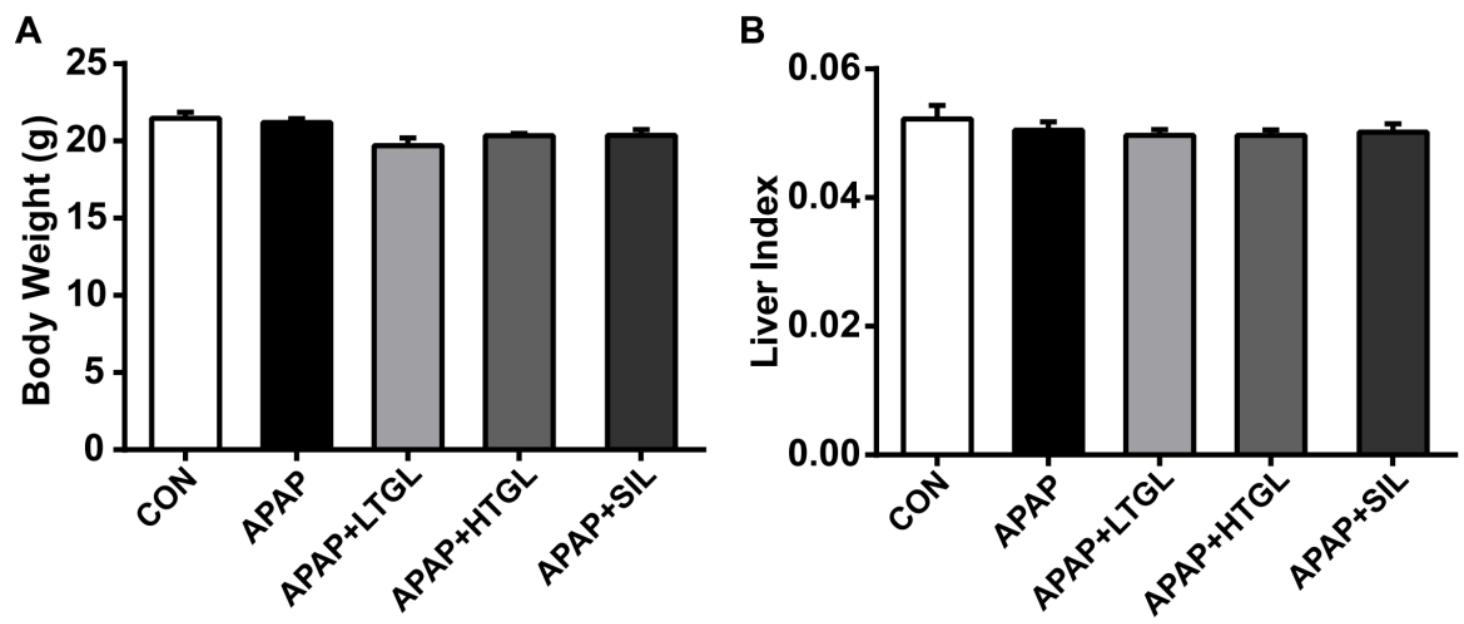

Figure S5. The effect of TGL on (A) body weight and (B) liver index in CON, APAP, APAP+LTGL (75 mg/kg), APAP+HTGL (150 mg/kg), and APAP+SIL (100 mg/kg) groups, respectively. $\mathrm{n}=8-10$ per group. Data are shown as mean $\pm \mathrm{SE}$.

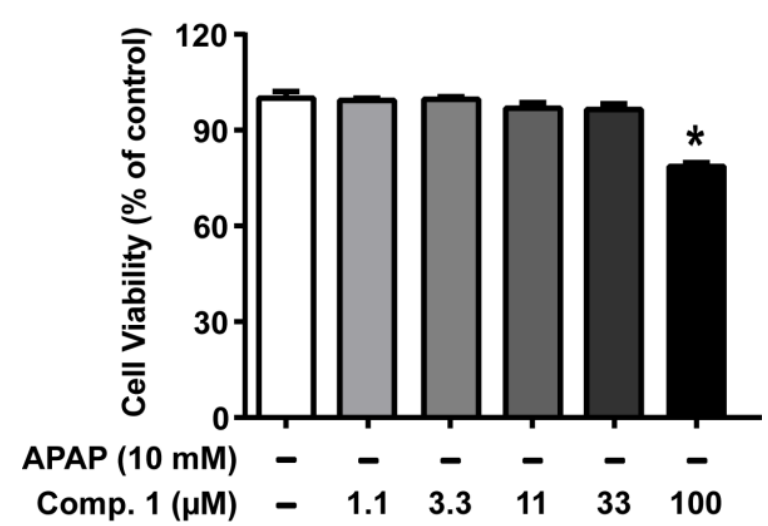

Figure S6. Impact of compound $\mathbf{1}$ on cell viability of HepG2 cells. HepG2 cells were seeded onto 96 -well plates at $8 \times 10^{3}$ cells/well, and allowed to grow overnight at $37^{\circ} \mathrm{C}$. Then, cells were exposed to different concentrations of compound $\mathbf{1}(1.1,3.3,11,33$ and $100 \mu \mathrm{M}$ ) for $48 \mathrm{~h}$. Cell viability was determined by MTT method. Relative cell viability was expressed as a percentage compared to control group. The experiment was repeated for three independent times and data were presented as mean $\pm \mathrm{SE}$. 


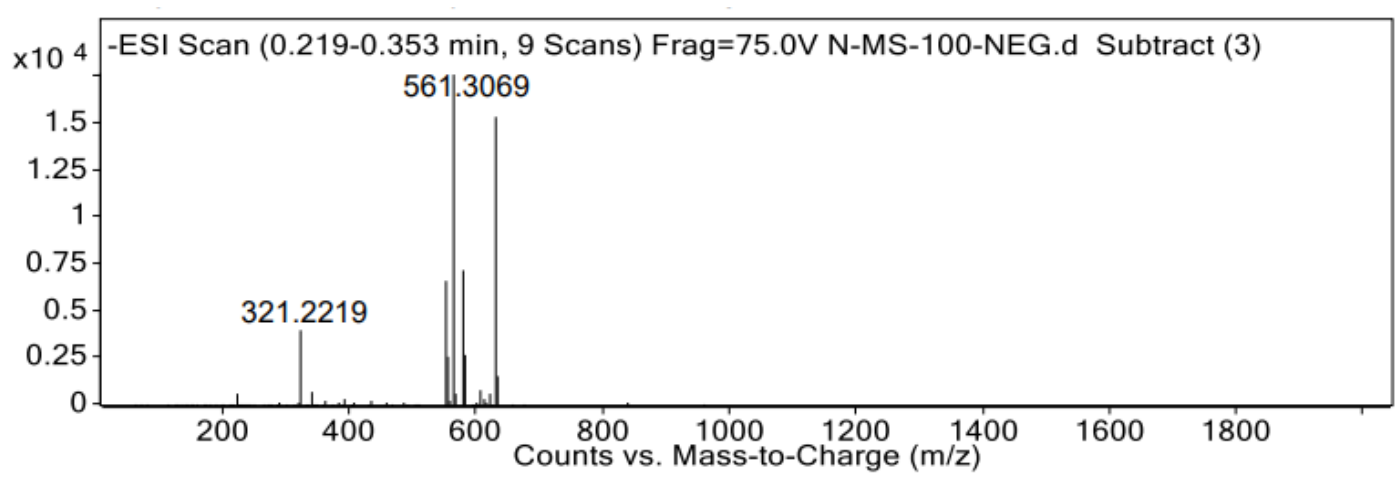

Figure S7. HRESI-MS spectrum of compound 1

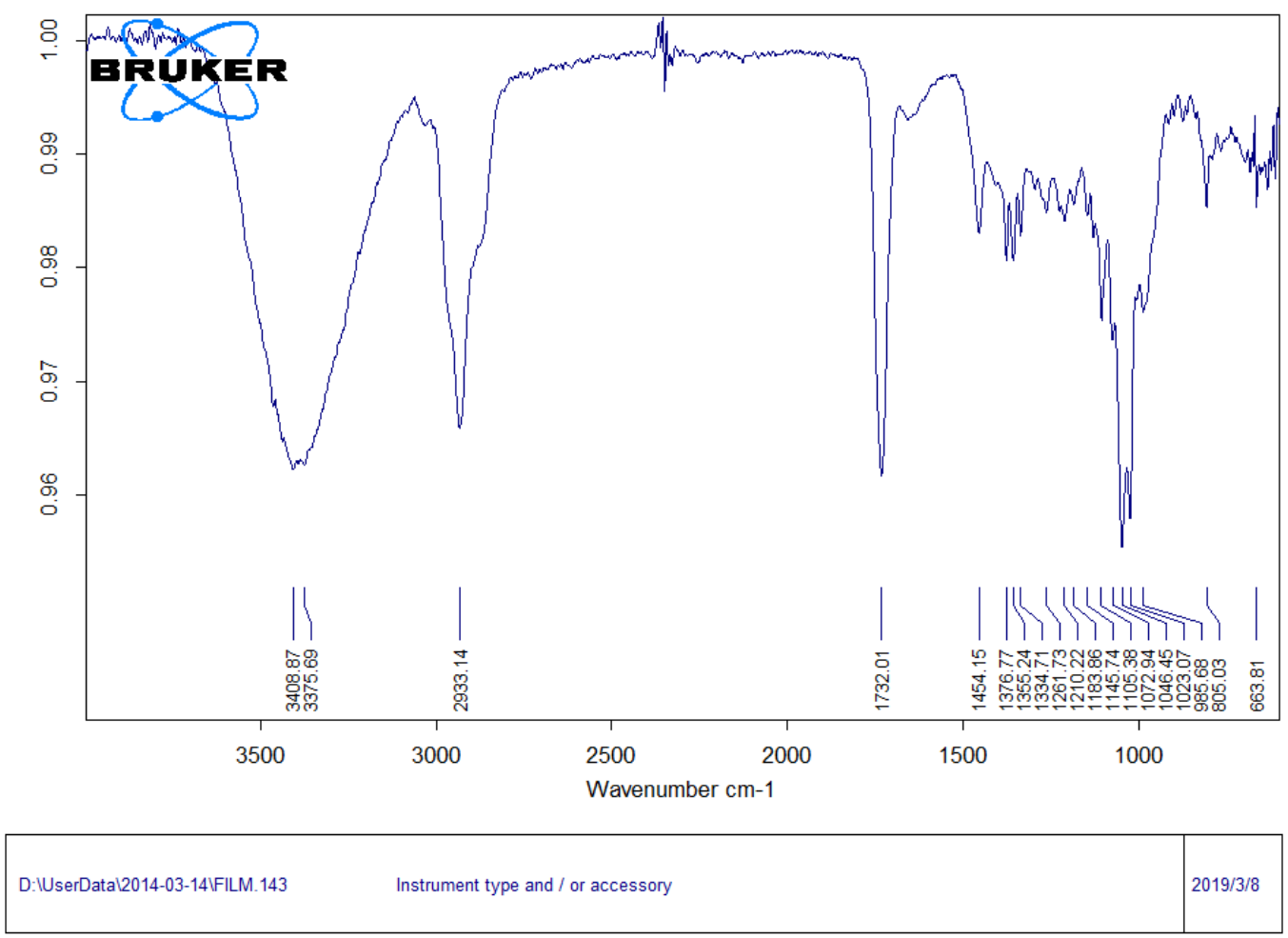

Page 1/1

Figure S8. IR spectrum of compound 1 


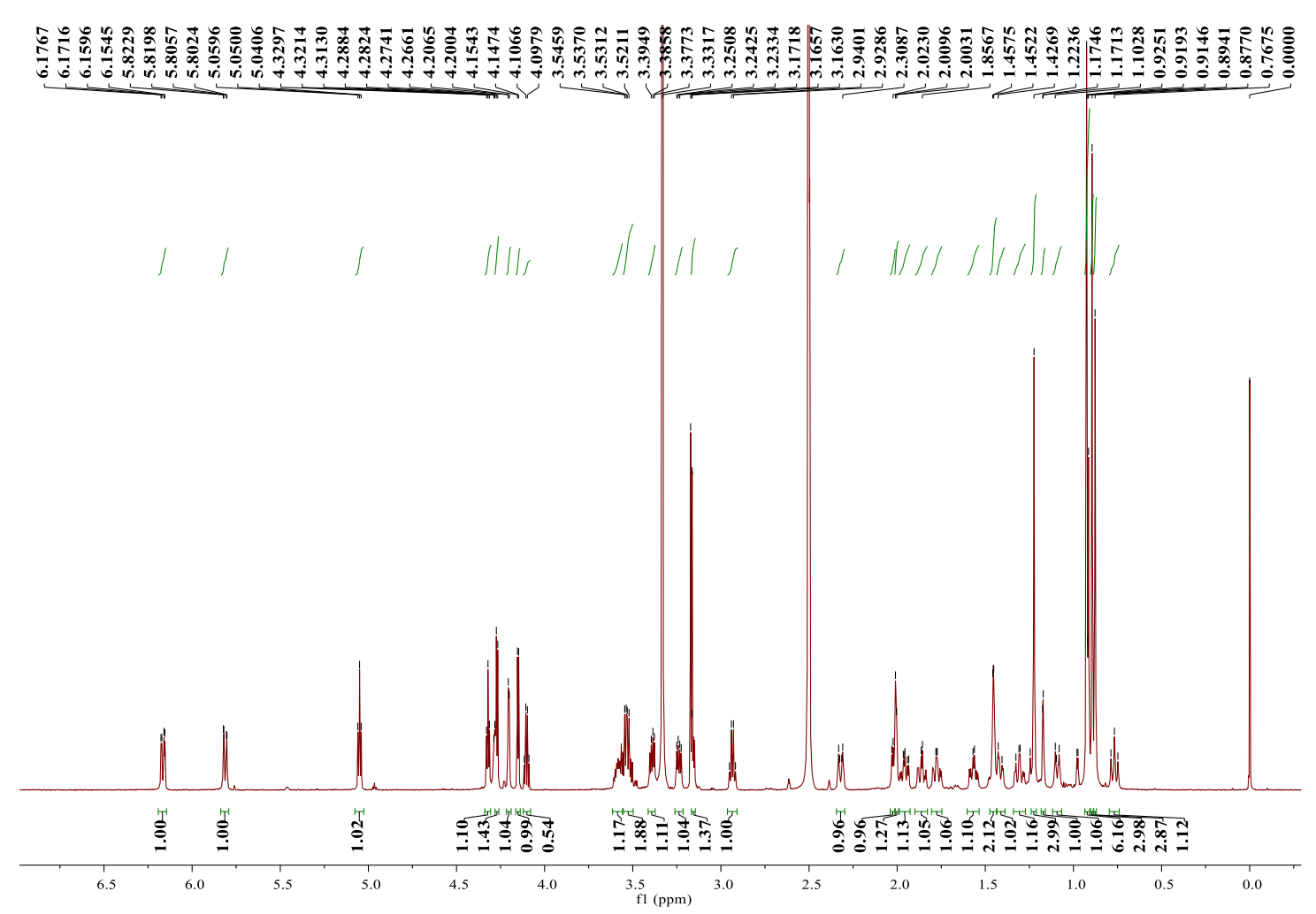

Figure S9. ${ }^{1} \mathrm{H}$ NMR $\left(600 \mathrm{MHz}, \mathrm{DMSO}-d_{6}\right)$ spectrum of compound 1

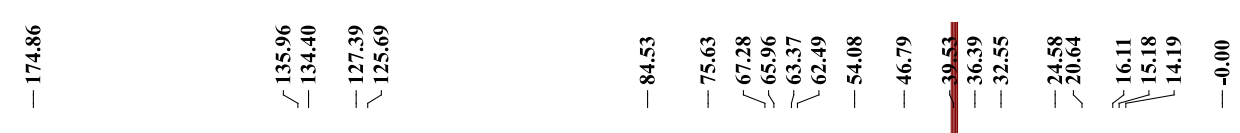
$\begin{array}{lllllllllllllllllllll}190 & 180 & 170 & 160 & 150 & 140 & 130 & 120 & 110 & 100 & 90 & 80 & 70 & 60 & 50 & 40 & 30 & 20 & 10 & 0 & 10\end{array}$

Figure S10. ${ }^{13} \mathrm{C}$ NMR (150 MHz, DMSO- $\left.d_{6}\right)$ spectrum of compound 1 


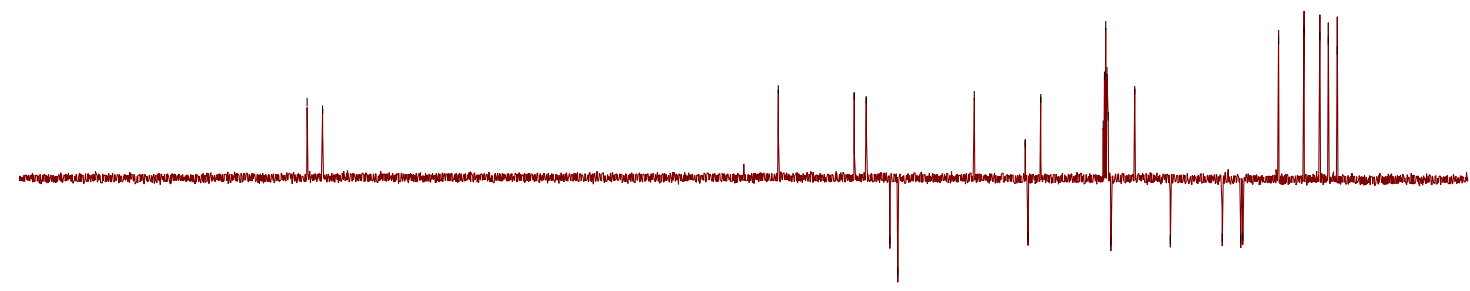

Figure S11. DEPT spectrum of compound 1

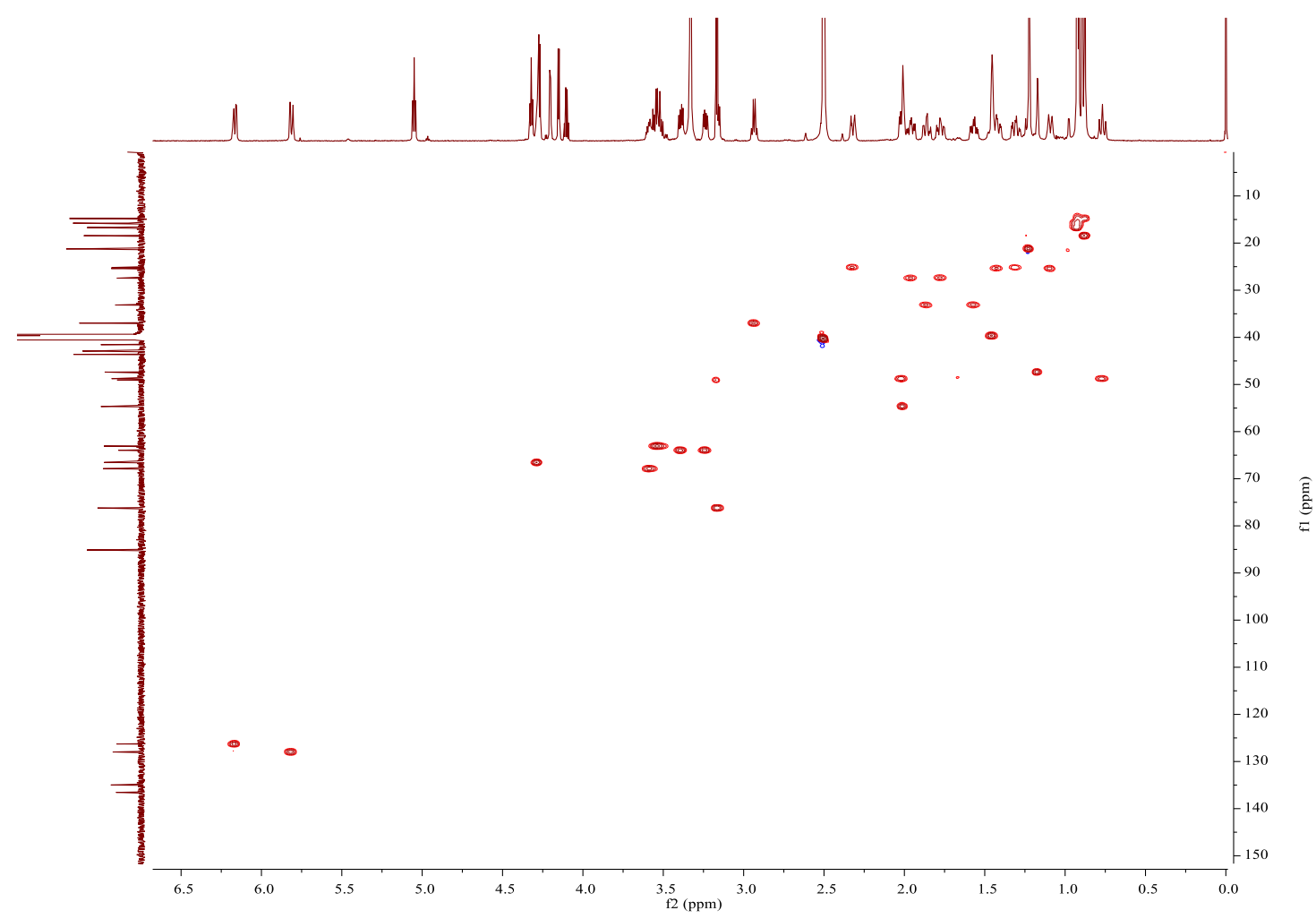

Figure S12. HSQC spectrum of compound 1 


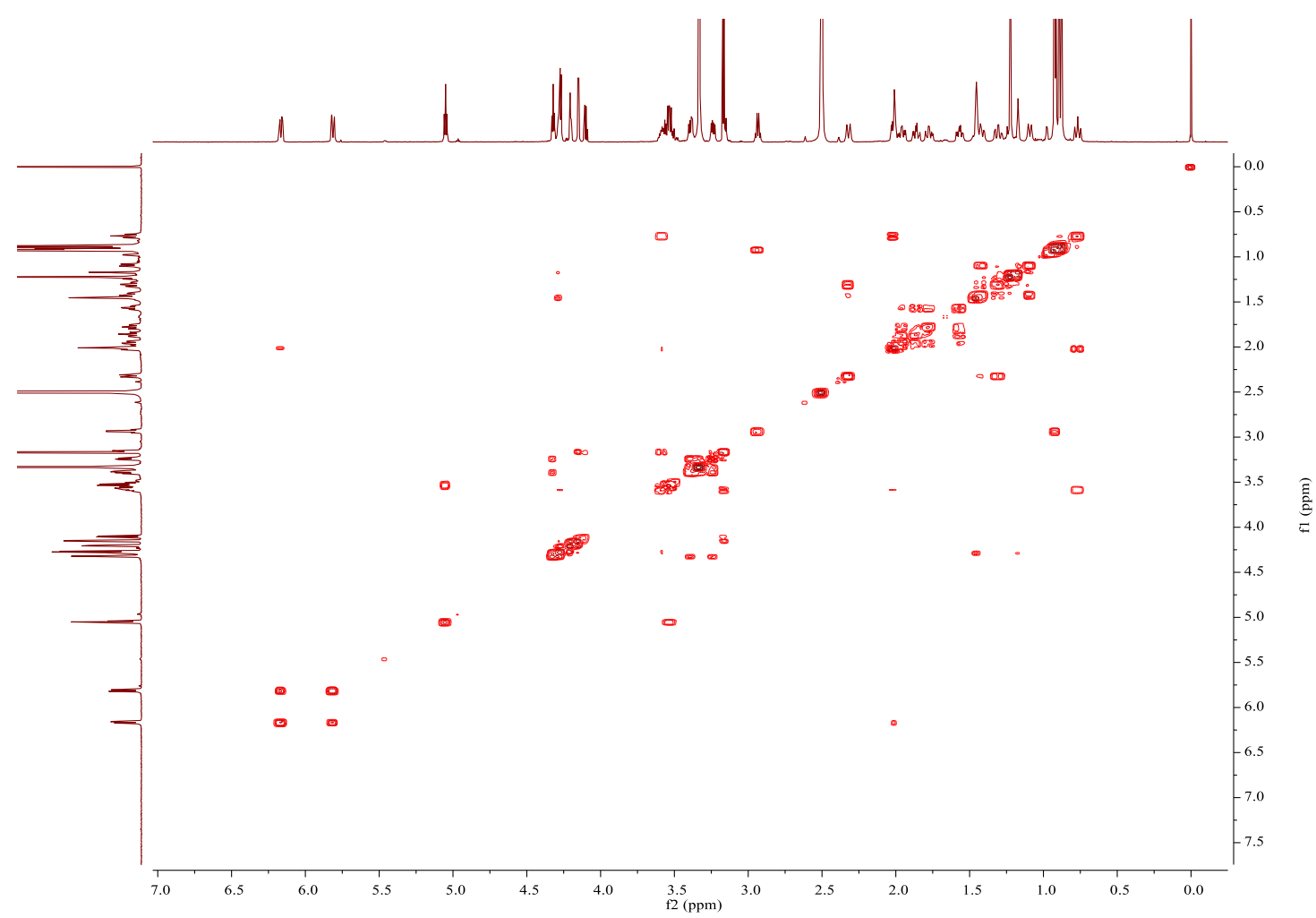

Figure S13. ${ }^{1} \mathrm{H}-{ }^{1} \mathrm{H}$ COSY spectrum of compound 1

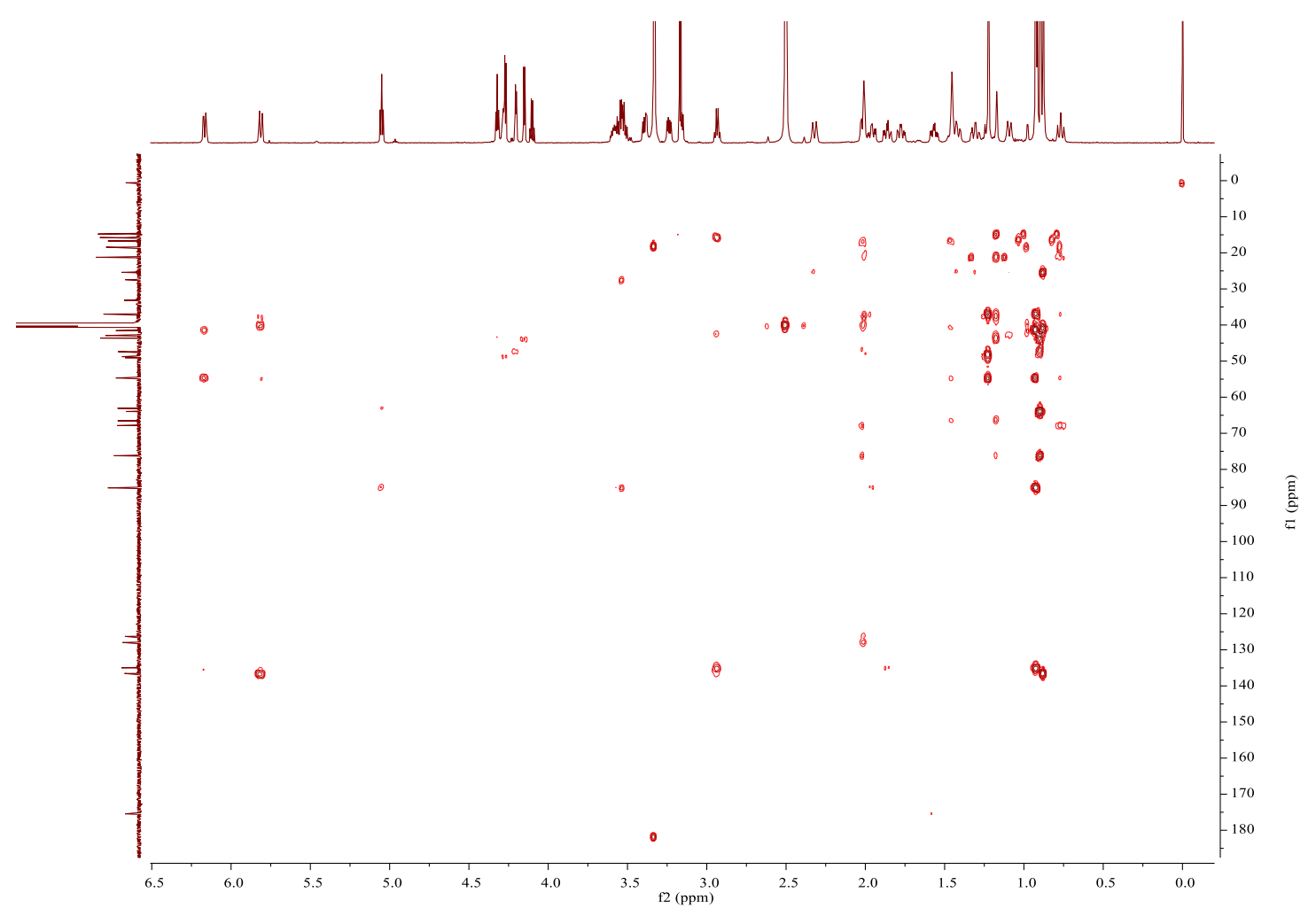

Figure S14. HMBC spectrum of compound 1 


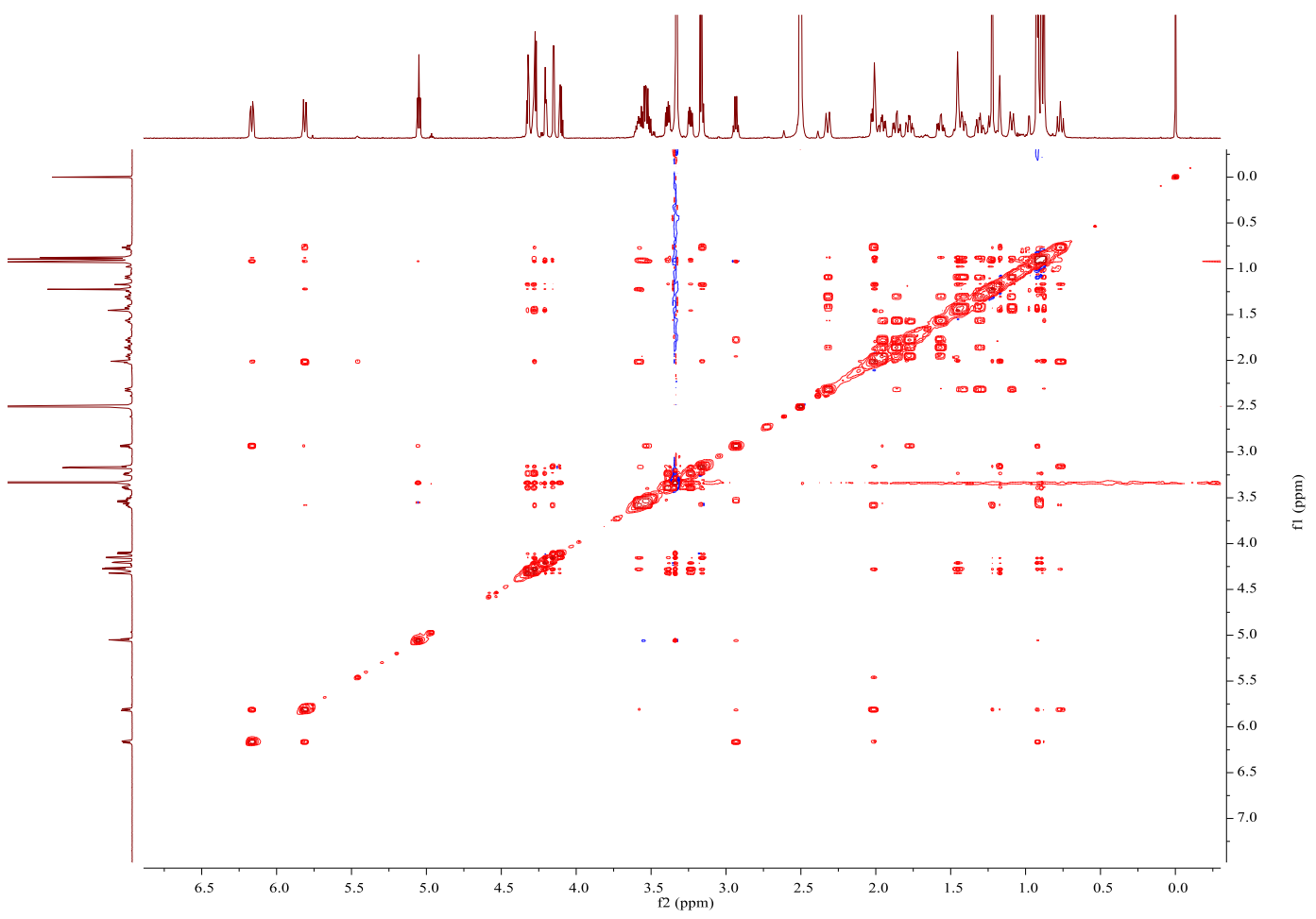

Figure S15. NOESY spectrum of compound 1 
Table S1. Analytical parameters for quantification experiment

\begin{tabular}{cccc}
\hline Peak & ${\text { Rt }(\mathbf{m i n})^{a}}^{a}$ & Calibration curve $^{b}$ & $\mathbf{R}^{2}$ \\
\hline Ursolic acid & 20.10 & $\mathrm{Y}=10678.2564 \mathrm{x}+99124.6868$ & 0.9994 \\
Oleanolic acid & 19.43 & $\mathrm{Y}=14426.6657 \mathrm{x}+141729.4405$ & 0.9992 \\
Corosolic acid & 10.62 & $\mathrm{Y}=13211.9001 \mathrm{x}+265607.8388$ & 0.9993 \\
Maslinic acid & 9.91 & $\mathrm{Y}=13982.8370 \mathrm{x}+270950.6382$ & 0.9995 \\
\hline
\end{tabular}

${ }^{a}$ Rt: Retention time

${ }^{b}$ The unit for $\mathrm{X}$ in is $\mu \mathrm{g} / \mathrm{mL}$.

Table S2 Primer sequences for quantitative real-time PCR.

\begin{tabular}{lll}
\hline Genes & \multicolumn{1}{c}{ Forward } & Reverse \\
\hline $18 \mathrm{~S}$ & AGTCCCTGCCCTTTGTACACA & CGATCCGAGGGCCTCACTA \\
GCLC & AACACAGACCCAACCCAGAG & CCGCATCTTCTGGAAATGTT \\
NQO1 & CAGATCCTGGAAGGATGGAA & TCTGGTTGTCAGCTGGAATG \\
Nrf2 & CGAGATATACGCAGGAGAGGTAAGA & GCTCGACAATGTTCTCCAGCTT \\
\hline
\end{tabular}


Isolation and Identification of Compounds 2-24 in TGL. A portion of prepared TGL (8.0 g) was chromatographed over a silica gel column $\left(\mathrm{CH}_{2} \mathrm{Cl}_{2} / \mathrm{MeOH} 30: 1\right.$, v/v) to yield five subfractions (Fr.1-5). Fr.1 was subjected to a silica gel column $\left(\mathrm{CH}_{2} \mathrm{Cl}_{2}-\right.$ $\mathrm{MeOH} 20: 1, \mathrm{v} / \mathrm{v})$ to produce three subfractions Fr.1.1-1.3. Fr. 1.2 was put on an ODS column $(95 \% \mathrm{MeOH})$ to yield compounds $6(1.0 \mathrm{~g})$ and $16(500 \mathrm{mg})$. Fr.1.3 was sequentially separated over a Sephadex LH-20 column $\left(\mathrm{CH}_{2} \mathrm{Cl}_{2} / \mathrm{MeOH} 1: 1\right.$, v/v), and further purified by an ODS column $(90 \% \mathrm{MeOH})$ to yield compounds 10 (10.3 $\mathrm{mg})$ and 20 (10.7 mg). Fr.2 was subjected to Sephadex LH-20 column chromatography $\left(\mathrm{CH}_{2} \mathrm{Cl}_{2} / \mathrm{MeOH}\right.$ 1:1, v/v) to produce two subfractions (Fr.2.1-2.2). Fr.2.1 was sequentially separated over a silica gel column $\left(\mathrm{CH}_{2} \mathrm{Cl}_{2}-\mathrm{MeOH} 20: 1\right.$, v/v), and then purified by ODS column $(85 \% \mathrm{MeOH})$ to yield compounds $7(800.0 \mathrm{mg}), 15(18.2 \mathrm{mg})$ and 17 (200.0 mg). Fr.2.2 was chromatographed over a silica gel column $\left(\mathrm{CH}_{2} \mathrm{Cl}_{2-}\right.$ $\mathrm{MeOH} 30: 1, \mathrm{v} / \mathrm{v})$, and purified by an ODS column $(75 \% \mathrm{MeOH})$ to yield compounds 2 (21.3 mg) and 3 (11.8 mg). Fr.3 was subjected to a silica gel column $\left(\mathrm{CH}_{2} \mathrm{Cl}_{2}-\mathrm{MeOH}\right.$ $30: 1, \mathrm{v} / \mathrm{v})$ to produce two subfractions (Fr.3.1-3.2). Each subfraction was subjected to Sephadex LH-20 column chromatography $\left(\mathrm{CH}_{2} \mathrm{Cl}_{2} / \mathrm{MeOH} 1: 1, \mathrm{v} / \mathrm{v}\right)$ individually, and further purified by an ODS column $(80 \% \mathrm{MeOH})$, and semipreparative HPLC (90\% $\left.\mathrm{MeOH} / \mathrm{H}_{2} \mathrm{O}, \mathrm{v} / \mathrm{v}\right)$ to yield compounds 5 (12.8 mg), 11 (2.4 mg), 12 (3.1 mg), 21 (2.7 $\mathrm{mg}$ ) and $22(2.5 \mathrm{mg})$, respectively. Fr.4 was sequentially separated over a silica gel column $\left(\mathrm{CH}_{2} \mathrm{Cl}_{2}-\mathrm{MeOH} 40: 1, \mathrm{v} / \mathrm{v}\right)$ to yield three subfractions (Fr.4.1-4.3). Each subfraction was subjected to Sephadex LH-20 column chromatography $\left(\mathrm{CH}_{2} \mathrm{Cl}_{2} / \mathrm{MeOH}\right.$ $1: 1, \mathrm{v} / \mathrm{v})$ individually, and further purified by an ODS column $(75 \% \mathrm{MeOH})$, and semipreparative HPLC $\left(80 \% \mathrm{MeOH} / \mathrm{H}_{2} \mathrm{O}, \mathrm{v} / \mathrm{v}\right)$ to yield compounds 8 (445.0 mg), 13 (3.0 mg), $14(3.3 \mathrm{mg}), \mathbf{1 8}(22.5 \mathrm{mg}) \mathbf{2 3}(3.2 \mathrm{mg})$ and $\mathbf{2 4}(2.4 \mathrm{mg})$. Fr.5 was subjected to Sephadex LH-20 column chromatography $\left(\mathrm{CH}_{2} \mathrm{Cl}_{2} / \mathrm{MeOH} 1: 1, \mathrm{v} / \mathrm{v}\right)$ to produce three subfractions (Fr.5.1-5.3). Fr.5.2 was sequentially separated over a silica gel column $\left(\mathrm{CH}_{2} \mathrm{Cl}_{2}-\mathrm{MeOH} 30: 1, \mathrm{v} / \mathrm{v}\right)$, and then purified by an ODS column $(65 \% \mathrm{MeOH})$ to yield compounds 4 (40.0 mg), 9 (6.8 mg) and $19(8.7 \mathrm{mg})$.

The structures of 23 known triterpenoids, including ehretiolide (2), ${ }^{1}$ ilelatifol D $(\mathbf{3}),{ }^{2}$ guavenoic acid (4), ${ }^{3} 3 \beta$-O-cis-p-coumaroyl actinidic acid (5), ${ }^{4}$ ursolic acid (6), ${ }^{5}$ 
corosolic acid (7), ${ }^{5}$ asiatic acid (8), ${ }^{5}$ brahmic acid (9), ${ }^{6}$ ursaldehyde (10), ${ }^{7} 3 \beta$-O-cis- $p$ coumaroyl corosolic acid (11), ${ }^{8} 3 \beta$-O-trans- $p$-coumaroyl corosolic acid (12), ${ }^{8} 3 \beta$-Ocis-p-coumaroyl asiatic acid (13), ${ }^{9} \quad 3 \beta$-O-trans- $p$-coumaroyl asiatic acid (14), ${ }^{9}$ alphitolic acid (15), ${ }^{10}$ oleanolic acid (16), ${ }^{5}$ maslinic acid $(\mathbf{1 7}),{ }^{5}$ arjunolic acid (18), ${ }^{5}$ terminolic acid (19), ${ }^{11}$ oleanoaldehyde (20), ${ }^{12} 3 \beta$-O-cis-p-coumaroyl maslinic acid (21), ${ }^{10} 3 \beta$-O-trans-p-coumaroyl maslinic acid (22), ${ }^{10} 3 \beta$-O-cis-p-coumaroyl arjunolic acid (23), ${ }^{13} 3 \beta$-O-trans- $p$-coumaroyl arjunolic acid (24), ${ }^{13}$ were elucidated on the basis of NMR and MS data as well as comparison with literature. 


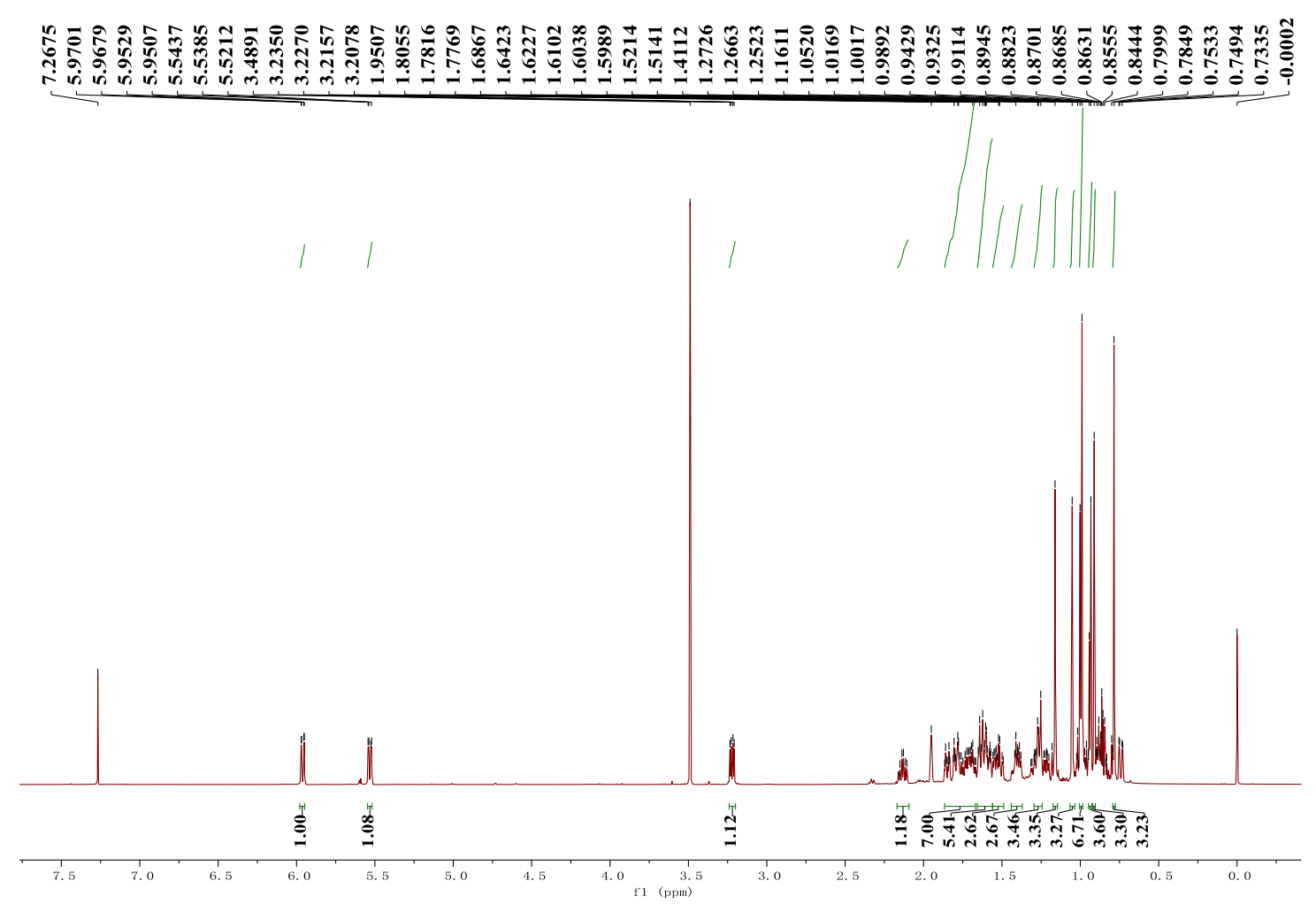

Figure S16. ${ }^{1} \mathrm{H}-\mathrm{NMR}\left(\mathrm{CDCl}_{3}-d, 600 \mathrm{MHz}\right)$ spectrum of ehretiolide (2)

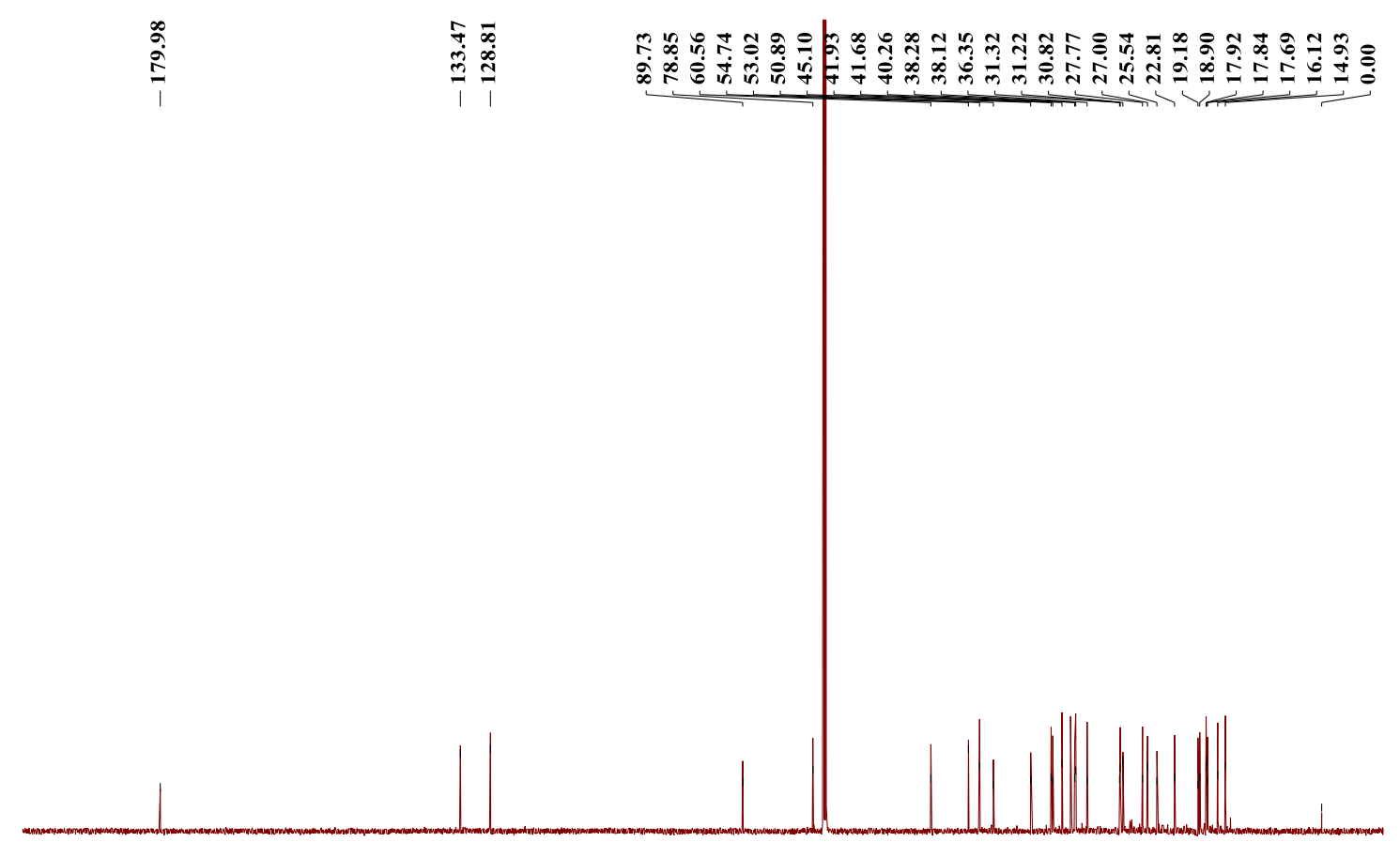

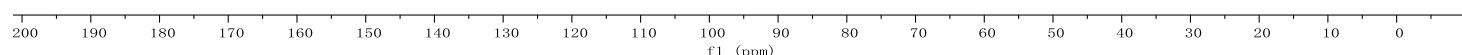

Figure S17. ${ }^{13} \mathrm{C}$ NMR $\left(\mathrm{CDCl}_{3}-d, 150 \mathrm{MHz}\right)$ spectrum of ehretiolide (2) 


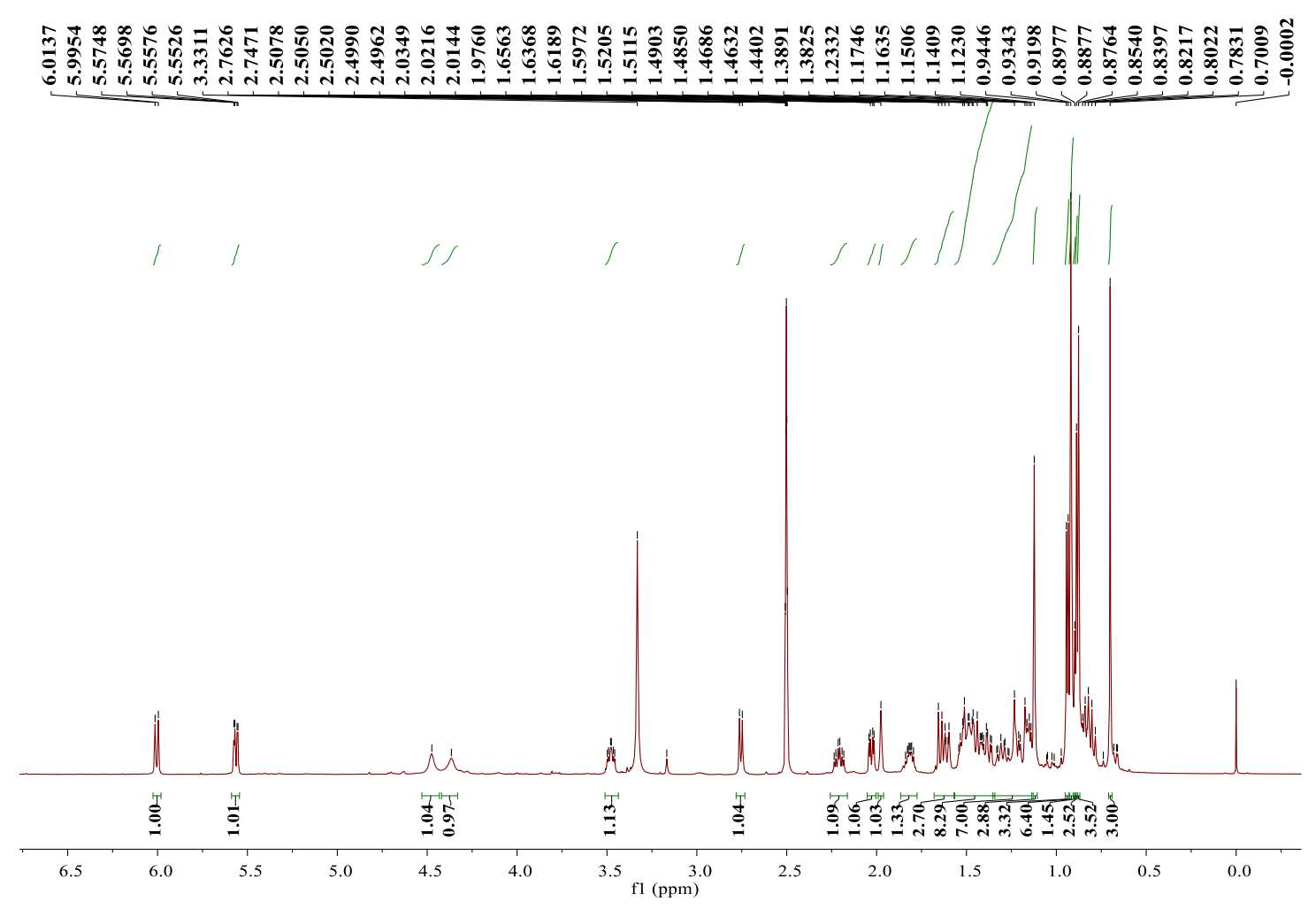

Figure S18. ${ }^{1} \mathrm{H}-\mathrm{NMR}$ (DMSO- $d_{6}, 600 \mathrm{MHz}$ ) spectrum of ilelatifol D (3)
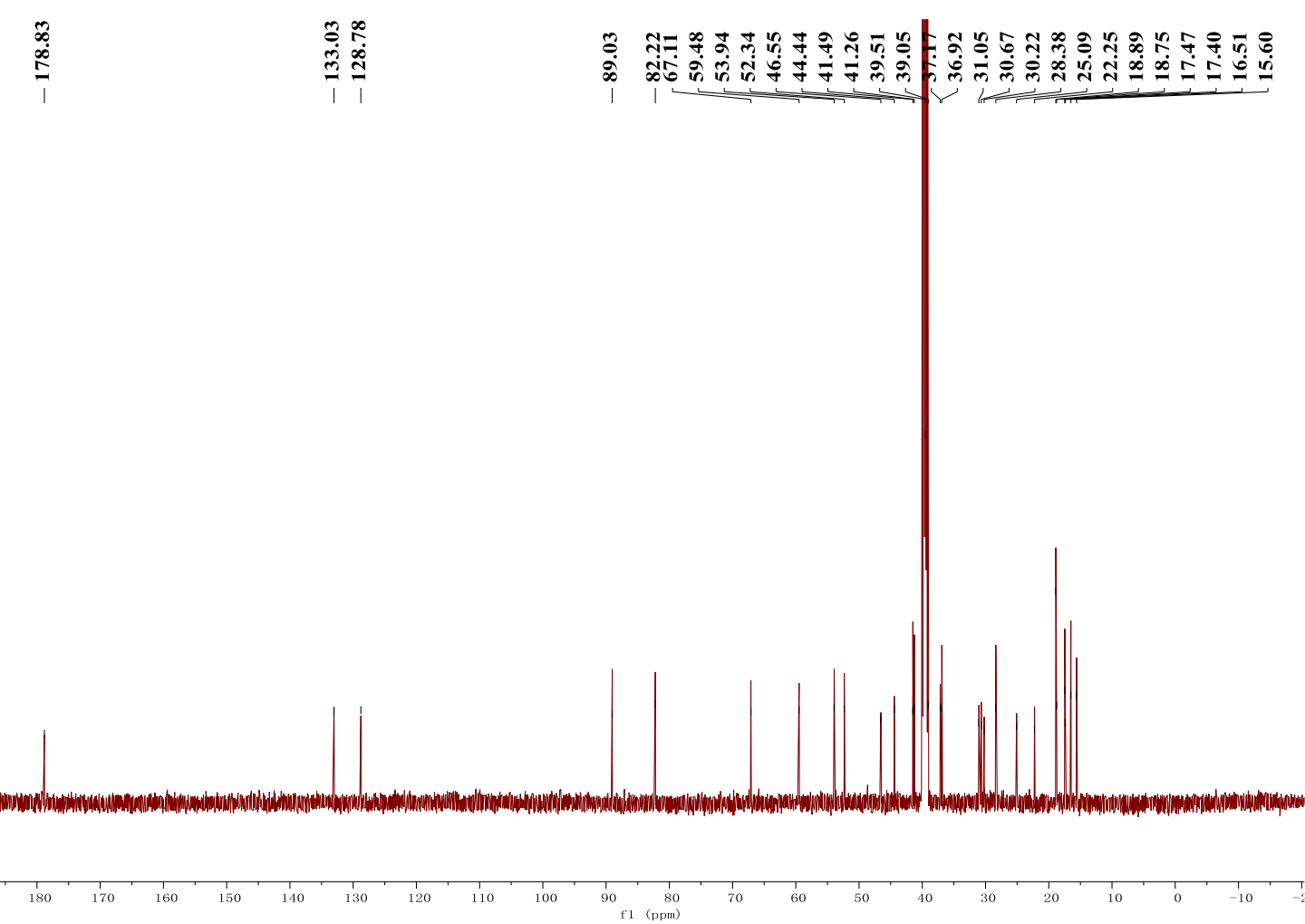

Figure S19. ${ }^{13} \mathrm{C}-\mathrm{NMR}\left(\mathrm{DMSO}-d_{6}, 150 \mathrm{MHz}\right)$ spectrum of ilelatifol D (3) 


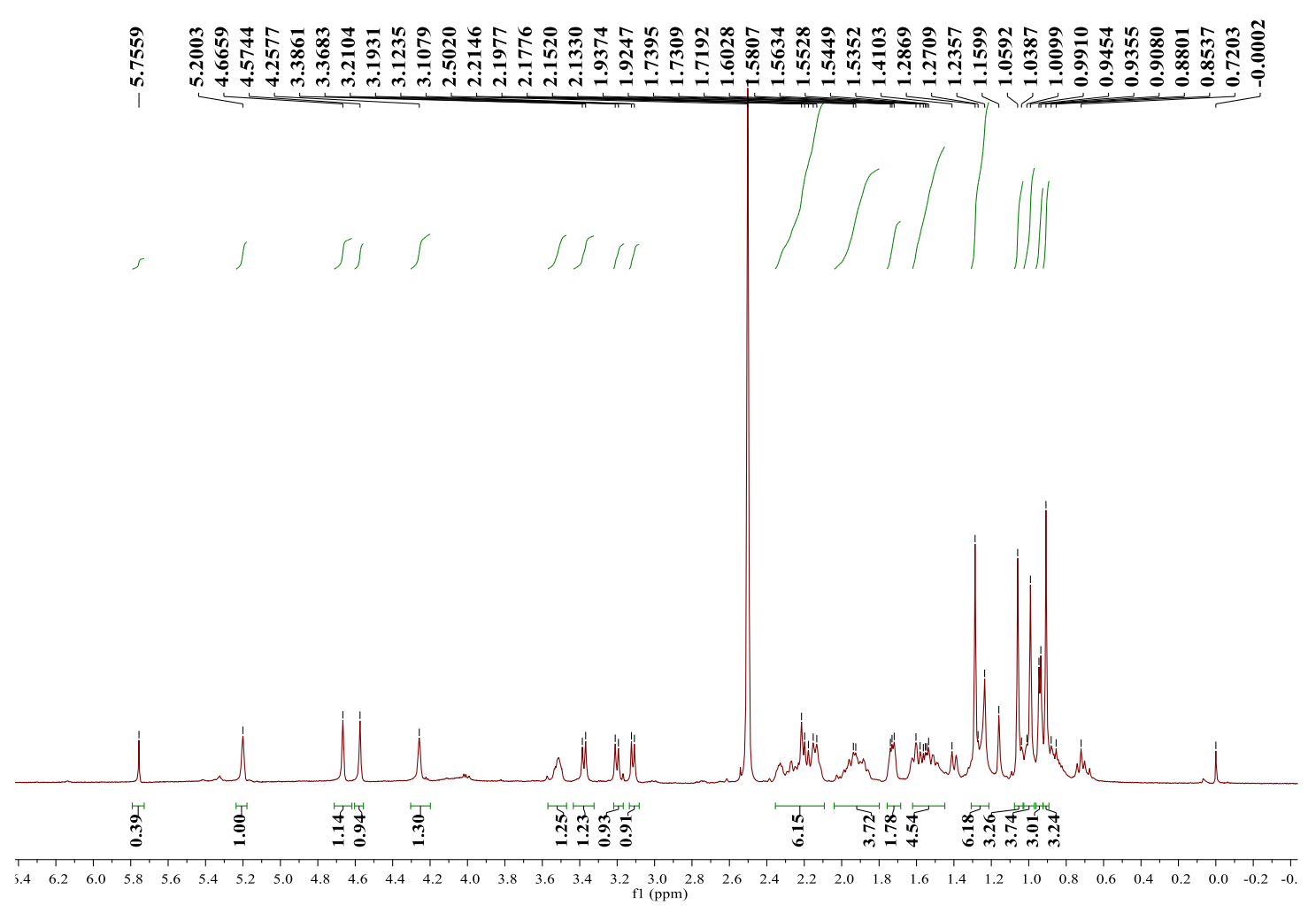

Figure S20. ${ }^{1} \mathrm{H}-\mathrm{NMR}\left(\mathrm{DMSO}-d_{6}, 600 \mathrm{MHz}\right.$ ) spectrum of guavenoic acid (4)

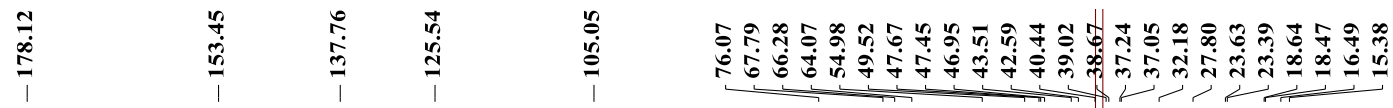

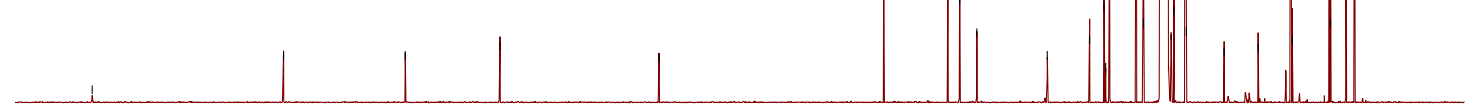

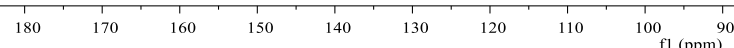

Figure S21. ${ }^{13} \mathrm{C}-\mathrm{NMR}$ (DMSO- $d_{6}, 150 \mathrm{MHz}$ ) spectrum of guavenoic acid (4) 


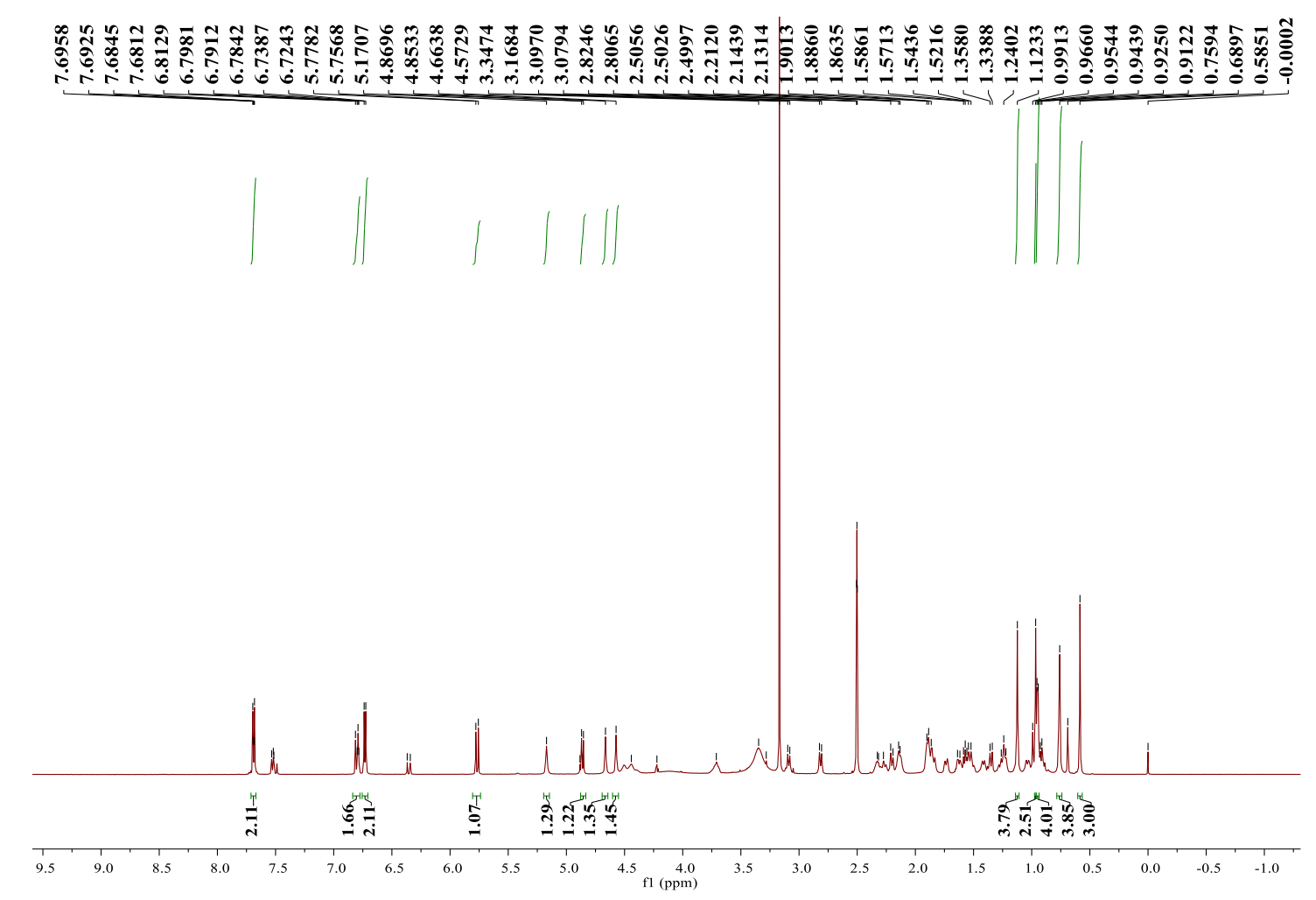

Figure S22. ${ }^{1} \mathrm{H}-\mathrm{NMR}$ (DMSO- $d_{6}, 600 \mathrm{MHz}$ ) spectrum of $3 \beta$-O-cis- $p$-coumaroyl actinidic acid (5)

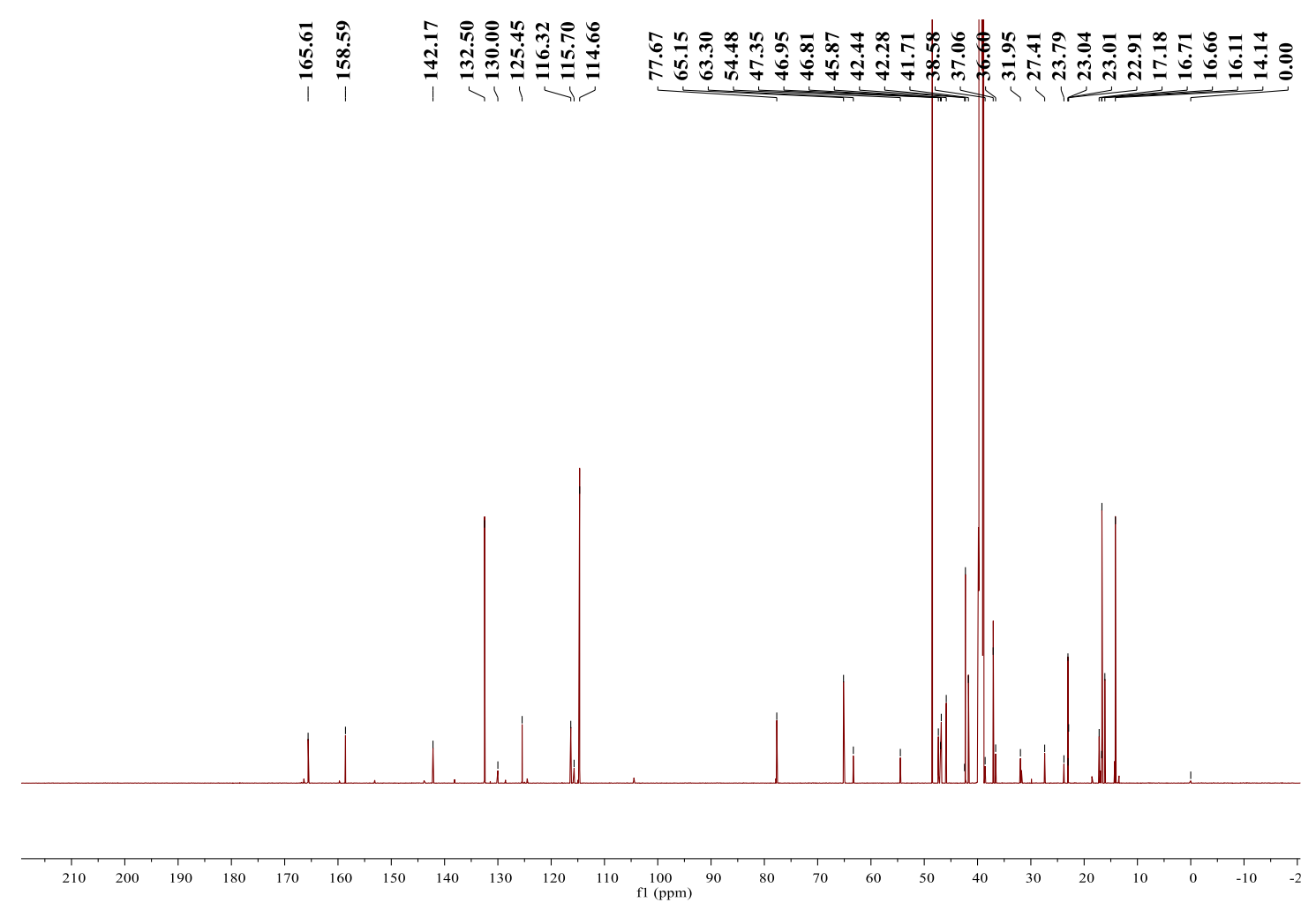

Figure S23. ${ }^{13} \mathrm{C}$-NMR (DMSO- $d_{6}, 150 \mathrm{MHz}$ ) spectrum of compound $3 \beta$-O-cis- $p$ coumaroyl actinidic acid (5) 

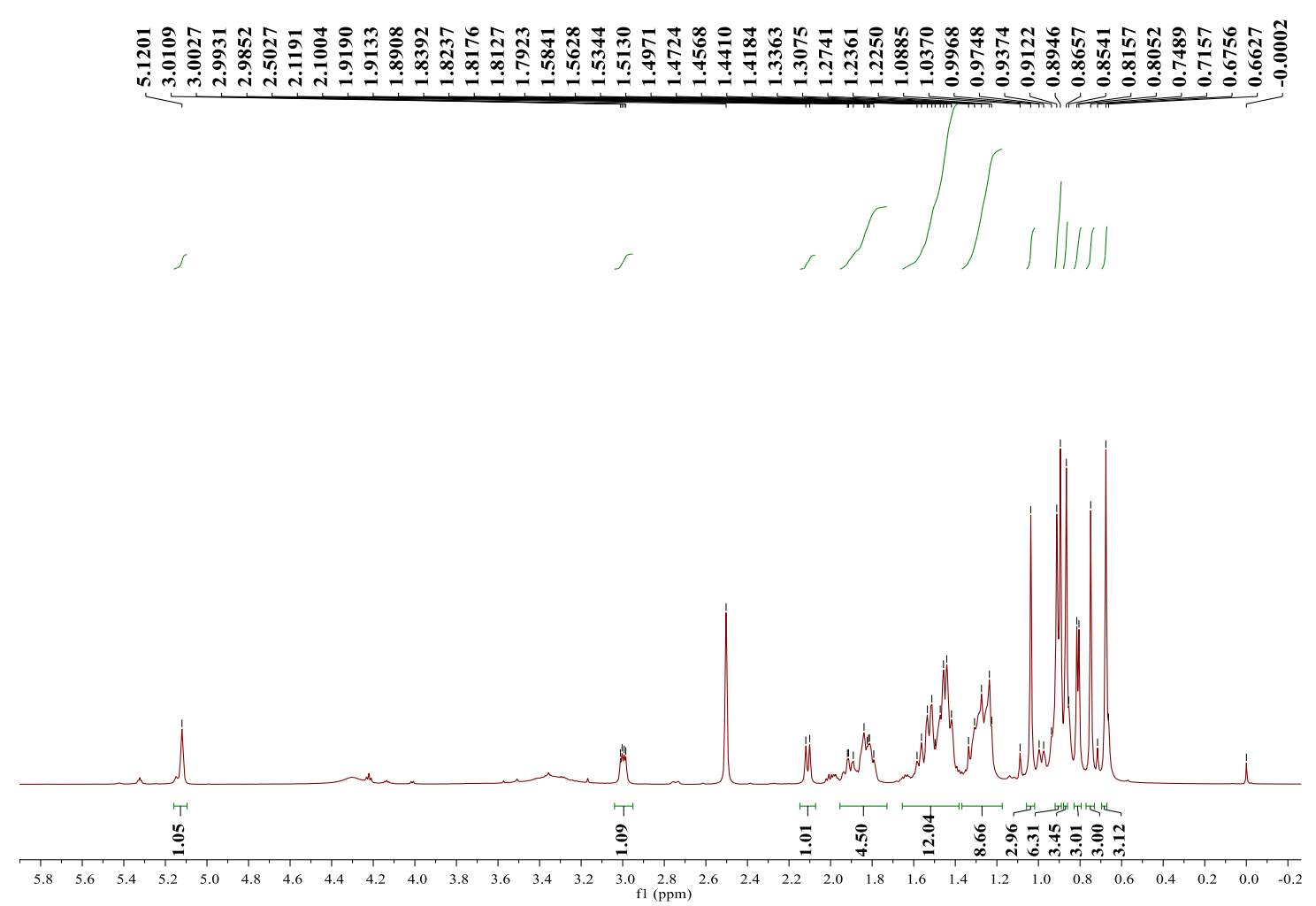

Figure S24. ${ }^{1} \mathrm{H}-\mathrm{NMR}$ (DMSO- $d_{6}, 600 \mathrm{MHz}$ ) spectrum of ursolic acid (6)
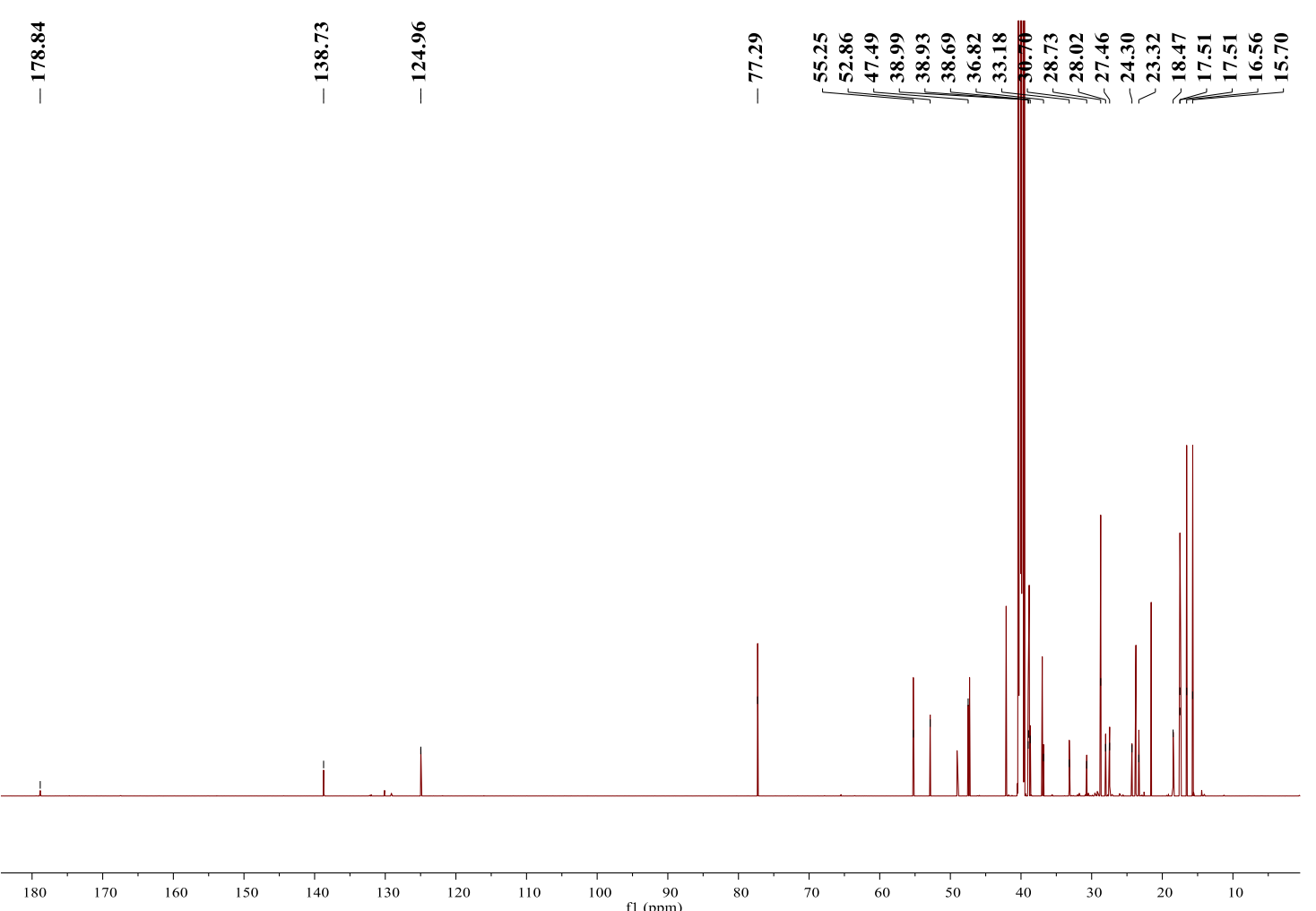

Figure S25. ${ }^{13} \mathrm{C}-\mathrm{NMR}$ (DMSO- $d_{6}, 150 \mathrm{MHz}$ ) spectrum of ursolic acid (6) 


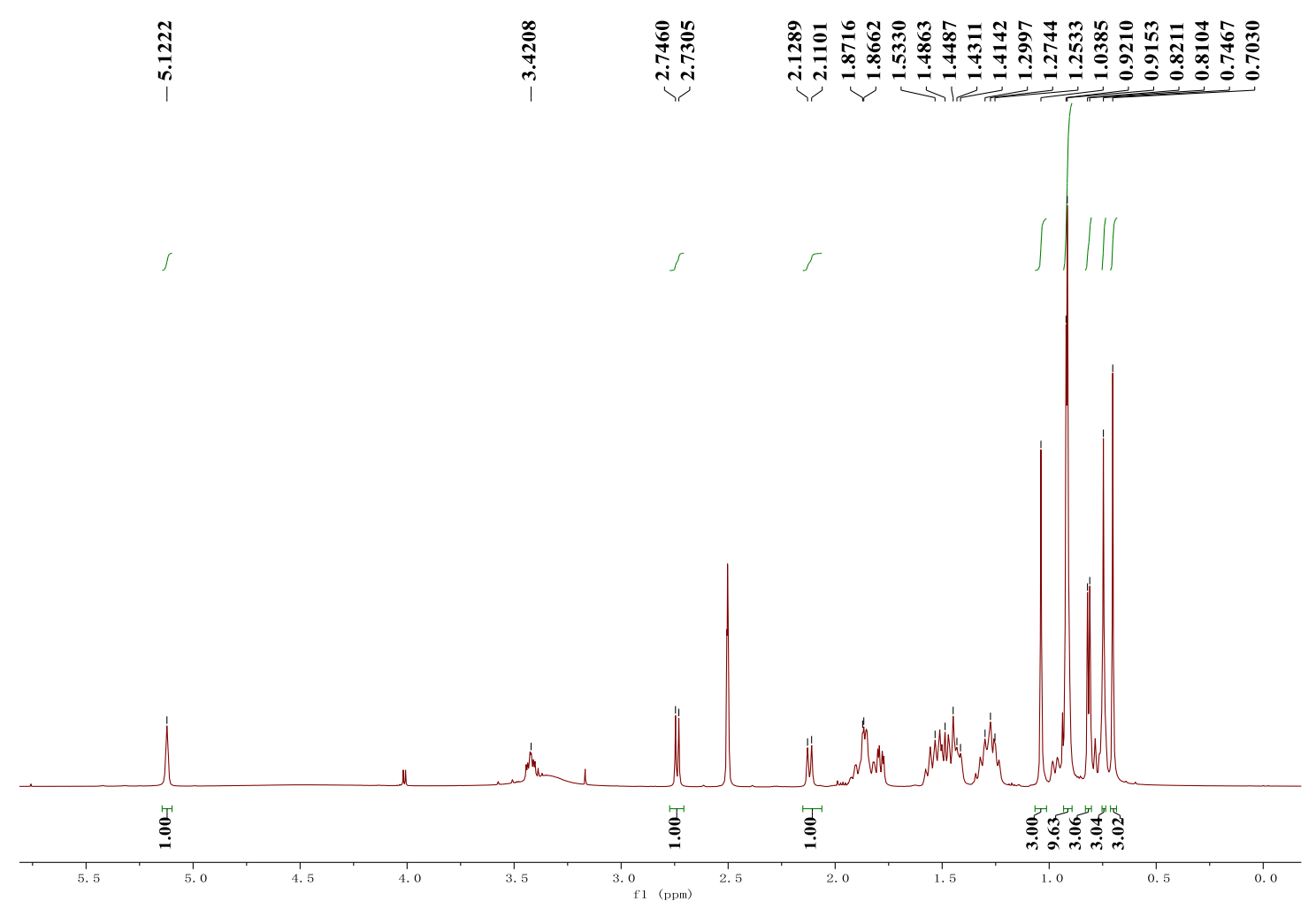

Figure S26. ${ }^{1} \mathrm{H}-\mathrm{NMR}\left(\mathrm{DMSO}-d_{6}, 600 \mathrm{MHz}\right)$ spectrum of corosolic acid (7)
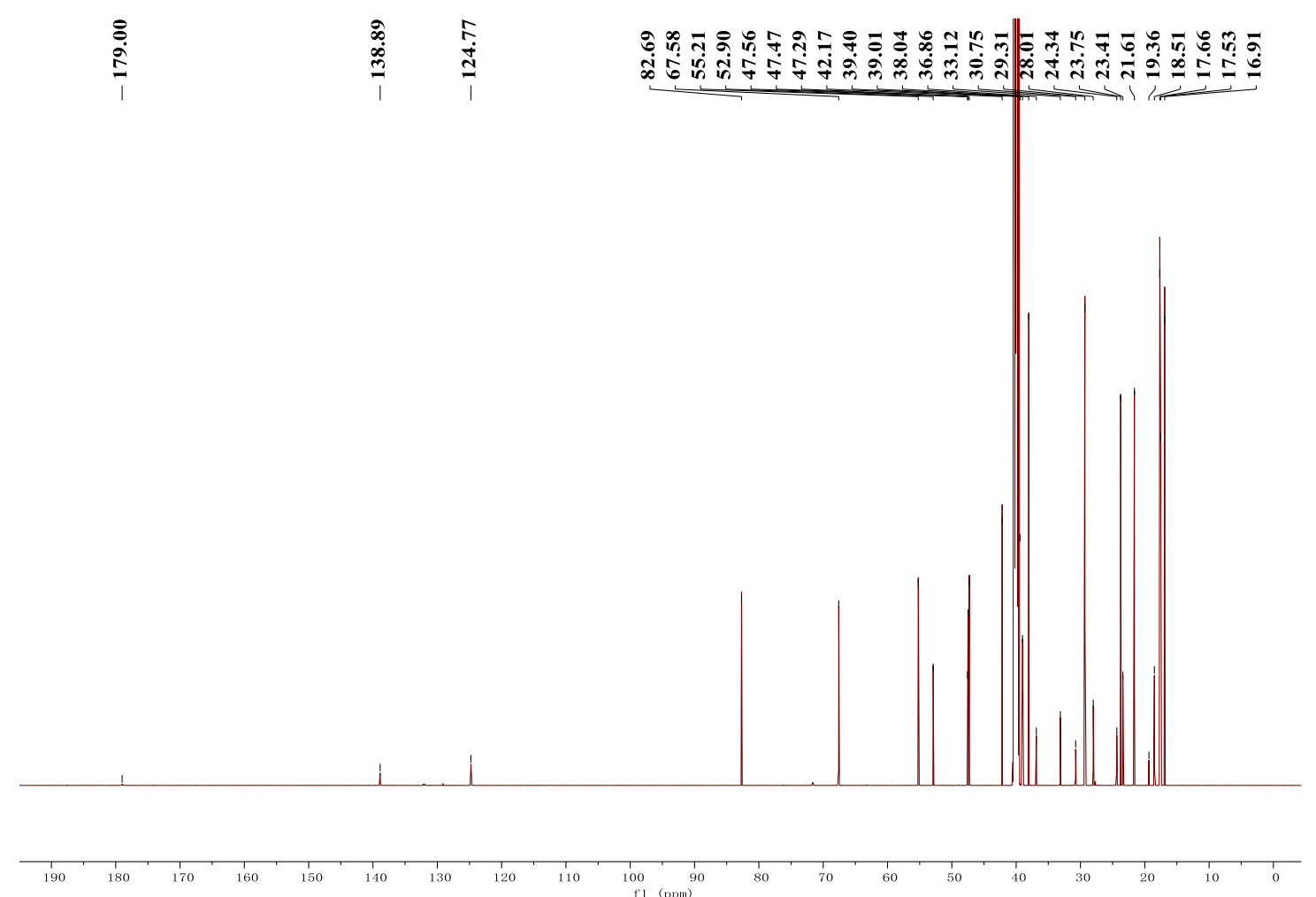

Figure S27. ${ }^{13} \mathrm{C}-\mathrm{NMR}$ (DMSO- $d_{6}, 150 \mathrm{MHz}$ ) spectrum of corosolic acid (7) 


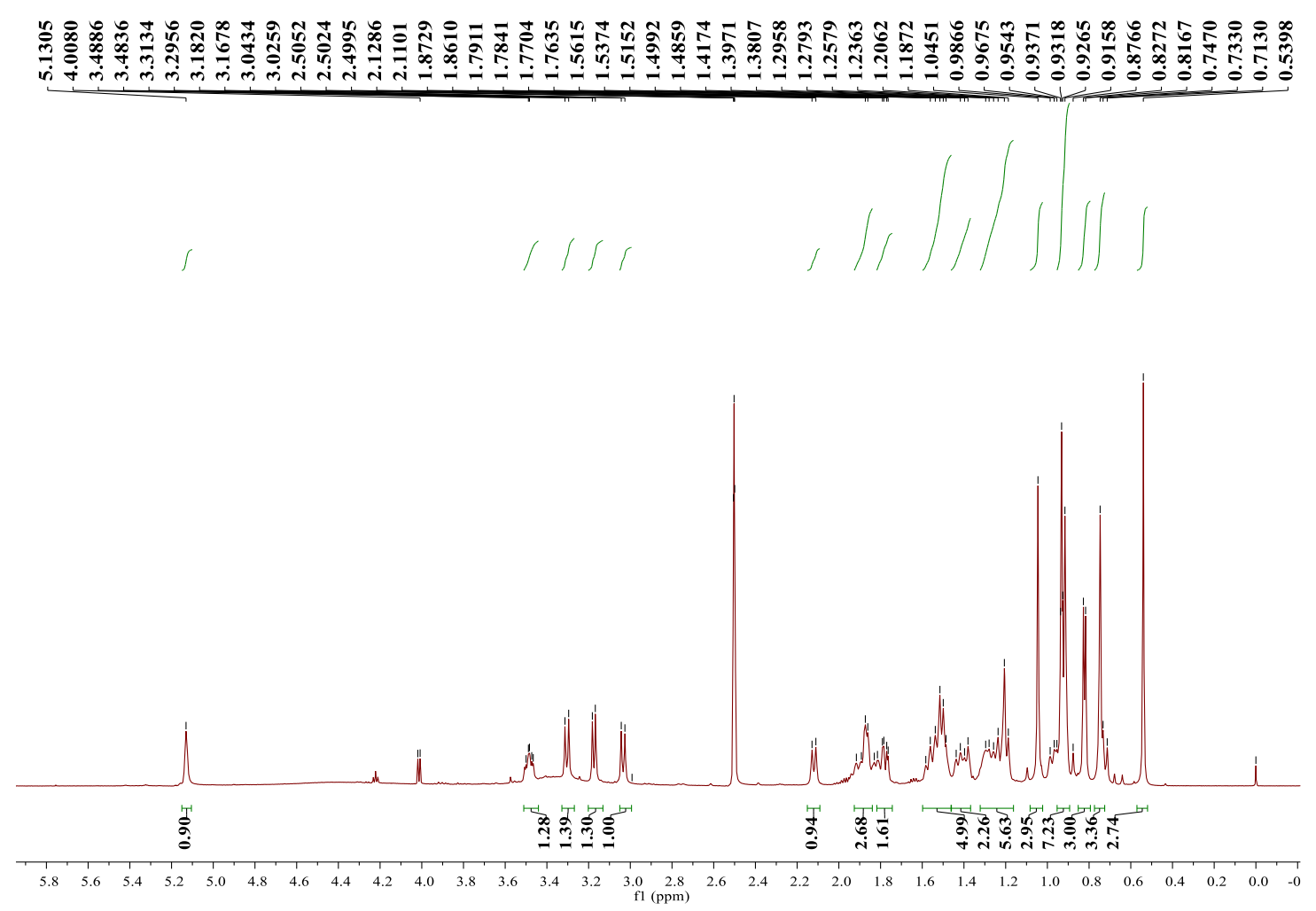

Figure S28. ${ }^{1} \mathrm{H}-\mathrm{NMR}$ (DMSO- $d_{6}, 600 \mathrm{MHz}$ ) spectrum of asiatic acid (8)

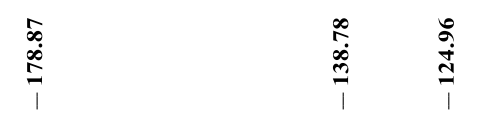

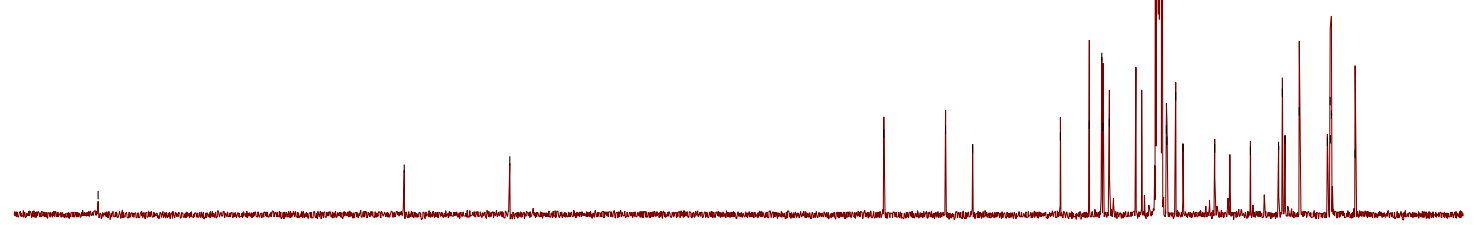

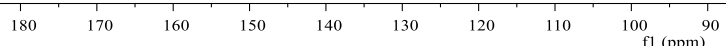

Figure S29. ${ }^{13} \mathrm{C}-\mathrm{NMR}\left(\mathrm{DMSO}-d_{6}, 150 \mathrm{MHz}\right)$ spectrum of asiatic acid (8) 


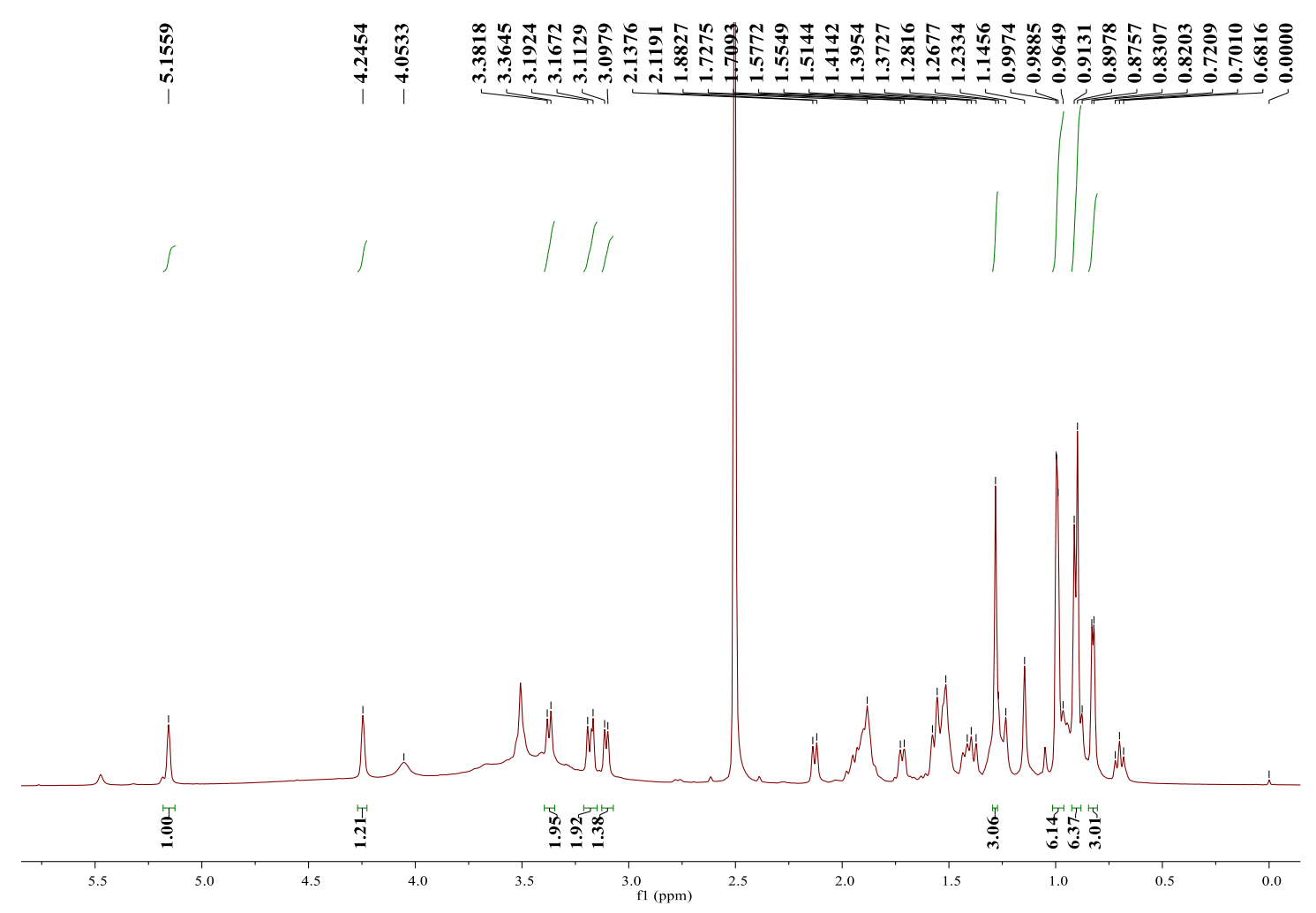

Figure S30. ${ }^{1} \mathrm{H}-\mathrm{NMR}\left(\mathrm{DMSO}-d_{6}, 600 \mathrm{MHz}\right.$ ) spectrum of brahmic acid (9)

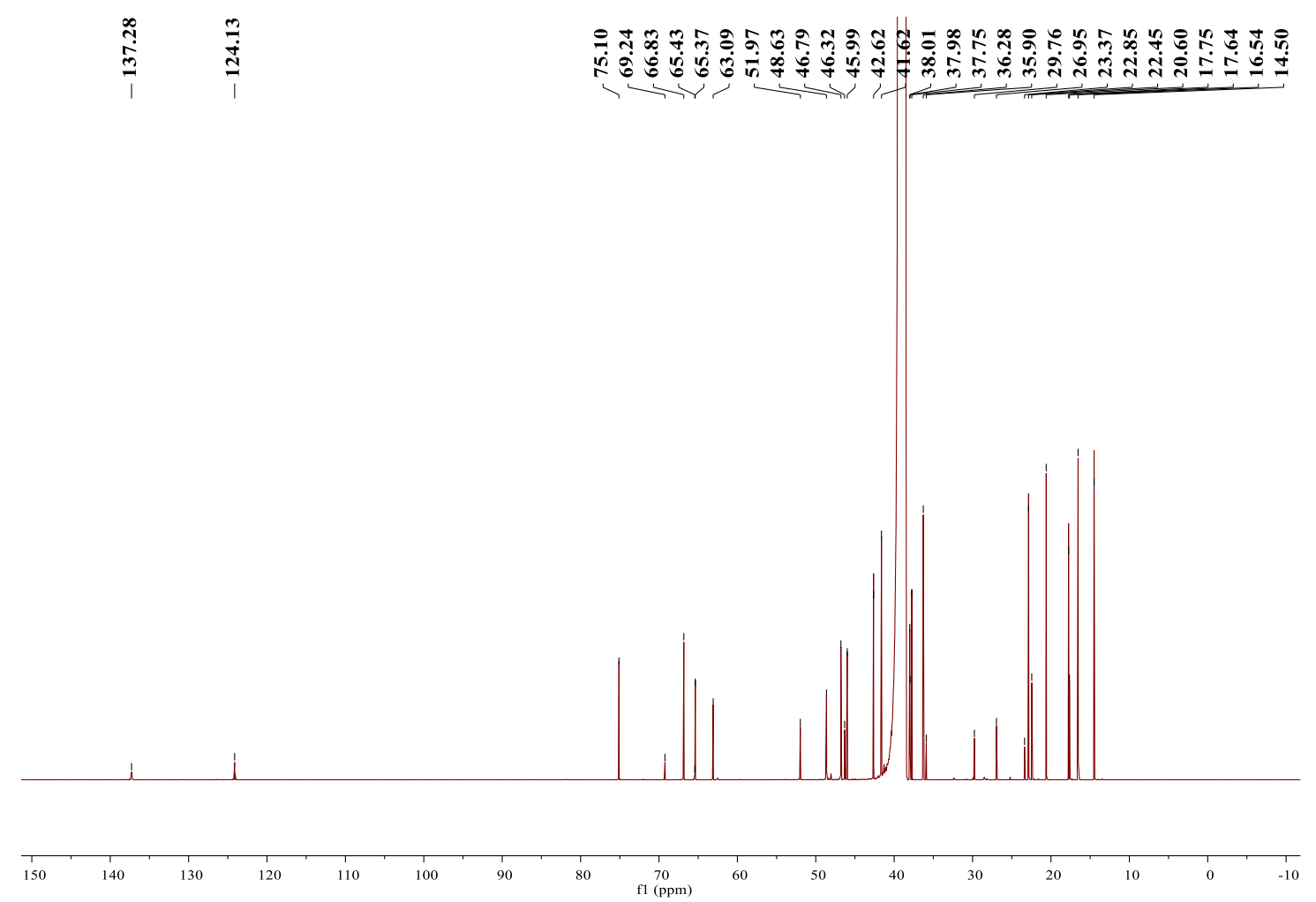

Figure S31. ${ }^{13} \mathrm{C}-\mathrm{NMR}$ (DMSO- $d_{6}, 150 \mathrm{MHz}$ ) spectrum of brahmic acid (9) 


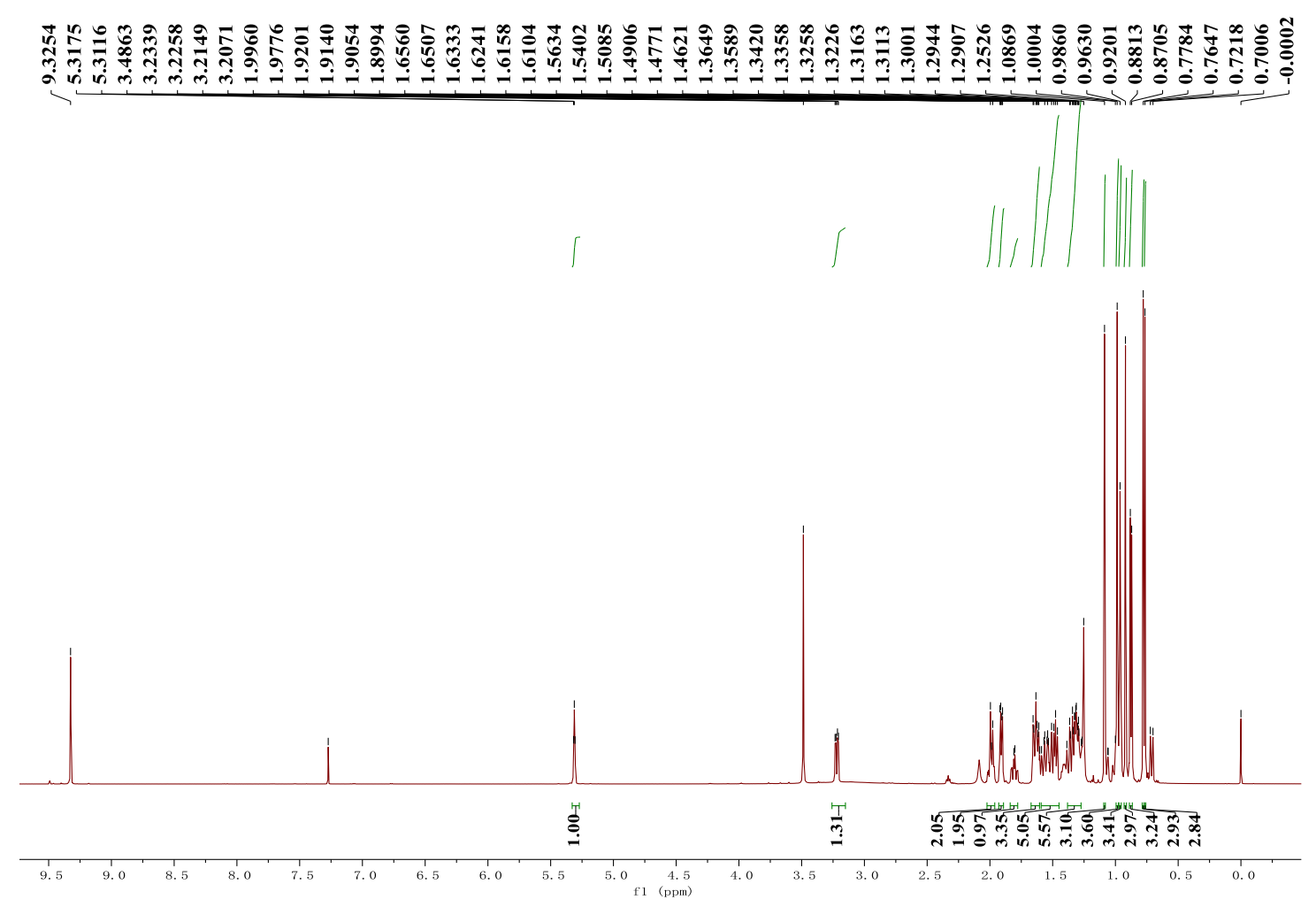

Figure S32. ${ }^{1} \mathrm{H}-\mathrm{NMR}\left(\mathrm{CDCl}_{3}-d, 600 \mathrm{MHz}\right)$ spectrum of ursaldehyde (10)

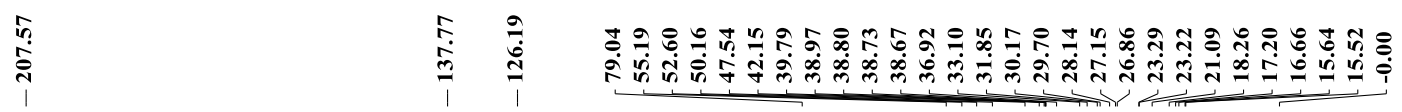

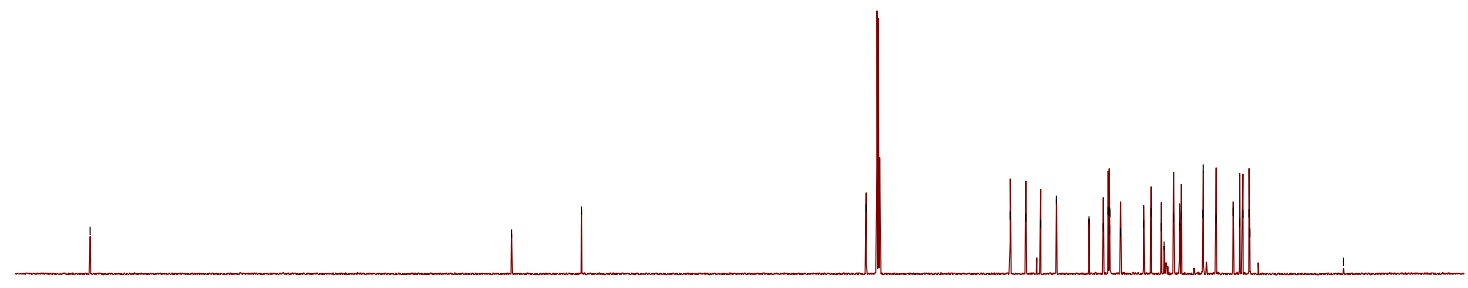

Figure S33. ${ }^{13} \mathrm{C}-\mathrm{NMR}\left(\mathrm{CDCl}_{3}-d, 150 \mathrm{MHz}\right)$ spectrum of ursaldehyde (10) 


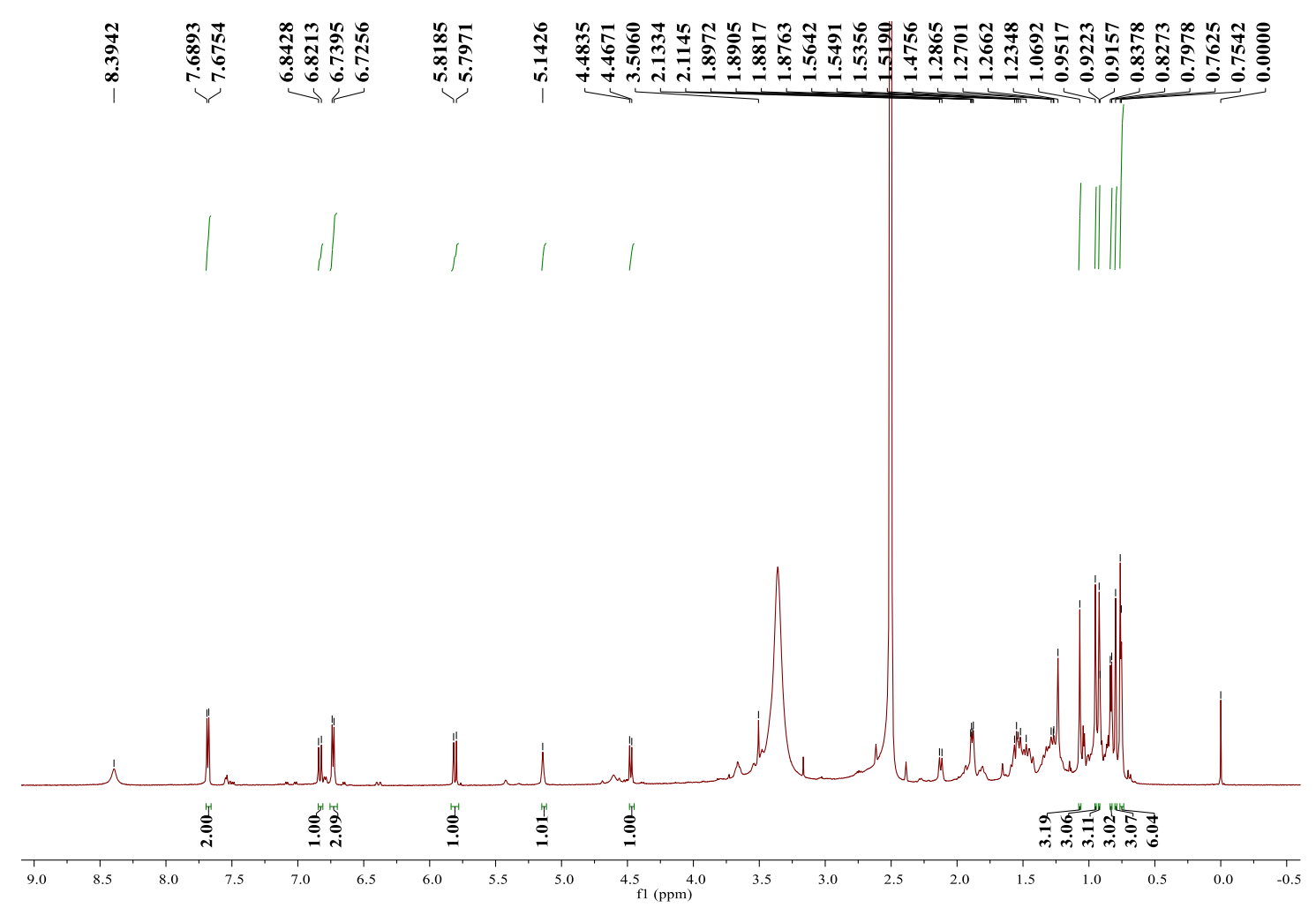

Figure S34. ${ }^{1} \mathrm{H}-\mathrm{NMR}$ (DMSO- $d_{6}, 600 \mathrm{MHz}$ ) spectrum of $3 \beta$-O-cis-p-coumaroyl corosolic acid (11)
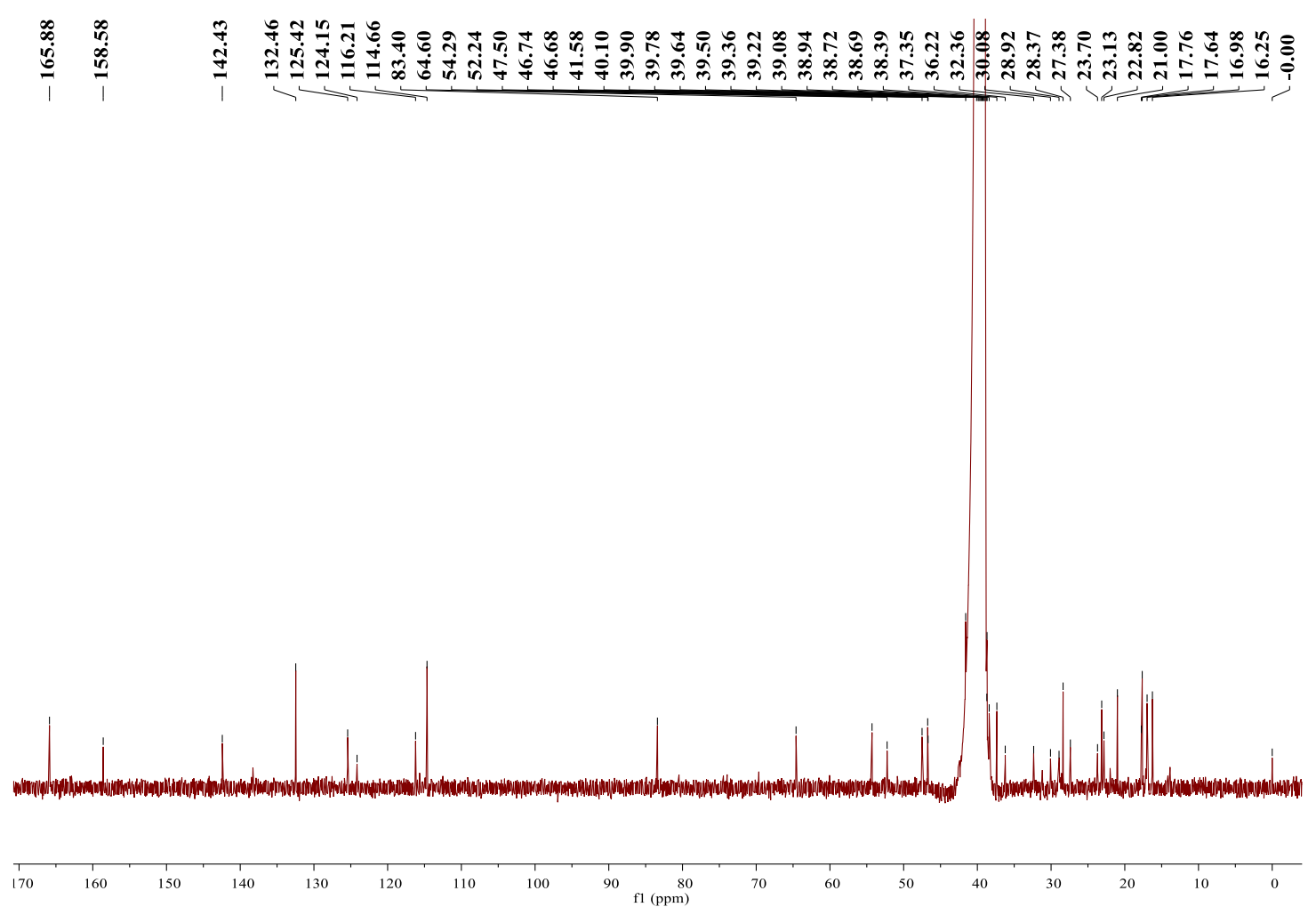

Figure S35. ${ }^{13} \mathrm{C}-\mathrm{NMR}$ (DMSO- $d_{6}, 150 \mathrm{MHz}$ ) spectrum of $3 \beta$-O-cis-p-coumaroyl corosolic acid (11) 


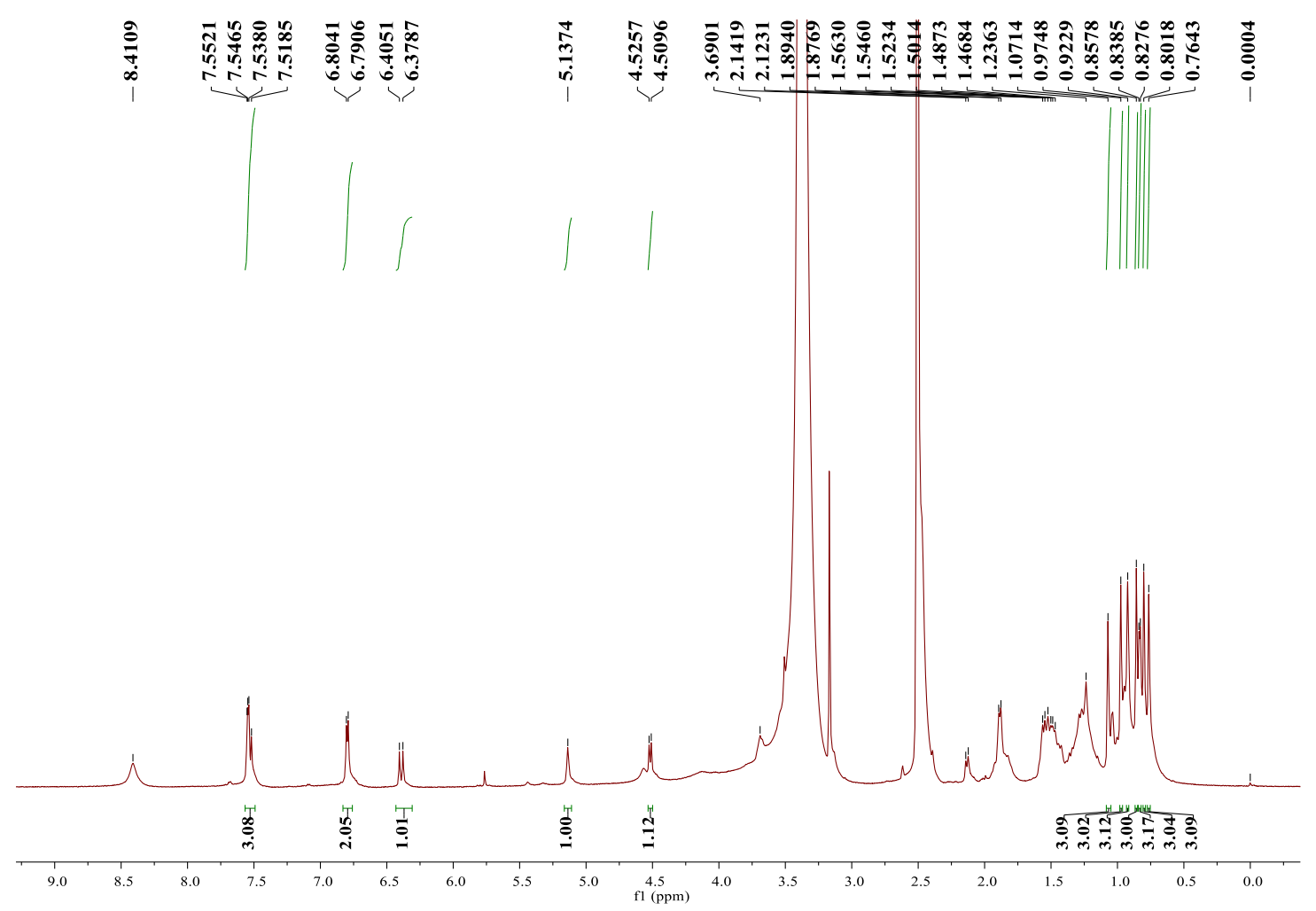

Figure S36. ${ }^{1} \mathrm{H}-\mathrm{NMR}$ (DMSO- $d_{6}, 600 \mathrm{MHz}$ ) spectrum of $3 \beta$-O-trans-p-coumaroyl corosolic acid (12)

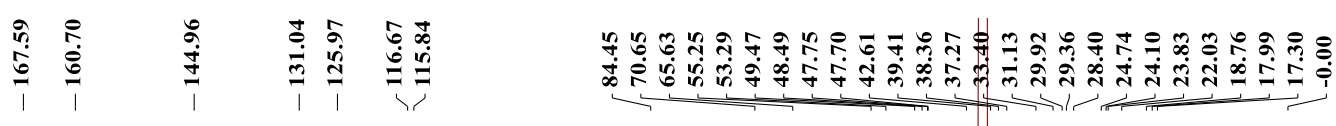
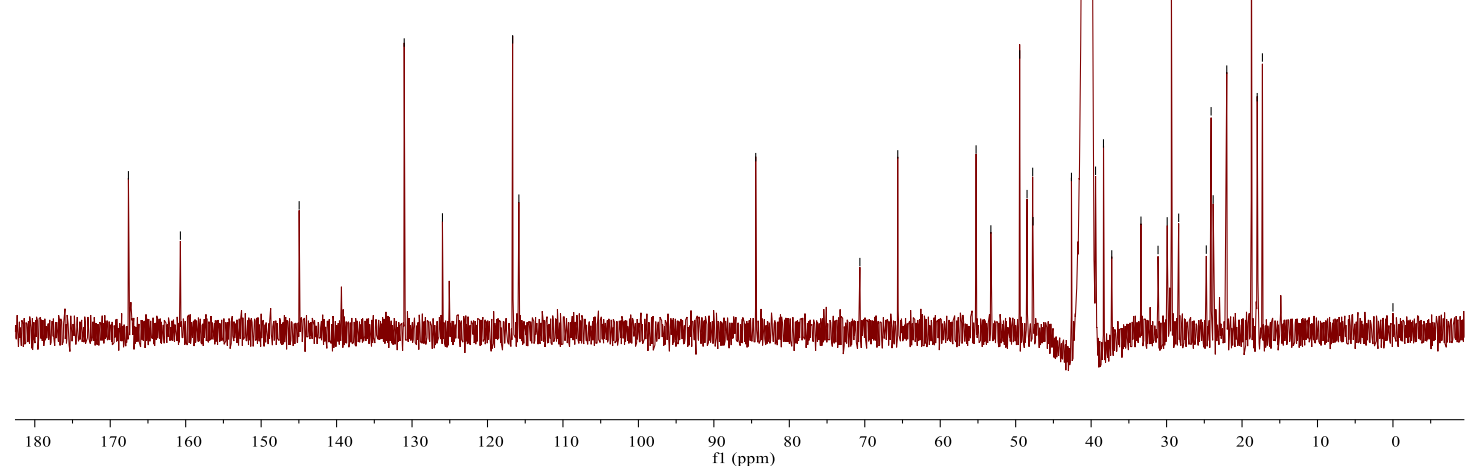

Figure S37. ${ }^{13} \mathrm{C}$-NMR (DMSO- $d_{6}, 150 \mathrm{MHz}$ ) spectrum of $3 \beta$-O-trans-p-coumaroyl corosolic acid (12) 


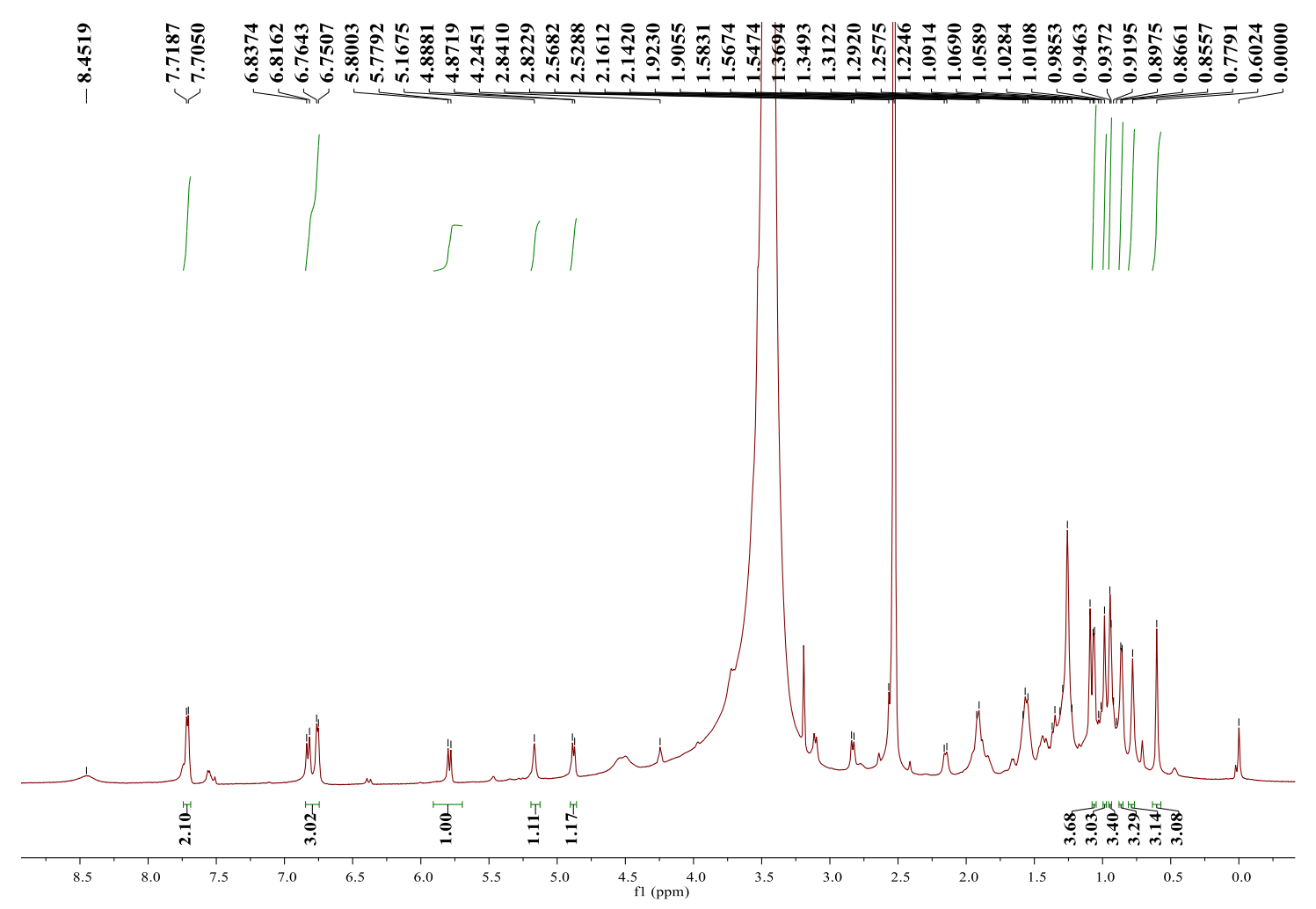

Figure S38. ${ }^{1} \mathrm{H}-\mathrm{NMR}$ (DMSO- $d_{6}, 600 \mathrm{MHz}$ ) spectrum of $3 \beta$-O-cis- $p$-coumaroyl asiatic acid (13)

舀
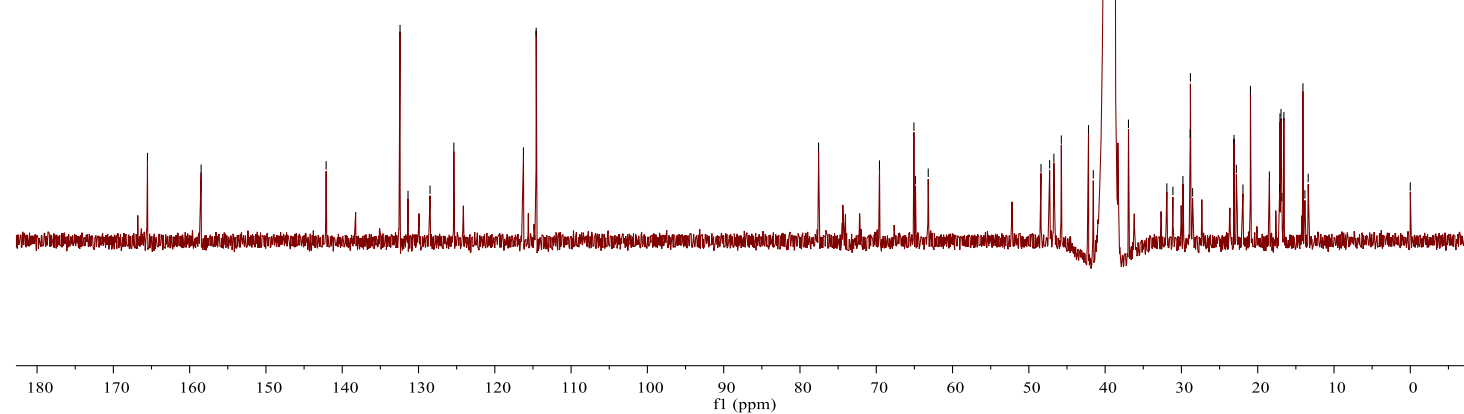

Figure S39. ${ }^{13} \mathrm{C}-\mathrm{NMR}$ (DMSO- $d_{6}, 150 \mathrm{MHz}$ ) spectrum of $3 \beta$-O-cis-p-coumaroyl asiatic acid (13) 


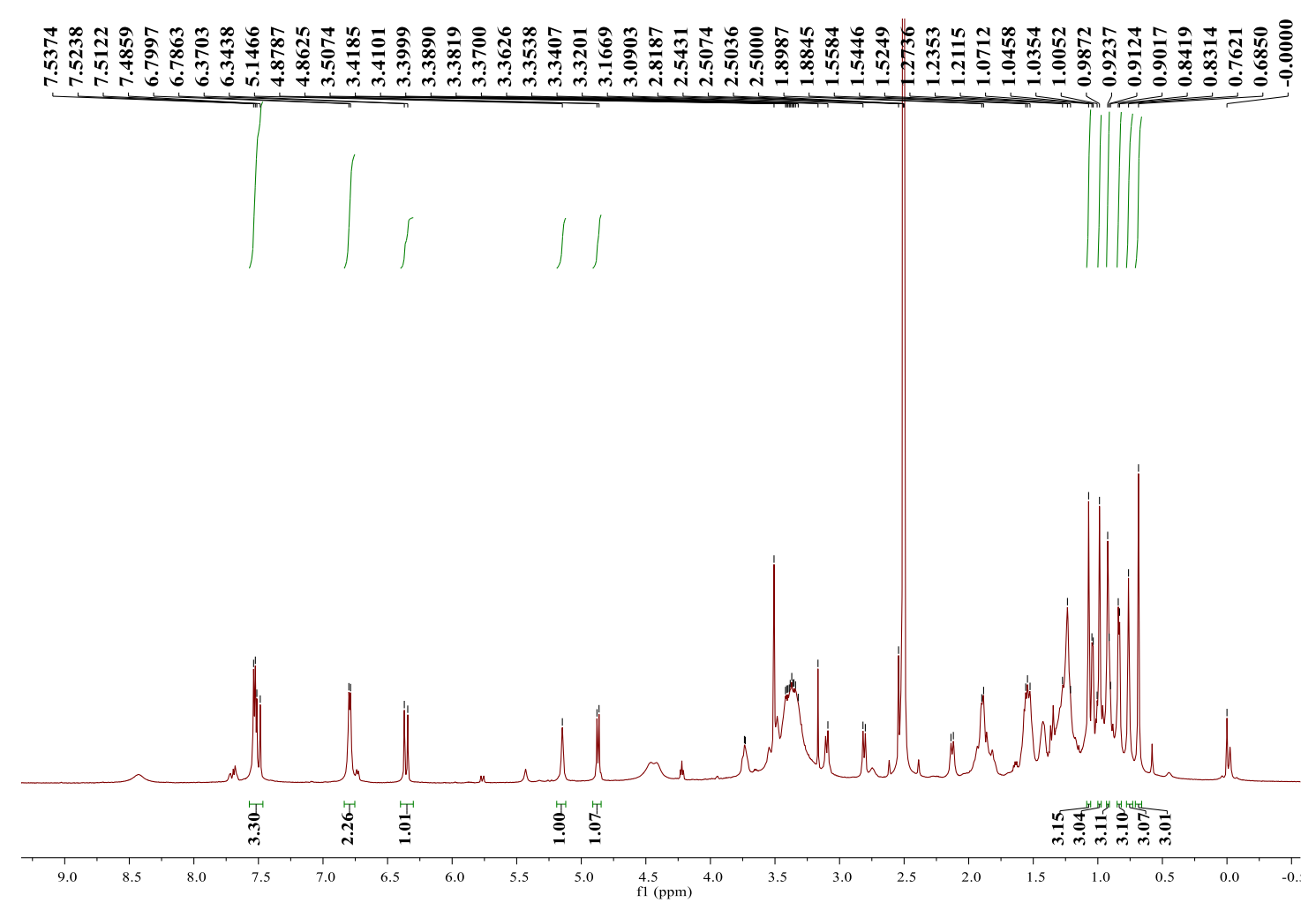

Figure S40. ${ }^{1} \mathrm{H}-\mathrm{NMR}$ (DMSO- $d_{6}, 600 \mathrm{MHz}$ ) spectrum of $3 \beta$-O-trans-p-coumaroyl asiatic acid (14)

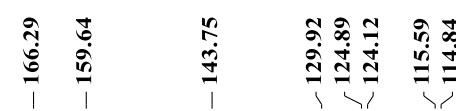

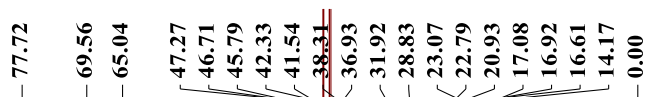

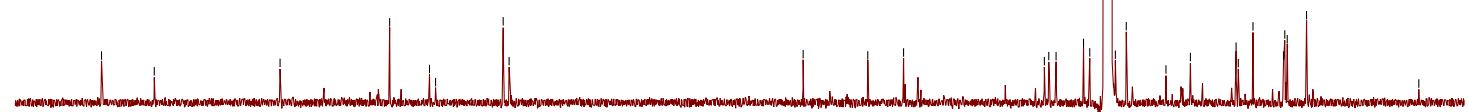

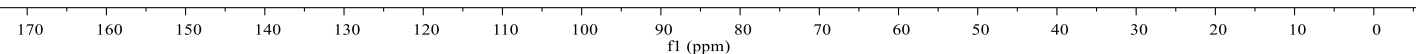

Figure S41. ${ }^{13} \mathrm{C}$-NMR (DMSO- $d_{6}, 150 \mathrm{MHz}$ ) spectrum of $3 \beta$-O-trans-p-coumaroyl asiatic acid (14) 


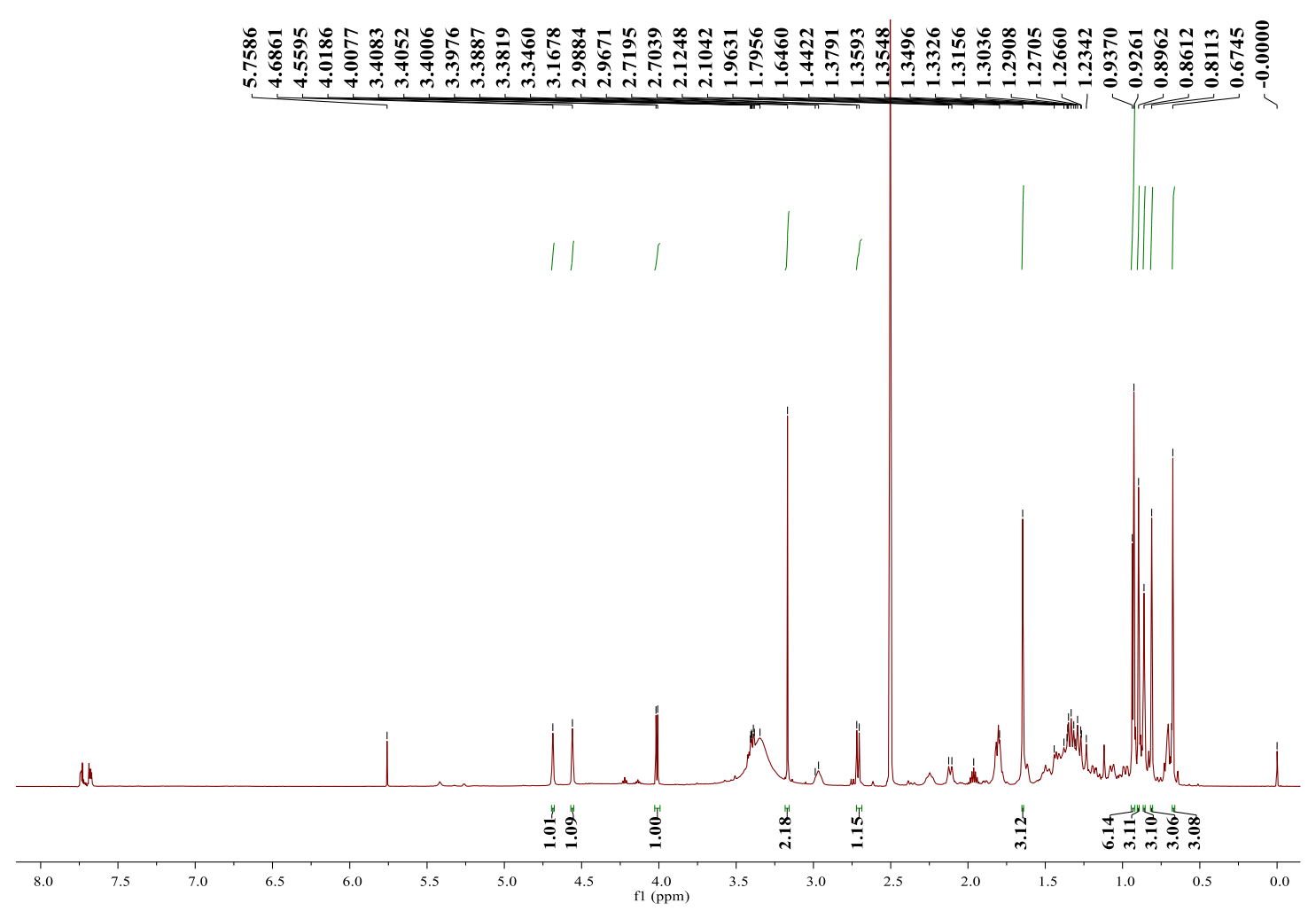

Figure S42. ${ }^{1} \mathrm{H}-\mathrm{NMR}$ (DMSO- $d_{6}, 600 \mathrm{MHz}$ ) spectrum of alphitolic acid (15)
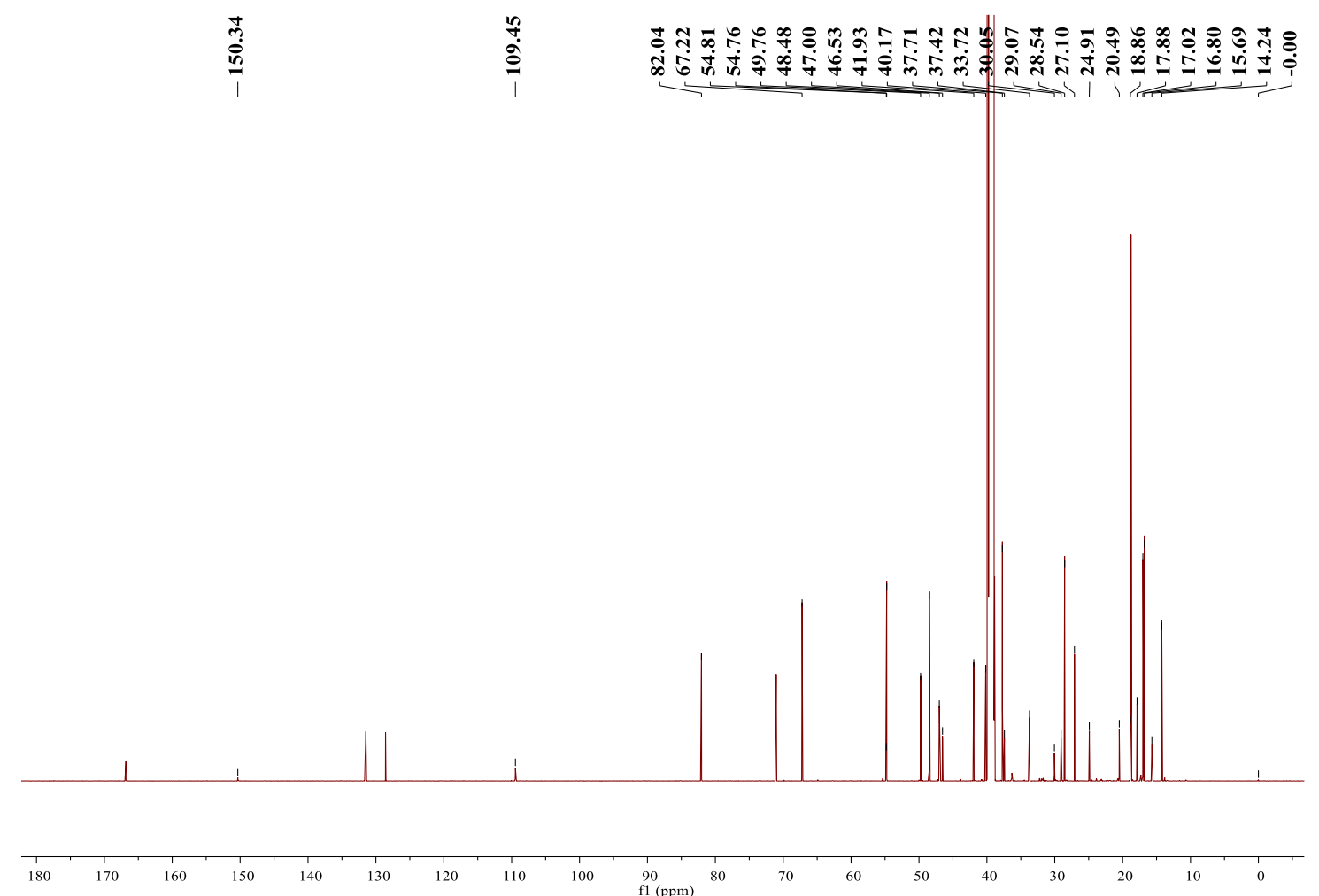

Figure S43. ${ }^{13} \mathrm{C}-\mathrm{NMR}$ (DMSO- $d_{6}, 150 \mathrm{MHz}$ ) spectrum of alphitolic acid (15) 


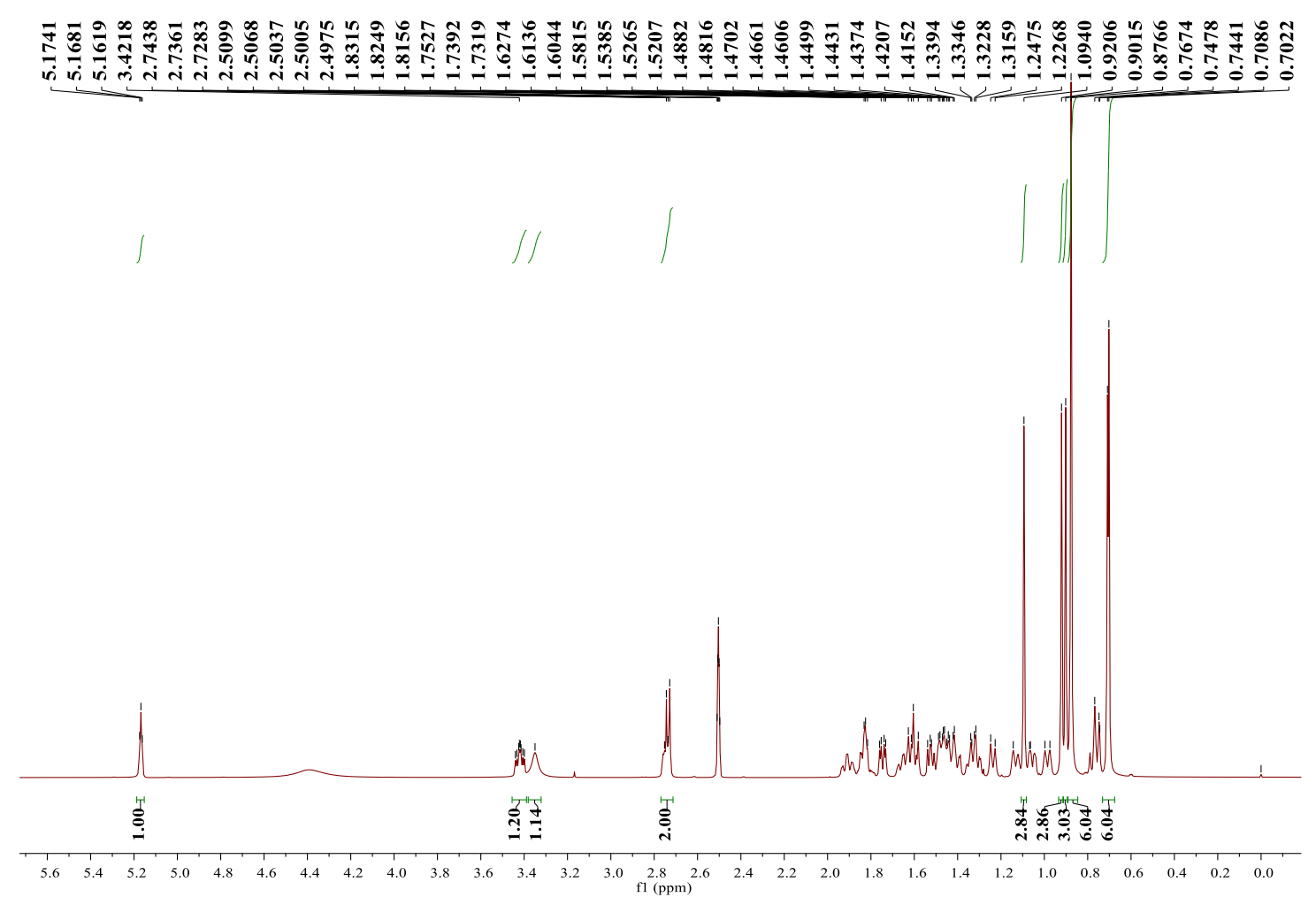

Figure S46. ${ }^{1} \mathrm{H}-\mathrm{NMR}$ (DMSO- $d_{6}, 600 \mathrm{MHz}$ ) spectrum of maslinic acid (17)
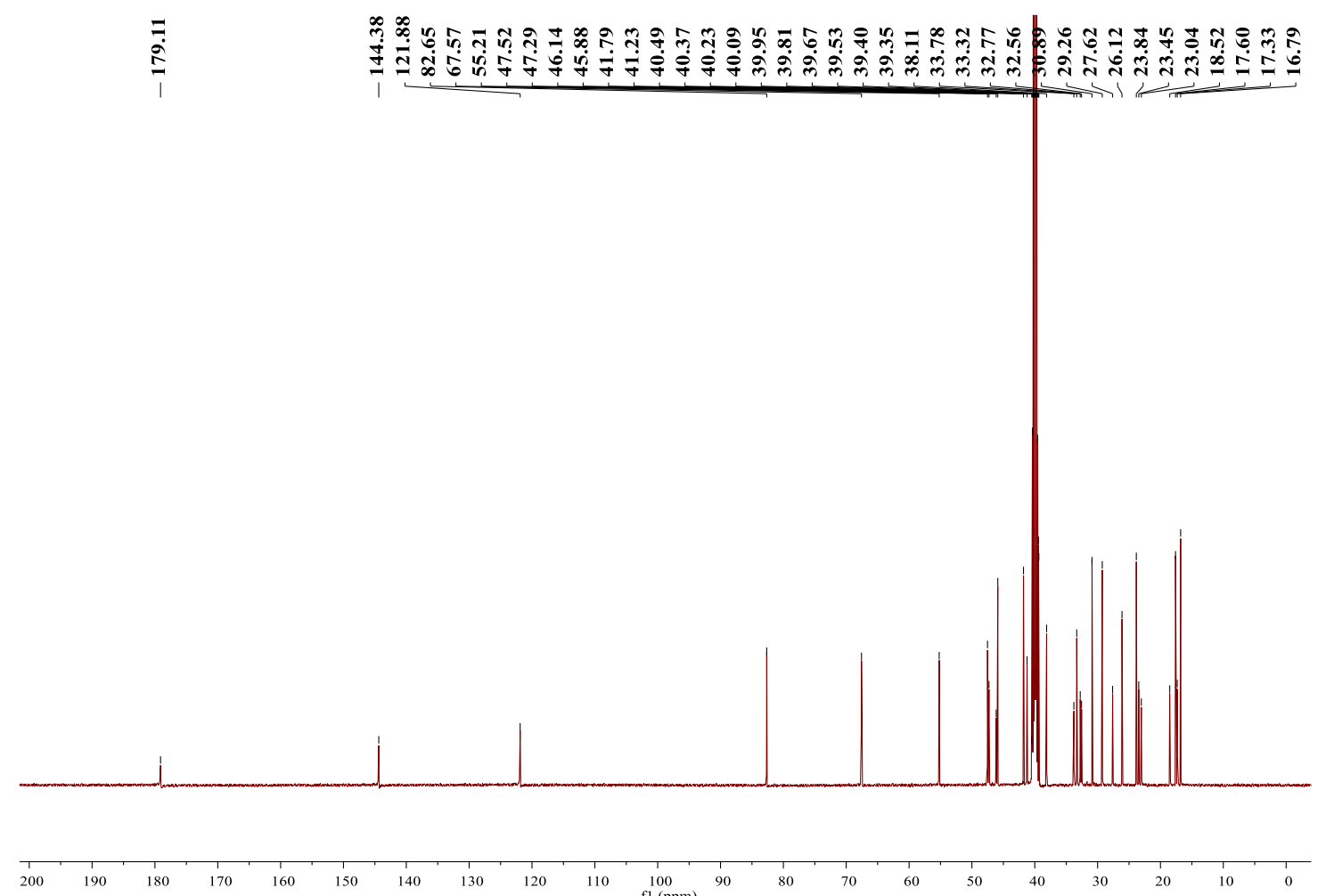

Figure S47. ${ }^{13} \mathrm{C}-\mathrm{NMR}$ (DMSO- $d_{6}, 150 \mathrm{MHz}$ ) spectrum of maslinic acid (17) 


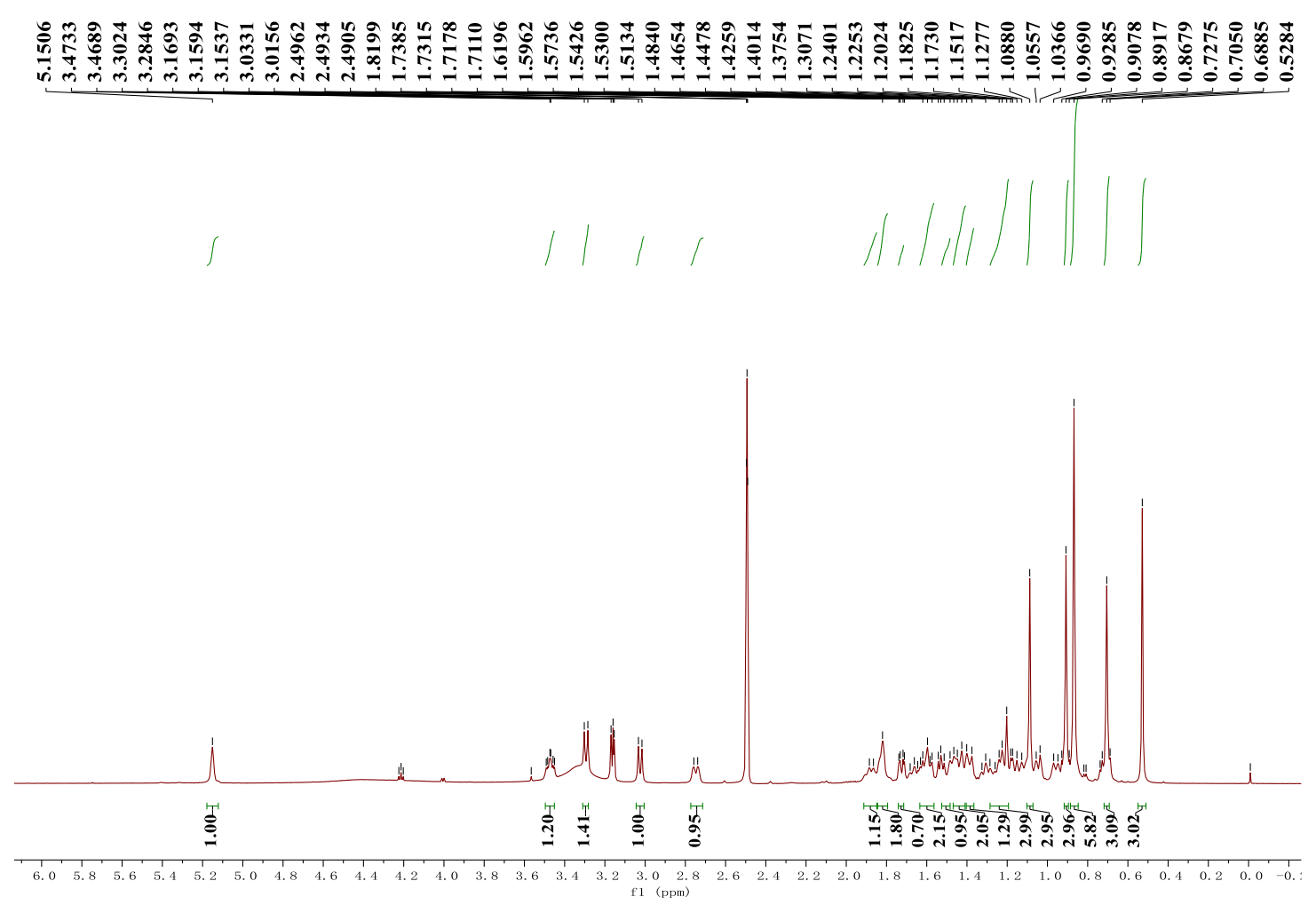

Figure S48. ${ }^{1} \mathrm{H}-\mathrm{NMR}\left(\mathrm{DMSO}-d_{6}, 600 \mathrm{MHz}\right.$ ) spectrum of arjunolic acid (18)
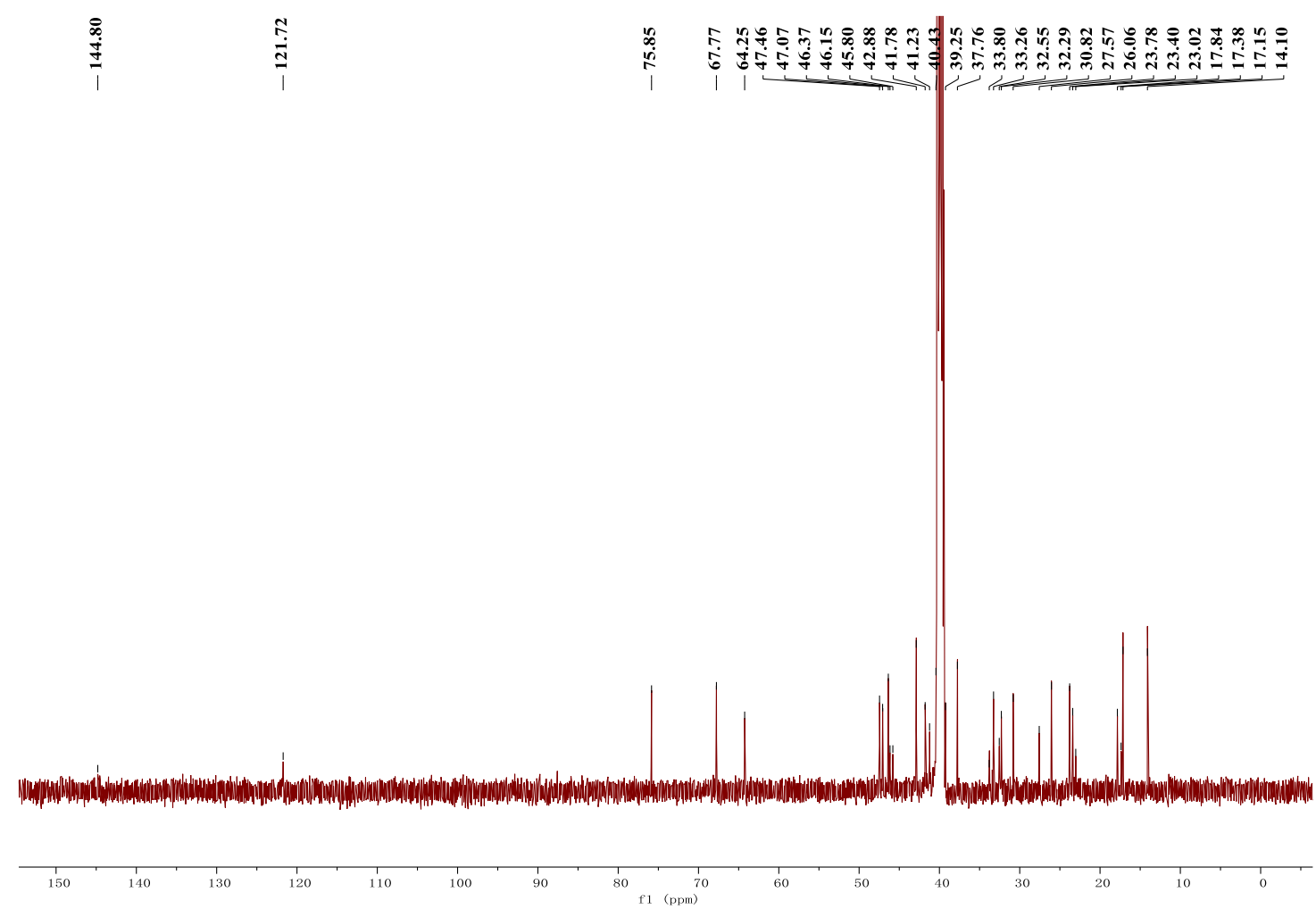

Figure S49. ${ }^{13} \mathrm{C}-\mathrm{NMR}$ (DMSO- $d_{6}, 150 \mathrm{MHz}$ ) spectrum of arjunolic acid (18) 


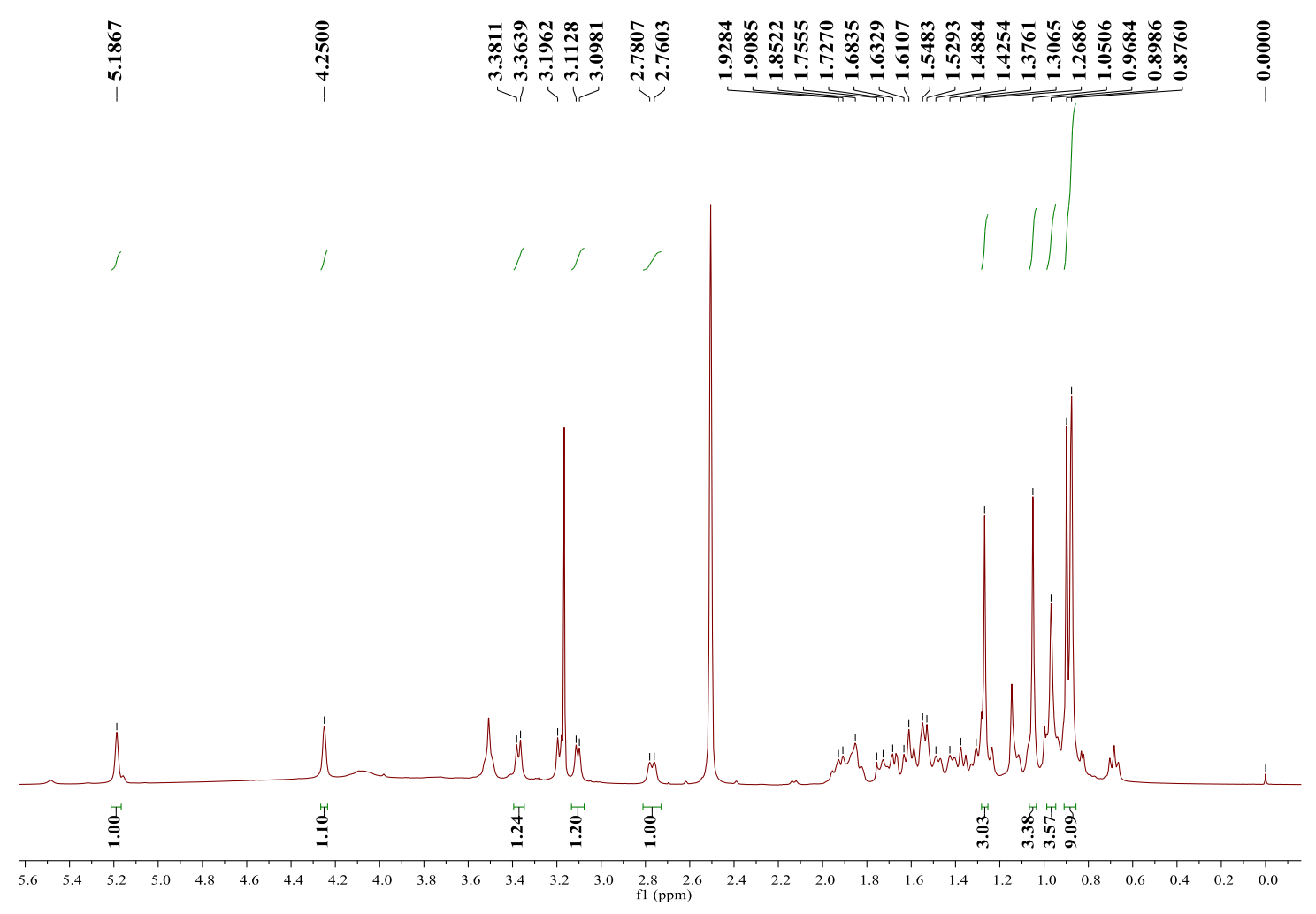

Figure S50. ${ }^{1} \mathrm{H}-\mathrm{NMR}\left(\mathrm{DMSO}-d_{6}, 600 \mathrm{MHz}\right)$ spectrum of terminolic acid (19)
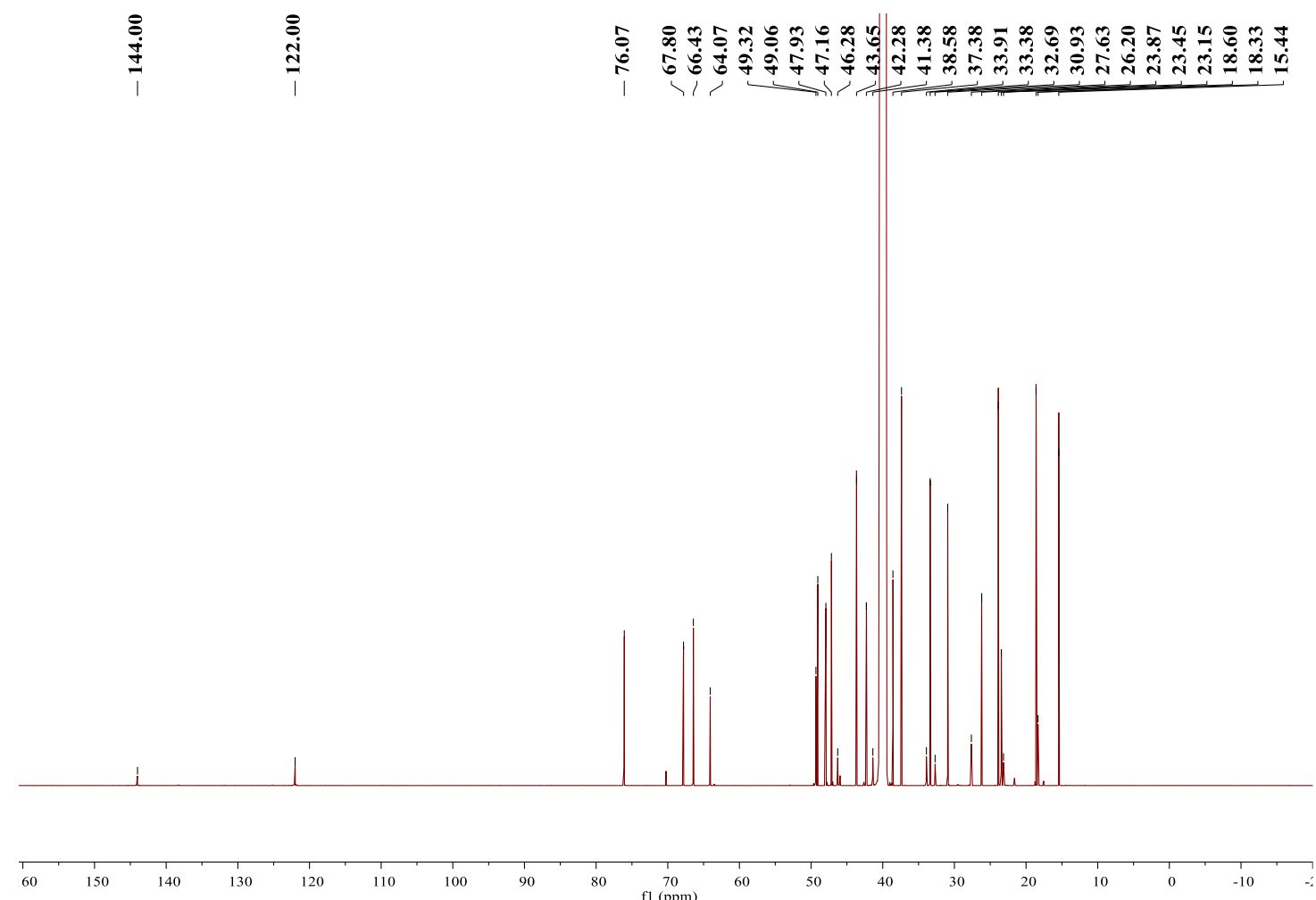

Figure S51. ${ }^{13} \mathrm{C}-\mathrm{NMR}$ (DMSO- $d_{6}, 150 \mathrm{MHz}$ ) spectrum of terminolic acid (19) 


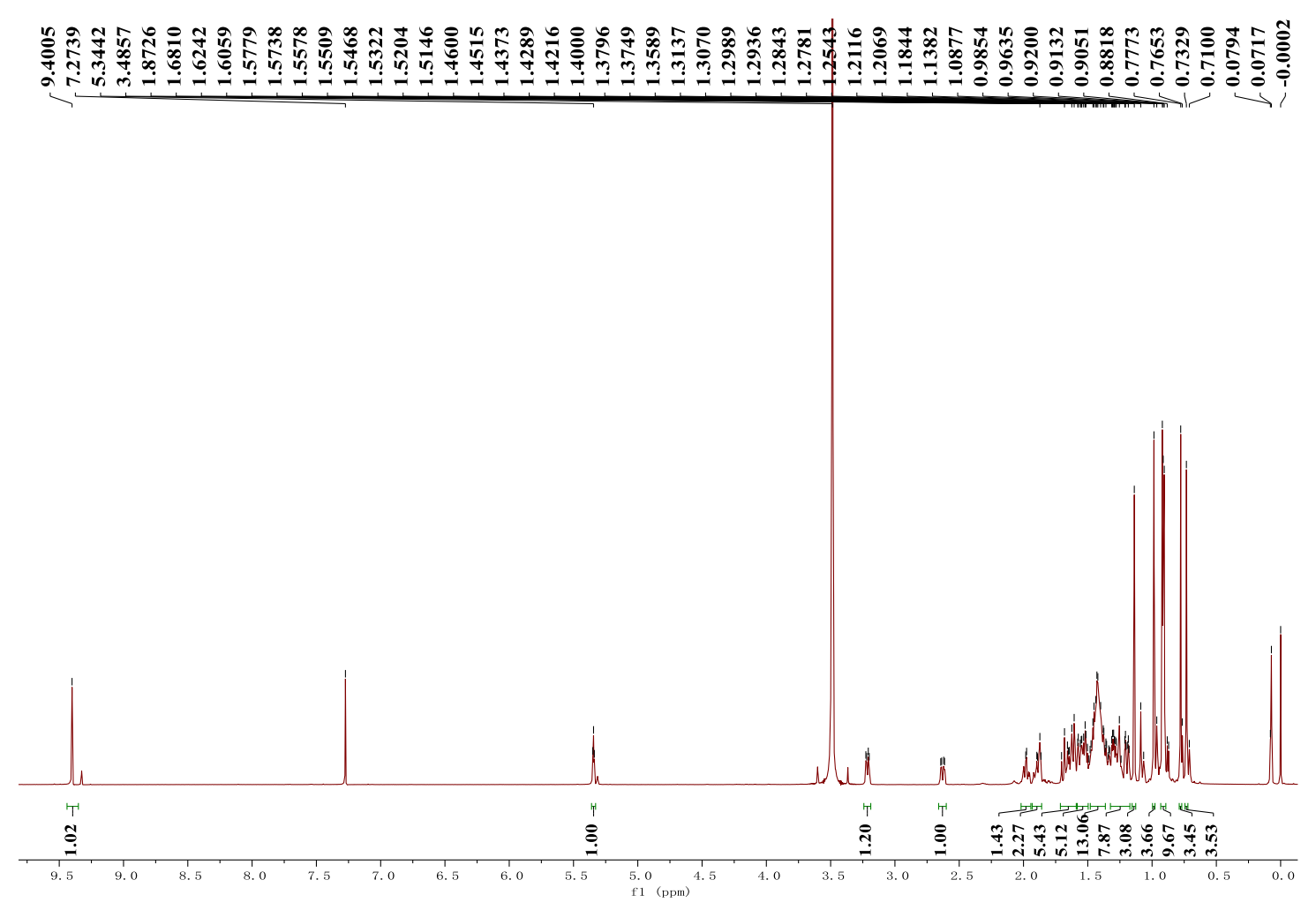

Figure S52. ${ }^{1} \mathrm{H}-\mathrm{NMR}\left(\mathrm{CDCl}_{3}-d, 600 \mathrm{MHz}\right)$ spectrum of oleanoaldehyde (20)

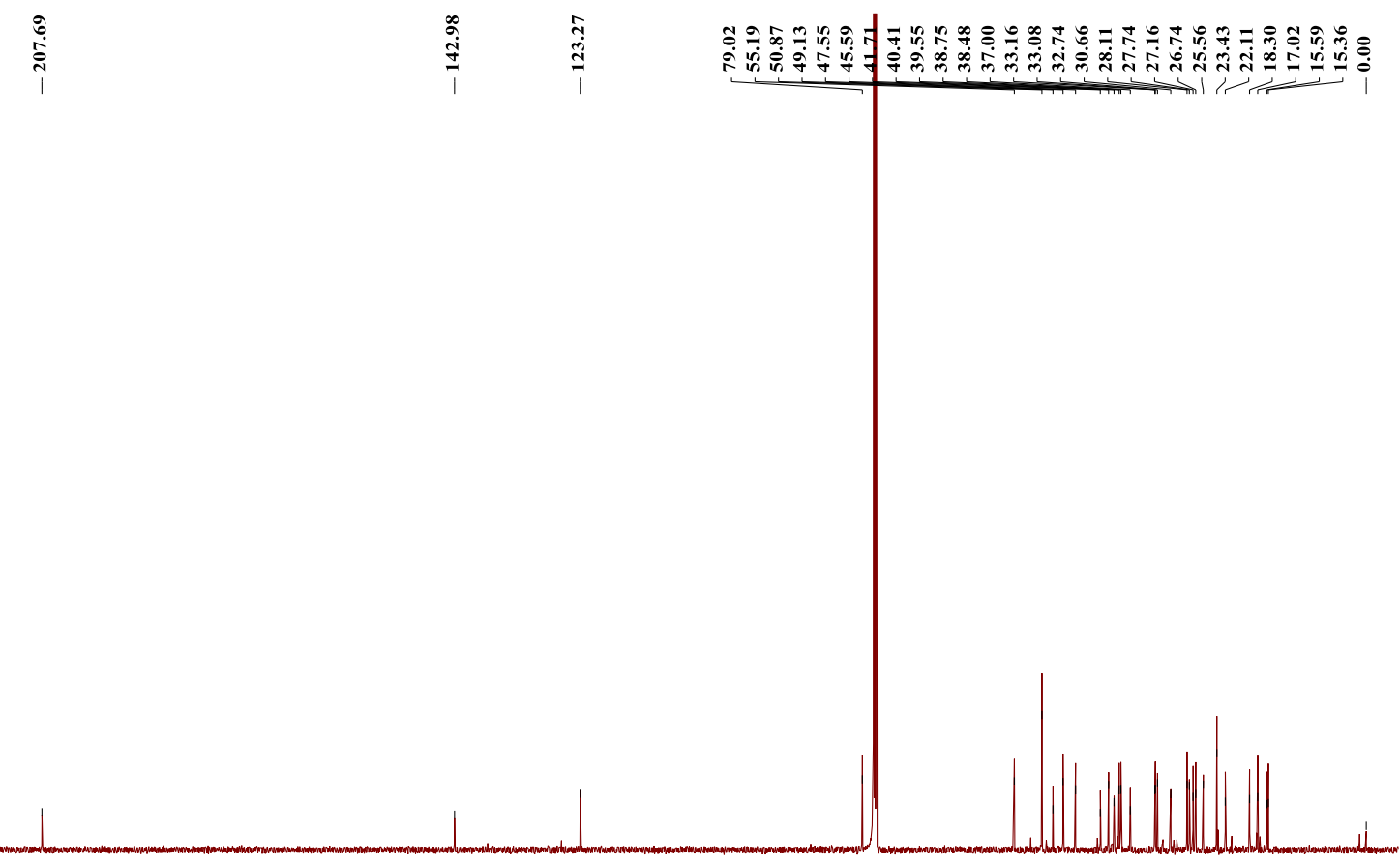

Figure S53. ${ }^{13} \mathrm{C}-\mathrm{NMR}\left(\mathrm{CDCl}_{3}-d, 150 \mathrm{MHz}\right)$ spectrum of oleanoaldehyde (20) 


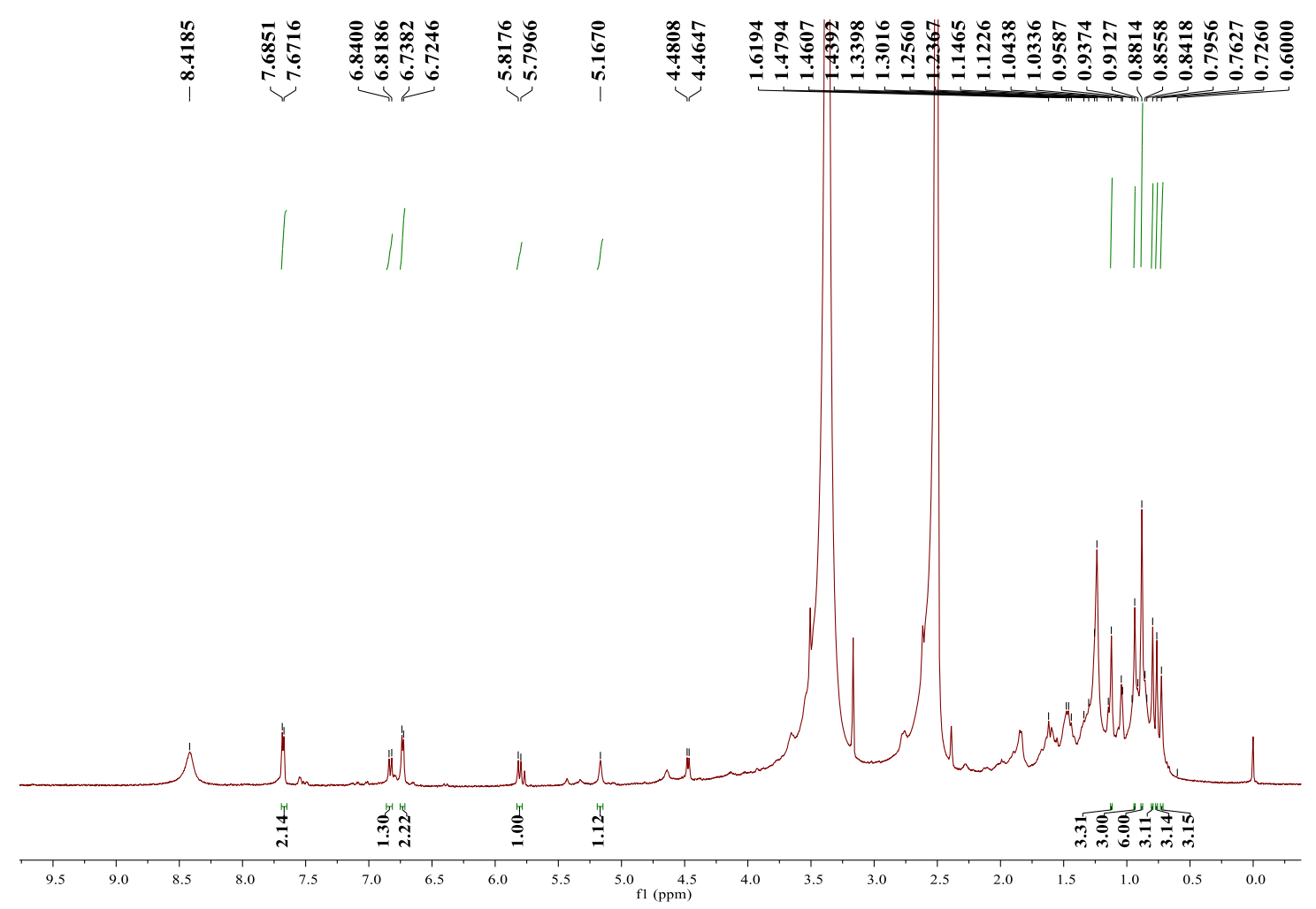

Figure S54. ${ }^{1} \mathrm{H}-\mathrm{NMR}$ (DMSO- $d_{6}, 600 \mathrm{MHz}$ ) spectrum of $3 \beta$-O-cis-p-coumaroyl maslinic acid (21)

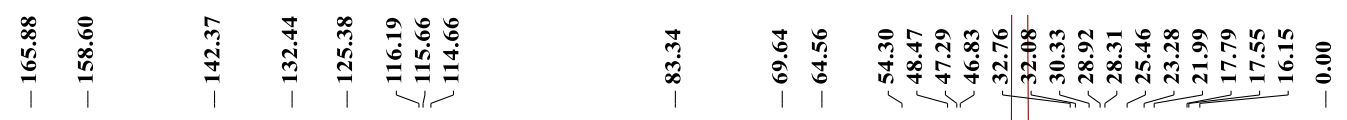

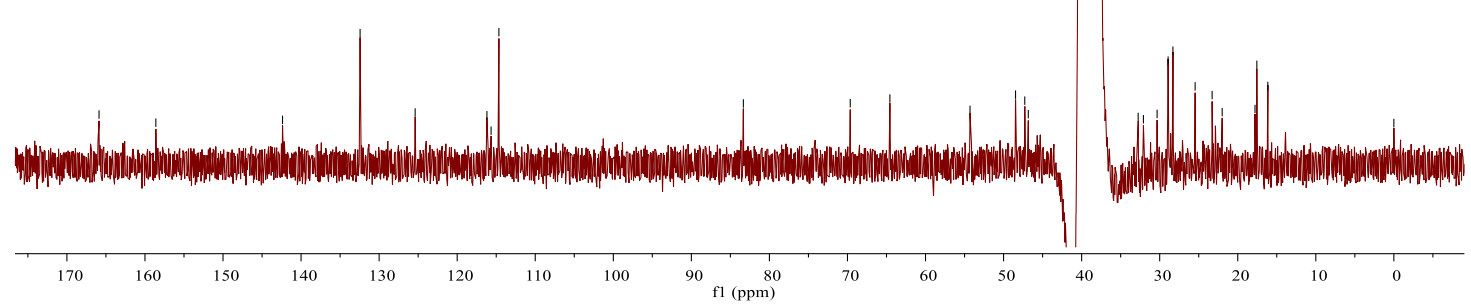

Figure S55. ${ }^{13} \mathrm{C}-\mathrm{NMR}$ (DMSO- $d_{6}, 150 \mathrm{MHz}$ ) spectrum of $3 \beta$-O-cis-p-coumaroyl maslinic acid (21) 


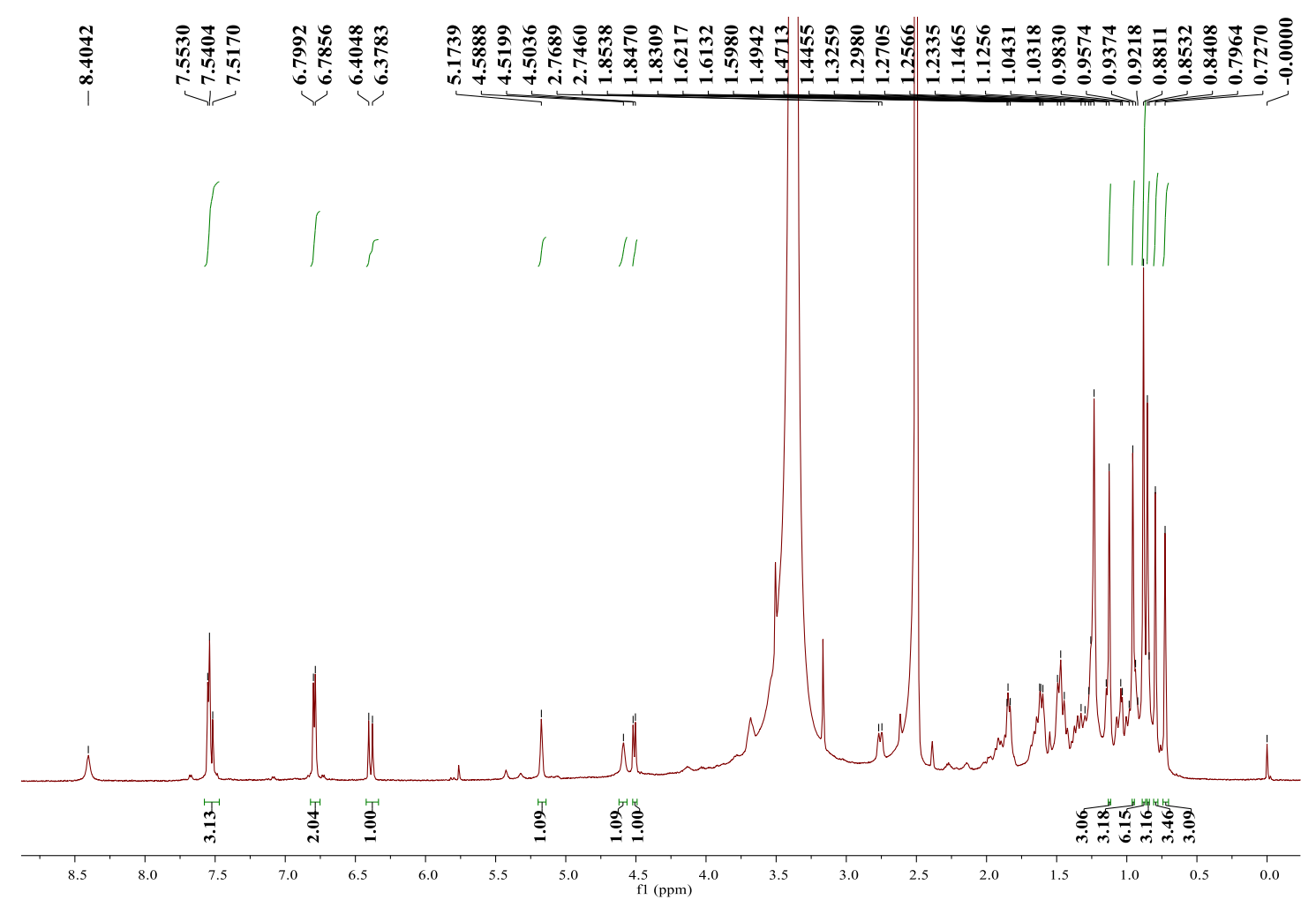

Figure S56. ${ }^{1} \mathrm{H}-\mathrm{NMR}\left(\mathrm{DMSO}-d_{6}, 600 \mathrm{MHz}\right.$ ) spectrum of $3 \beta$-O-trans-p-coumaroyl maslinic acid (22)

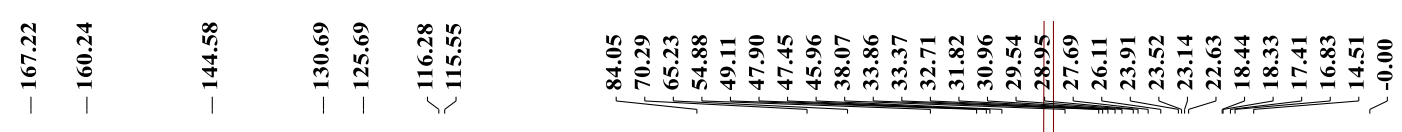
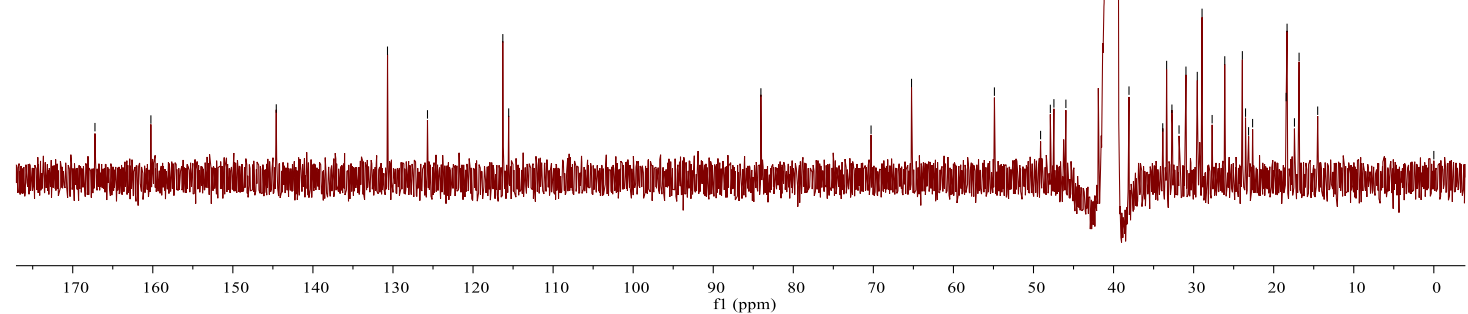

Figure S57. ${ }^{13} \mathrm{C}$-NMR (DMSO- $d_{6}, 150 \mathrm{MHz}$ ) spectrum of $3 \beta$-O-trans- $p$-coumaroyl maslinic acid (22) 


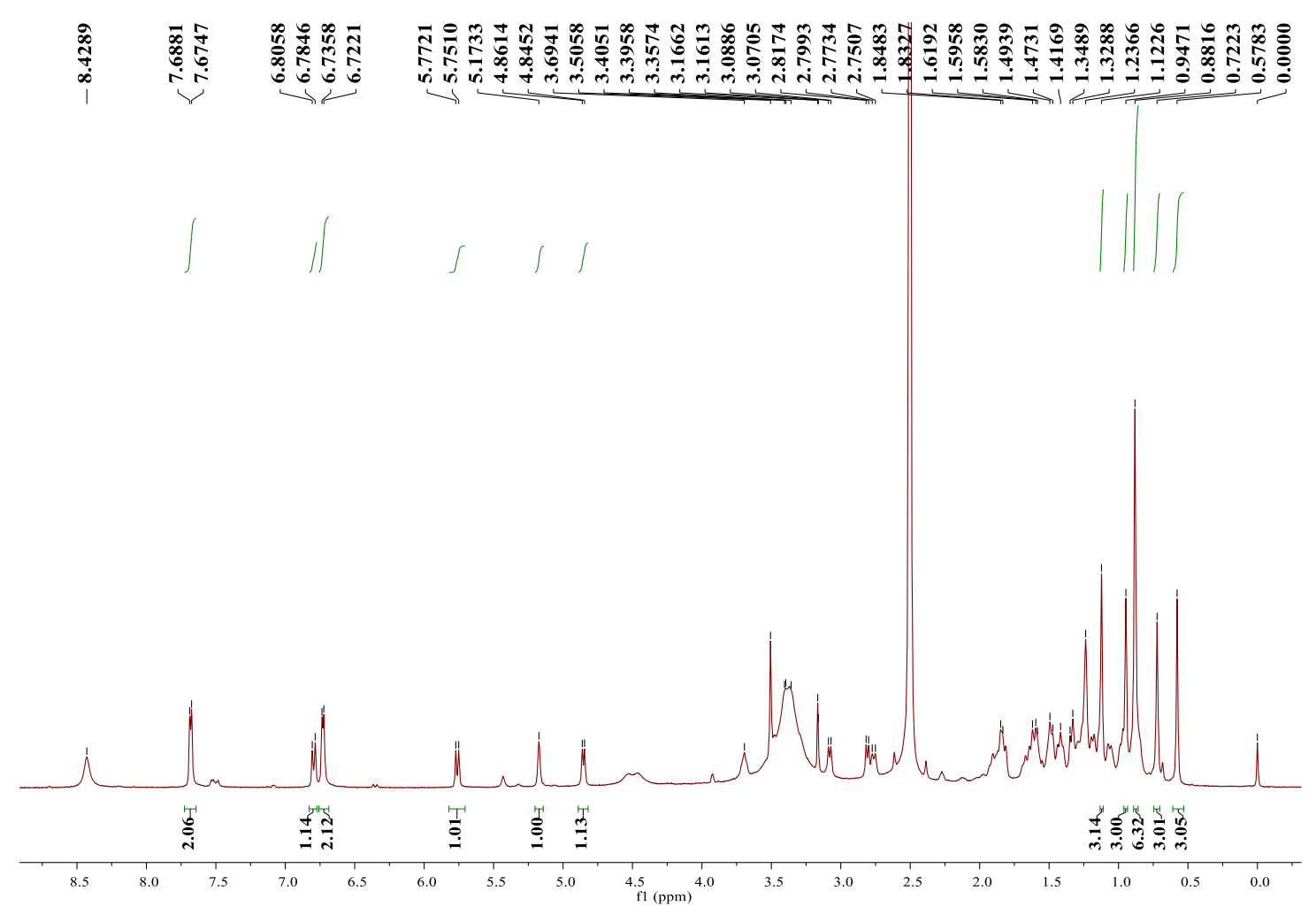

Figure S58. ${ }^{1} \mathrm{H}-\mathrm{NMR}$ (DMSO- $d_{6}, 600 \mathrm{MHz}$ ) spectrum of $3 \beta$-O-cis-p-coumaroyl arjunolic acid (23)

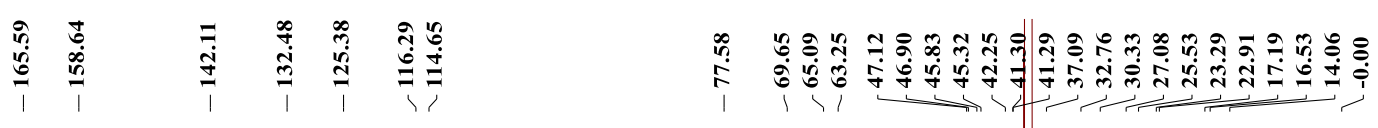
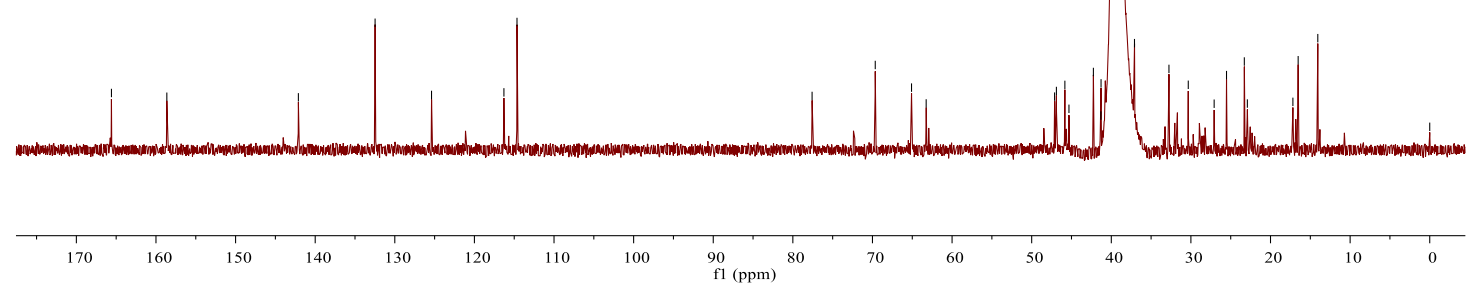

Figure S59. ${ }^{13} \mathrm{C}$-NMR (DMSO- $d_{6}, 150 \mathrm{MHz}$ ) spectrum of $3 \beta$-O-cis-p-coumaroyl arjunolic acid (23) 


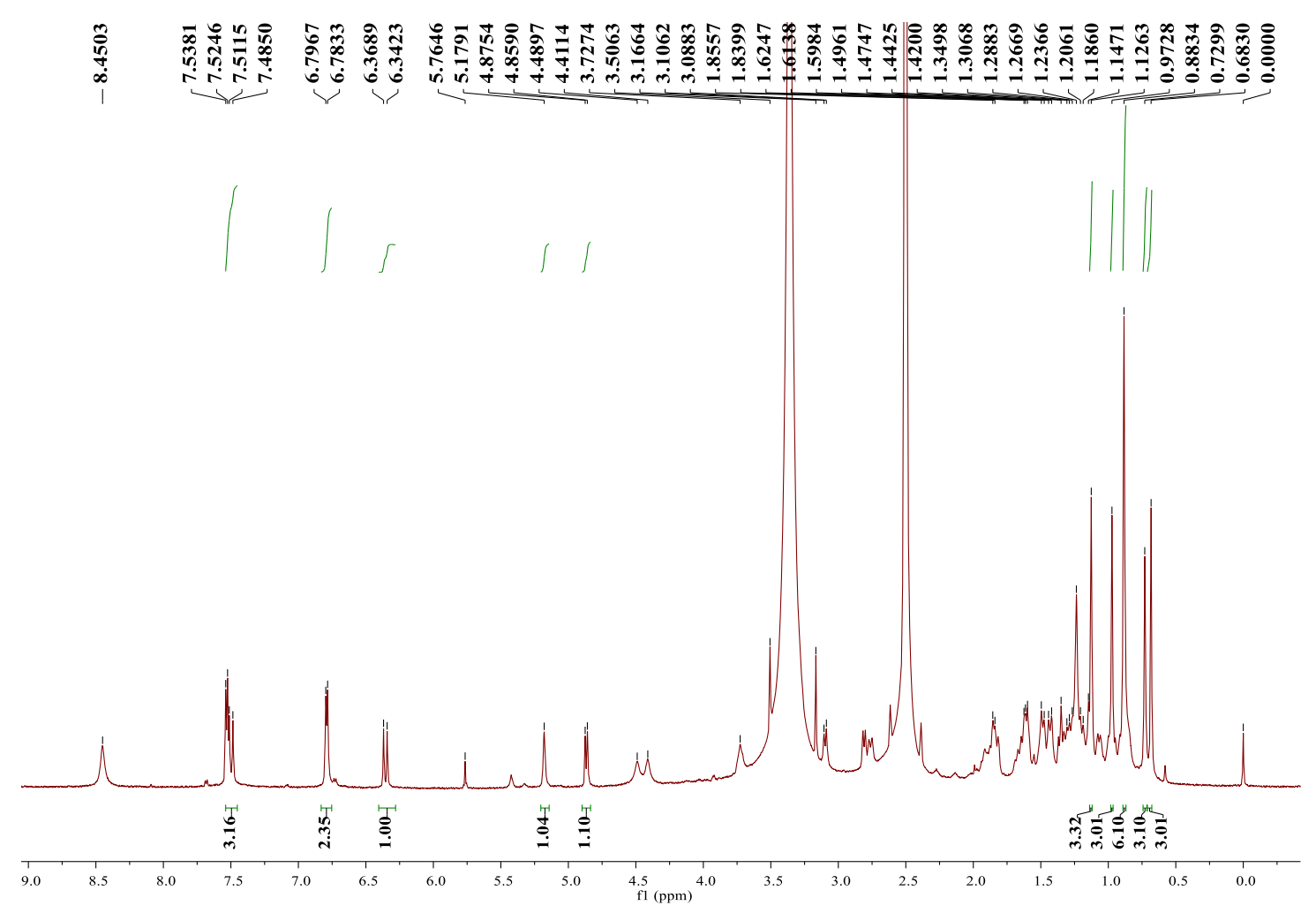

Figure S60. ${ }^{1} \mathrm{H}-\mathrm{NMR}$ (DMSO- $d_{6}, 600 \mathrm{MHz}$ ) spectrum of $3 \beta$-O-trans-p-coumaroyl arjunolic acid (24)

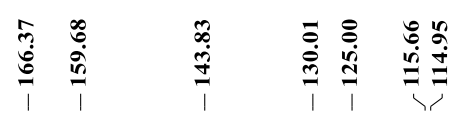

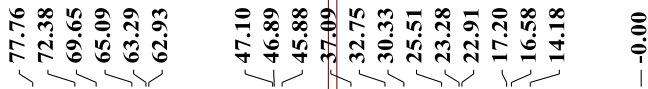
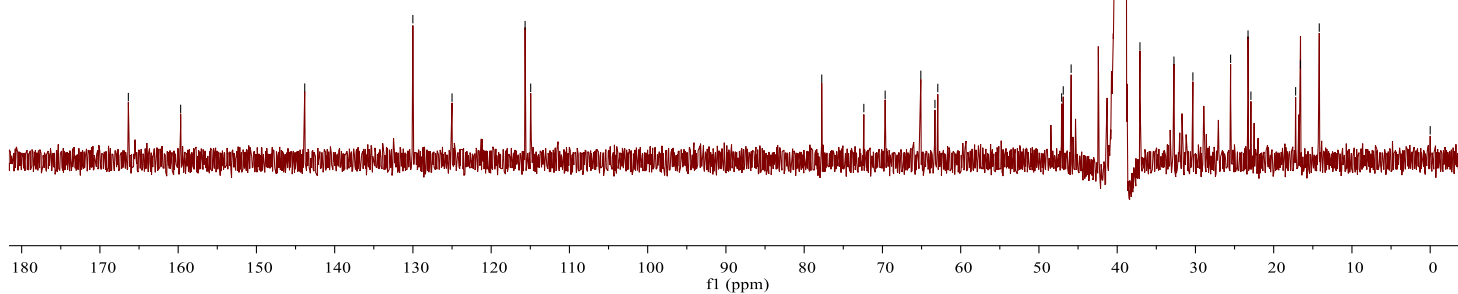

Figure S61. ${ }^{13} \mathrm{C}$-NMR (DMSO- $d_{6}, 150 \mathrm{MHz}$ ) spectrum of $3 \beta$-O-trans-p-coumaroyl arjunolic acid (24) 


\section{Reference:}

1. Begum, S.; Farhat; Sultana, I.; Siddiqui, B. S.; Shaheen, F.; Gilani, A. H., Spasmolytic constituents from Eucalyptus camaldulensis var. obtusa leaves. J. Nat. Prod. 2000, 63, 1265-1268.

2. Ikuta, A.; Tomiyasu, H.; Morita, Y.; Yoshimura, K., Ursane- and oleanane-type triterpenes from Ternstroemia gymnanthera callus tissues. J. Nat. Prod. 2003, 66, 10511054.

3. Begum, S.; Hassan, S. I.; Siddiqui, B. S., Two new triterpenoids from the fresh leaves of Psidium guajava. Planta Med. 2002, 68, 1149-1152.

4. Jang, D. S.; Lee, G. Y.; Kim, J.; Lee, Y. M.; Kim, J. M.; Kim, Y. S.; Kim, J. S., A new pancreatic lipase inhibitor isolated from the roots of Actinidia arguta. Arch. Pharm. Res. 2008, 31, 666-670.

5. Acebey-Castellon, I. L.; Voutquenne-Nazabadioko, L.; Doan Thi Mai, H.; Roseau, N.; Bouthagane, N.; Muhammad, D.; Le Magrex Debar, E.; Gangloff, S. C.; Litaudon, M.; Sevenet, T.; Hung, N. V.; Lavaud, C., Triterpenoid saponins from Symplocos lancifolia. J. Nat. Prod. 2011, 74, 163-168.

6. Du, Q.; Jerz, G.; Chen, P.; Winterhalter, P., Preparation of ursane triterpenoids from Centella asiatica using high speed countercurrent chromatography with step-gradient elution. J. Liq. Chromatogr. Relat. Technol. 2004, 27, 2201-2215.

7. Hota, R. K.; Bapuji, M., Triterpenoids from the resin of Shorea robusta. Phytochemistry 1994, 35, 1073-1074.

8. Jeong, D.; Shim, S.; Lee, M., Anti-inflammatory activity of phenylpropyl triterpenoids from Osmanthus fragrans var. aurantiacus leaves. Int. Immunopharmacol. 2020, 86, 106576.

9. Sashida, Y.; Ogawa, K.; Mori, N.; Yamanouchi, T., Triterpenoids from the fruit galls of Actinidia polygama. Phytochemistry 1992, 31, 2801-2804.

10. Lee, S. M.; Park, J. G.; Lee, Y. H.; Lee, C. G.; Min, B. S.; Kim, J. H.; Lee, H. K., Anti-complementary activity of triterpenoides from fruits of Zizyphus jujuba. Biol. Pharm. Bull. 2004, 27, 1883-1886.

11. Li, X.; Joshi, A. S.; ElSohly, H. N.; Khan, S. I.; Jacob, M. R.; Zhang, Z.; Khan, I. A.; Ferreira, D.; Walker, L. A.; Broedel, S. E.; Raulli, R. E.; Cihlar, R. L., Fatty acid synthase inhibitors from plants: isolation, structure elucidation, and SAR studies. $J$. Nat. Prod. 2002, 65, 1909-1914.

12. Zhang, Y.; Jayaprakasam, B.; Seeram, N. P.; Olson, L. K.; DeWitt, D.; Nair, M. G., Insulin secretion and cyclooxygenase enzyme inhibition by Cabernet Sauvignon Grape skin compounds. J. Agric. Food Chem. 2004, 52, 228-233.

13. Gu, J.; Park, E. J.; Luyengi, L.; Hawthorne, M. E.; Mehta, R. G.; Farnsworth, N. R.; Pezzuto, J. M.; Kinghorn, A. D., Constituents of Eugenia sandwicensis with potential cancer chemopreventive activity. Phytochemistry 2001, 58, 121-127. 